Ana Paula Garcia Ferreira

\title{
Preparação e Estudo Fotofísico de Nanopartículas de Sílica Marcadas com Compostos Fluorescentes
}

Tese apresentada ao Instituto de Química de São Carlos, da Universidade de São Paulo para obtenção do título de Doutor em Ciências (FísicoQuímica).

Orientador: Prof. Dr. Marcelo Henrique Gehlen 
À minha mãe, Gelia, meu exemplo de amor, coragem, força e determinação: sempre necessários nos caminhos da vida. 


\section{AGRADECIMENTOS}

A Deus pela oportunidade e suporte.

Ao Prof. Dr. Marcelo Henrique Gehlen por sua orientação em minha formação acadêmica.

Ao Prof. Dr. Laudemir Carlos Varanda por me auxiliar na preparação das nanopartículas, e também ao Prof. Dr. Fergus Gessner, pelas ricas discussões no exame da qualificação.

Aos integrantes do Grupo de Fluorescência Molecular.

Aos integrantes do Grupo de Fotoquímica.

Ao Dr. Robson Valentim Pereira, pelos auxílios no laboratório e pelas muitas e muitas discussões a respeito de nossos trabalhos.

À minha família que está perto: Willy Glen e Frederico; à minha família que não está tão perto: Gelia, Luciane, André e Stella; aos raros e valiosos amigos que sempre estiveram perto, mesmo que às vezes estivessem longe.

Aos técnicos da Central de Análises Químicas do IQSC.

Ao Instituto de Química de São Carlos - USP pela infra-estrutura.

À CAPES pela bolsa concedida. 
Ninguém pode construir em teu lugar as pontes que precisarás passar para atravessar o rio da vida - ninguém, exceto tu, só tu.

Existem, por certo, atalhos sem número, e pontes, e semideuses que se oferecerão para levar-te além do rio; mas isso te custaria a tua própria pessoa; tu te hipotecarias e te perderias.

Existe no mundo um único caminho por onde só tu podes passar. Onde leva? Não perguntes, segue-o!

(Friedrich Wilhelm Nietzsche) 


\section{RESUMO}

Foi estudado o comportamento fotofísico da 9-aminoacridina (9AA) e derivados, safranina $\mathrm{O}$, auramina e 9-vinilantraceno, em partículas de sílica. Inicialmente, partículas de sílica obtidas comercialmente foram modificadas e marcadas com corantes acridínicos, porém sua morfologia tornou inviável o estudo fotofísico, devido à sua irregularidade. Foram preparadas nanoesferas de sílica, pelo método de Stöber, com diâmetro médio de $50 \mathrm{~nm}$, que apresentaram altos sinais de fluorescência. Além disso, para evitar a dessorção dos marcadores nas nanopartículas em suspensão, foram preparadas nanopartículas do tipo cascacaroço, contendo um núcleo rico em marcador, protegido por uma casca de sílica. Estas nanopartículas, com diâmetro médio de $125 \mathrm{~nm}$, mostraram-se excelentes matrizes para o estudo dos corantes, retardando sua difusão para o solvente. Foram ainda preparadas nanopartículas contendo poli(metacrilato de metila) marcado com derivado acridínico. A interação entre grupos silanol na superfície e o grupo N-H do marcador bloqueou o processo de transferência de carga intramolecular, característico do corante. Por fim, foram preparadas nanopartículas marcadas com 9-aminoacridina e safranina $O$. Na presença de safranina $O$, o tempo de vida de fluorescência referente à desativação do cromóforo acridina passou de 12,2 ns para 9,71 ns, indicando processos de transferência de energia e supressão de fluorescência, no interior das partículas.

Palavras-chave: nanopartículas de sílica, polímeros, espectroscopia de fluorescência. 


\begin{abstract}
Photophysical behavior of 9-aminoacridine (9AA) and derivatives, safranine $O$, auramine and 9-vinylanthracene was investigated, in silica particles. Firstly, commercial silica was modified and grafted with acridinic dyes; however, photophysical studies became unviable, due to its morphology. Silica nanospheres were prepared by Stöber method, with mean diameter of $50 \mathrm{~nm}$, presenting high fluorescence emission. Moreover, in order to avoid de desorption of dyes from particles in suspension, systems containing a dye reach nucleus protected by silica shells were prepared (core-shell nanoparticles). The core-shell nanospheres, with mean diameter of $125 \mathrm{~nm}$, are excellent matrixes for fluorescence studies, since it retards dye diffusion to the solvent. It was also prepared nanoparticles containing poly(methylmethacrylate) grafted with 9AA derivative. Interaction between silica silanol groups and dye $\mathrm{N}-\mathrm{H}$ groups broke the intramolecular charge transfer, a characteristic process occurring in this dye. Finally, nanoparticles grafted with 9AA and safranine $\mathrm{O}$ were prepared. In the presence of safranine, fluorescence lifetime related to the deactivation of the chromophore acridine reduced from 12.2 ns to 9.71 ns, suggesting energy transfer and fluorescence quenching processes within the particles.
\end{abstract}

Keywords: silica nanoparticles, polymers, fluorescence spectroscopy. 


\section{LISTA DE FIGURAS}

Figura 1: Estruturas moleculares do (A) TEOS e do (B) TMOS. 19

Figura 2: Mecanismos de reação de hidrólise/condensação catalisadas por ácido ou base 20

Figura 3: Estrutura molecular da 9-aminoacridina monoprotonada. 22

Figura 4: (A) Absorção, emissão estacionária e (B) curva de decaimento de fluorescência da 9-aminoacridina, em metanol. 23

Figura 5: Estruturas moleculares de (I) dietiletoximetilenomalonato, (II) etil(etoximetileno)cianoacetato e (III) etoximetilenomalonitrila.

24

Figura 6: llustração do diagrama de energia envolvendo os estados excitados LE e ICT.

Figura 7: Espectros de absorção e emissão estacionária dos derivados acridínicos. $25 \underline{5}$

Figura 8: Exemplos de decaimentos de um dos derivados (composto II), em diferentes comprimentos de onda de emissão 26

Figura 9: Absorção, emissão estacionária e decaimento de fluorescência do derivado acridínico II ligado à cadeia de poli(ácido metacrílico)! 27

Figura 10: Representação da cadeia de poli(ácido metacrílico) marcado com derivado acridínico. $\mathrm{R}_{1}=\mathrm{CN}, \mathrm{R}_{2}=\mathrm{COOEt} ; m>>$.

Figura 11: Variação no tempo de relaxação, indicando a transição conformacional de poli(ácido metacrílico) marcado com 9-aminoacridinametilenocianoetilacetato ${ }^{[32]}$.... 30 Figura 12: Estrutura molecular do corante catiônico azul de metileno, utilizado no estudo da adsorção em esferas de sílica 31

Figura 13: Representação dos processos fotofísicos que ocorrem nas nanopartículas marcadas com fluoresceína modificada (ligada covalentemente) 33

Figura 14: Estruturas moleculares dos marcadores fluorescentes utilizados no decorrer do trabalho. 38

Figura 15: Configuração experimental das medidas realizadas com amostras no estado sólido.

Figura 16: Sistema laser utilizado no Laboratório de Fluorescência Molecular.

Figura 17: Reação de derivatização da 9-aminoacridina com compostos vinílicos... 42

Figura 18: Esquema de copolimerização do metilmetacrilato de metila com 9AA-III.43

Figura 19: Esquema de sililação das partículas comerciais. 44 
Figura 20: Incorporação dos derivados acridínicos à superfície de sílica. 45

Figura 21: Estrutura molecular do TEOS. 46

Figura 22: Esquema ilustrativo da preparação das partículas do tipo casca-caroço. 48 Figura 23: Emissão de fluorescência estacionária do 9AA I ligado e adsorvido à sílica; $\lambda_{\text {exc }}=400 \mathrm{~nm}$ 51

Figura 24: Decaimentos de fluorescência de partículas de sílica marcadas com 9AA I (a) e 9AA II (b); $\lambda_{\text {exc }}=400 \mathrm{~nm}$ 53

Figura 25: Imagem de MEV das partículas comerciais. 54

Figura 26: Emissão de fluorescência estacionária do 9VA em ciclohexano e dos sistemas 1_SigVA e 1_SigVA/TMSPM suspensos no mesmo solvente; $\lambda_{\mathrm{exc}}=360$ $\mathrm{nm}$. 57

Figura 27: Decaimentos de fluorescência dos sistemas 1-SigVA e 1-SigVA/TMSPM ; $\left(\lambda_{\text {exc }}=400 \mathrm{~nm}\right.$ e $\left.\lambda_{\mathrm{em}}=445 \mathrm{~nm}\right)$. 58

Figura 28: Fotos da sílica sem marcador (A) e do sistema 1_SigAAll, sólido amarelado (direita)

Figura 29: Emissão de fluorescência estacionária do sistema 1_Si9AAll; $\lambda_{\text {exc }}=400$ $\mathrm{nm} ; \lambda_{\text {máx em }}=413,434$ e $460 \mathrm{~nm}$.

Figura 30: Fotos da sílica sem marcador (A) e do sistema 1_SiSf, sólido rosa (B)... 61 Figura 31: Emissão de fluorescência estacionária do sistema 1_SiSf; $\lambda_{\text {exc }}=532$ nm; $\lambda_{\text {máx em }}=560 \mathrm{~nm}$.

Figura 32: Imagem de MEV da 1_Si9AAll, preparada com ácido acético como catalisador. 62

Figura 33: Imagem de MEV das nanopartículas de sílica preparadas em 2-propanol, sem adição de marcadores fluorescentes, com diâmetro médio de $100 \mathrm{~nm}$. 64

Figura 34: Emissão estacionária de 2_SigAAll $\left(\lambda_{\mathrm{exc}}=400 \mathrm{~nm} ; \lambda_{\text {máx em }}=427,453 \mathrm{e}\right.$ $485 \mathrm{~nm})$ 65

Figura 35: Emissão estacionária de 2_SiSf $\left(\lambda_{\text {exc }}=532 \mathrm{~nm} ; \lambda_{\text {máx em }}=565 \mathrm{~nm}\right) \ldots \ldots \ldots 6$ Figura 36: Imagem de MEV das nanopartículas preparadas em 2-propanol, com safranina $\mathrm{O}$, com diâmetro médio de $100 \mathrm{~nm}$.

Figura 37: Emissão estacionária das partículas 2_Si9AA; $\lambda_{\mathrm{exc}}=400 \mathrm{~nm} ; \lambda_{\operatorname{máx}}$ em $=$ 427,450 e $480 \mathrm{~nm}$. 68

Figura 38: Imagem de MEV das nanopartículas preparadas em 2-propanol, marcadas com 9-aminoacridina, com diâmetro médio de $100 \mathrm{~nm}$. 
Figura 39: Ilustração de partículas do tipo CS. ......................................................... 70

Figura 40: Imagem de MEV das partículas CS, marcadas com safranina O (CS_Sf), com diâmetro médio de $250 \mathrm{~nm}$.

Figura 41: Intensidade de absorção versus concentração de Sf, usados para calcular seu $\varepsilon$ em 2-propanol. 72

Figura 42: Absorção de solução de safranina $\mathrm{O}(-)$ no meio reacional e (---) no sobrenadante da preparação do sistema 2_SiSf. .73

Figura 43: Absorção de solução de safranina $\mathrm{O}(-)$ no meio reacional e (---) no sobrenadante da preparação do sistema CS_Sf. .74

Figura 44: Emissão estacionária das partículas 2_SiSf (---) e CS_Sf (-), em 2propanol. 75

Figura 45: Emissão estacionária das partículas $C S 9 A A ; \lambda_{\text {exc }}=400 \mathrm{~nm} ; \lambda_{\text {máx em }}=428$, 450 e $480 \mathrm{~nm}$ .77

Figura 46: Imagem de MEV das partículas CS, marcadas com 9AA, com diâmetro médio de $200 \mathrm{~nm}$. 77

Figura 47: Emissão estacionária das partículas $\operatorname{CS9AAl/;} \lambda_{\text {exc }}=400 \mathrm{~nm} ; \lambda_{\text {máx em }}=$ 426, 450 e $480 \mathrm{~nm}$. 78

Figura 48: Imagem de MEV das partículas CS, marcadas 9AAll, com diâmetro médio de $200 \mathrm{~nm}$. 79

Figura 49: Imagem de MEV das partículas CS, marcadas auramina, com diâmetro médio de $200 \mathrm{~nm}$. 80

Figura 50: Emissão estacionária das partículas CS_Au, no estado sólido; $\lambda_{\text {exc }}=380$ $\mathrm{nm} ; \lambda_{\text {máx em }}=423 \mathrm{~nm}$. 81

Figura 51: Representação da cadeia de poli(metacrilato de metila) marcado com derivado acridínico. $\mathrm{R}_{1}=\mathrm{R}_{2}=\mathrm{CN} ; m>n$. 81

Figura 52: Espectro de emissão estacionária do PMMA-9AAllI.; $\lambda_{\text {exc }}=400 \mathrm{~nm} ; \lambda_{\text {máx }}$ $\mathrm{em}=480 \mathrm{~nm}^{[54]}$

Figura 53: Espectros de emissão estacionária de PMMA-9AAlll e do sistema sílica/PMMA-9AAIII 83

Figura 54: Imagem de MEV das partículas CS_PMMA-9AAIII, com aumento de (A) 15000 vezes e (B) 30000 vezes. Partículas com diâmetro médio de $200 \mathrm{~nm}$. 85

Figura 55: Ilustração da formação das nanopartículas CS_PMMA-9AAIII. 87 
Figura 56: Espectros de excitação e emissão estacionária do sistema CS_PMMA9AAIII (-) em clorofórmio e (---) no estado sólido; $\left(\lambda_{\text {exc }}=380 \mathrm{~nm} ; \lambda_{\text {em }}=420 \mathrm{~nm}\right) \ldots 88$ Figura 57: Ilustração do diagrama de energia do sistema CS_PMMA-9AAIII, em clorofórmio e no estado sólido.

Figura 58: Espectros de emissão estacionária da 9AA ( $\left.\lambda_{\text {exc }}=400 \mathrm{~nm}\right)$ e absorção da safranina $\mathrm{O}$ 90

Figura 59: Ilustração idealizada do sistema CS_Sf_9AA. 91

Figura 60: Imagem de MEV das partículas CS_Sf_9AA. Partículas com diâmetros de 150 a $300 \mathrm{~nm}$ 92

Figura 61: Espectros de excitação e emissão estacionária do sistema CS_Sf_9AA; (-) $\lambda_{\text {exc }}=400 \mathrm{~nm}$ e (---) $\lambda_{\text {exc }}=525 \mathrm{~nm}$; no estado sólido. $\lambda_{\text {máx exc 9AA }}=378,397$ e 418 $\mathrm{nm} ; \lambda_{\text {máx em 9AA }}=427,450$ e $480 \mathrm{~nm} ; \lambda_{\text {máx exc Sf }}=526 \mathrm{~nm} ; \lambda_{\text {máx em Sf }}=560 \mathrm{~nm}$. 93

Figura 62: Decaimentos de fluorescência de dos sistemas contendo 9AA e safranina $\mathrm{O}$, em metanol 94

Figura 63: Decaimentos de fluorescência de dos sistemas contendo 9AA e safranina O, em clorofórmio: $(\square)$ IRF, ( o ) CS_9AA e ( $\diamond)$ CS_Sf_9AA. (detalhe: a mesma medida realizada em uma janela de tempo menor); $\lambda_{\text {exc }}=400 \mathrm{~nm}$. 96 


\section{LISTA DE TABELAS}

Tabela 1: Siglas utilizadas para denotar cada sistema e principais parâmetros de

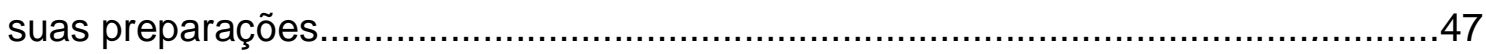

Tabela 2: Tempos de vida, e suas contribuições, das partículas de sílicas marcadas

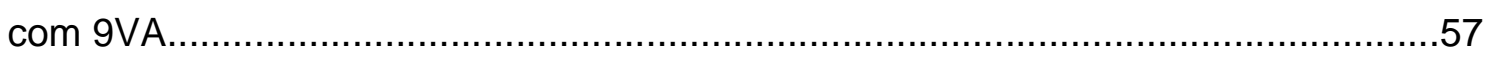

Tabela 3: Tempos de vida de fluorescência de CS_9AA e CS_Sf_9AA....................97 


\section{LISTA DE ABREVIATURAS E SILGAS}

TEOS: tetraetilortosilicato

TMOS: tetrametilortosilicato

LE: locally excited (estado excitado singlete localmente excitado)

ICT: intramolecular charge transfer (transferência de carga intramolecular)

PAM: poli(ácido metacrílico)

Sf: safranina $O$

Au: auramina

9AA: 9-aminoacridina

9VA: 9-vinilantraceno

9AA I: 9-aminoacridinametilenodietilmalonato

9AA II: 9-aminoacridinametilenocianoetilacetato

9AA III: 9-aminoacridinametilenomelonitrila

IRF: instrument resnponse function (resposta instrumental)

PMMA: poli(metacrilato de metila)

TMSPM: 3-(trimetoxisili)propilmetacrilato

CS: core-shell (casca-caroço)

MEV: microscopia eletrônica de varredura

$\varepsilon$ : coeficiente de extinção molar

D: doador de energia

A: aceptor de energia

1_Si9VA: nanopartículas de sílica marcada com 9VA, preparada em etanol

1_Si9VA/TMSPM: nanopartículas de sílica marcada com 9VA, preparada em etanol, na presença de TMSPM

1_SigAAll: nanopartículas de sílica marcada com 9AAll, preparada em etanol

1_SiSf: nanopartículas de sílica marcada com Sf, preparada em etanol

2_Si9AAll: nanopartículas de sílica marcada com 9AAll, preparada em 2-propanol

2_SiSf: nanopartículas de sílica marcada com Sf, preparada em 2-propanol

2_Si9AA: nanopartículas de sílica marcada com 9AA, preparada em 2-propanol

CS_Sf: nanopartículas casca-caroço marcadas com Sf

CS_9AA: nanopartículas casca-caroço marcadas com 9AA

CS_9AAll: nanopartículas casca-caroço marcadas com 9AAll 
CS_Au: nanopartículas casca-caroço marcadas com $\mathrm{Au}$ CS_PMMA_9AAlll: nanopartículas casca-caroço marcadas com PMMA-9AAllI CS_Sf_9AA: nanopartículas casca-caroço marcadas com Sf e 9AA 


\section{SUMÁRIO}

1 - INTRODUÇÃO

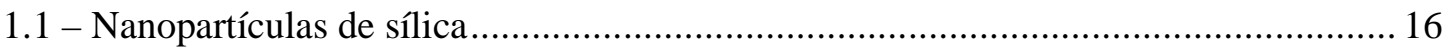

1.2 - Mecanismos e métodos de preparação de nanopartículas de sílica............................... 18

1.3 - Corantes fluorescentes acridínicos e derivados (aspectos fotofísicos e fotoquímicos):

1.4 - Sondas fluorescentes como marcadores em polímeros e nanopartículas: .................... 27

2 - OBJETIVOS ............................................................................................................... 35

3 - PARTE EXPERIMENTAL ........................................................................................ 37

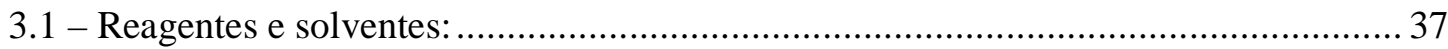

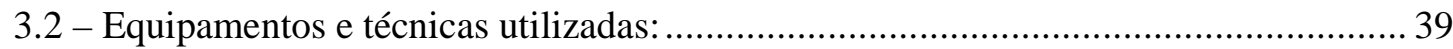

3.3 - Preparação de sondas acridínicas modificadas:........................................................... 42

3.4 - Inserção de compostos fluorescentes em polímero: ....................................................... 43

3.5 - Funcionalização de partículas de sílica comercial e inclusão de sondas na superfície:

3.6 - Preparação de nanopartículas de sílica pelo método de Stöber: .................................... 45

3.7 - Preparação de nanopartículas de sílica do tipo casca-caroço (core-chell - CS): ......... 47

4 - RESULTADOS E DISCUSSÃO ................................................................................50

4.1 - Partículas de sílica comerciais: ........................................................................... 50

4.2 - Nanopartículas preparadas pelo método de Stöber: morfologia e emissão de

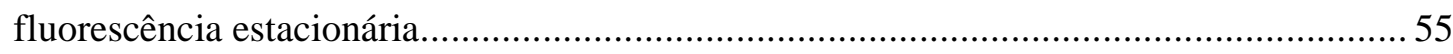

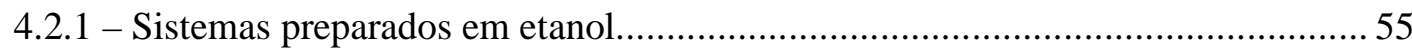

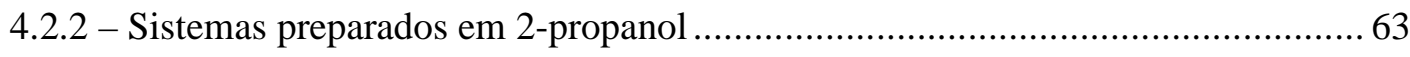

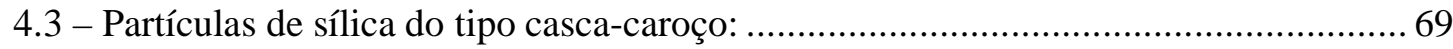

4.4 - Estudos de interação polímero/nanopartículas de sílica:............................................... 81

4.5 - Nanopartículas de sílica casca-caroço contendo dois corantes: estudos de transferência de energia e supressão de fluorescência .......................................................... 89

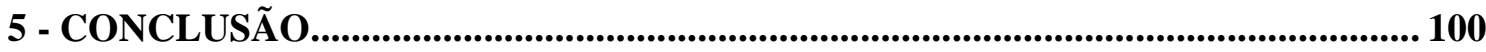

6 - REFERÊNICAS BIBLIOGRÁFICAS ....................................................................... 103 
1 - INTRODUÇÃO 


\section{1 - INTRODUÇÃO}

\section{1 - Nanopartículas de sílica}

Nos dias de hoje, muito interesse tem sido voltado para a pesquisa de nanomateriais e desenvolvimento de nanotecnologias. Nanopartículas de sílica recebem atenção especial por apresentarem uma gama de aplicações em diversas áreas da ciência que vão desde seu uso como agentes de recobrimento, de transporte e liberação controlada de compostos, assim como em sistemas que envolvem óptica e microscopia.

Atenção especial tem sido dada à utilização de nanopartículas aplicadas a ensaios biológicos e em estudos na área da saúde, devido a sua biocompatibilidade, contribuindo para o surgimento da então chamada nano-medicina, onde diferentes técnicas são empregadas para a criação de nano-sistemas multifuncionais. Dentre as aplicações, estão o transporte de moléculas de DNA e a liberação controlada de proteínas encapsuladas em sílica mesoporosa, sob condições fisiológicas. Neste sentido, outro material que chama atenção são os chamados pontos quânticos (quantum dots), que podem ser utilizados na obtenção de imagens em diagnósticos, devido à sua maior estabilidade fotoquímica e metabólica, quando comparados com fluoróforos convencionais ${ }^{[1,2]}$.

Diversos trabalhos têm sido reportados na literatura envolvendo a aplicação de nanopartículas de sílica marcadas com compostos luminescentes, onde se destacam nanopartículas contendo complexos inorgânicos (de rutênio, por exemplo) utilizadas como amplificadoras do sinal de luminescência em ensaios 
bioanalíticos $^{[13,4]}$. Seguindo a proposta de aplicação em sistemas biológicos, mas utilizando marcadores orgânicos, nanopartículas de sílica compostas por um núcleo magnético e uma camada de sílica contendo azul de metileno foram preparadas por Tada e colaboradores, para aplicação em terapia fotodinâmica no tratamento contra o câncer. A terapia se baseia no conceito de que, após irradiação, moléculas fotosensitizadoras geram espécies reativas de oxigênio $\left({ }^{1} \mathrm{O}_{2}\right)$ que causam danos aos tecidos doentes. A localização das moléculas de fotosensitizador pelos núcleos magnéticos minimiza a geração de compostos citotóxicos nas vizinhanças de tecidos não atingidos pela doença ${ }^{[5]}$.

O desenvolvimento de sensores é uma área de grande interesse de pesquisadores envolvidos no desenvolvimento de nanomateriais e nanotecnologia, uma vez que a área superficial de partículas nanométricas faz com que elas apresentem propriedades únicas no que diz respeito a efeitos eletrônicos e quânticos. Os materiais usados como sensores químicos podem apresentar diferentes estruturas que vão desde nanoesferas e pontos quânticos, usados especialmente em óptica e em ensaios bioquímicos, até nanotubos e nanobastões, geralmente empregados em sensores elétricos e eletroquímicos ${ }^{[6]}$.

Além das aplicações já mencionadas, a presença de sílica pode causar interferências em propriedades físicas/químicas de outros sistemas como, por exemplo, propriedade de materiais magnéticos e comportamento fotofísico de diferentes corantes.

O uso de nanopartículas metálicas no desenvolvimento da tecnologia de gravação magnética tem sido alvo de investigação. Como exemplo, pode-se citar o recobrimento de partículas nanométricas de ferrita de ítrio com sílica que permitiu o 
estudo de suas propriedades magnéticas, de maneira que as diferentes espessuras das camadas de recobrimento levaram a materiais com propriedades distintas ${ }^{[7]}$.

A análise do comportamento de corantes como benzoxazola e rodamina $6 \mathrm{G}$ foi realizada com o objetivo de se avaliar as variações espectrais de sua emissão de fluorescência quando inseridos em matrizes de sílica ${ }^{[8-10]}$. Análises mais apuradas, como espectroscopia de fluorescência resolvida no tempo, foram realizadas para corantes catiônicos (9-aminoacridina e auramina O) em três tipos distintos de sólidos: monólito, pó e vidros preparados por compactação sob alta pressão, sugerindo variações nas dinâmicas do estado excitado, dependendo do grau de restrição das moléculas fluoróforas ${ }^{[11]}$.

De maneira geral, pode-se visualizar as nanopartículas de sílica como um campo de pesquisa que tem levado a importantes inovações e descobertas de novos materiais, com diversas aplicações em química, fotoquímica, catálise, óptica, espectroscopia, entre outras áreas.

\section{2 - Mecanismos e métodos de preparação de nanopartículas de sílica}

Nanopartículas esféricas nanométricas podem ser obtidas pelo método de

Stöber ${ }^{[12]}$, pelo qual ocorre a hidrólise/policondensação de precursores silicatos. A reação de hidrólise/policondensação pode envolver catálise ácida ou básica. No entanto uma base como amônia aquosa, por exemplo, é usualmente empregada.

Dentre os alcoxisilanos utilizados nos processos sol-gel, destacam-se o tetraetoxiortosilicato (TEOS) e o tetrametoxiortosilicato (TMOS), cujas estruturas moleculares estão representadas na Figura 1. 
(A)<smiles>CCO[Si](OCC)(OCC)OCC</smiles>

(B)

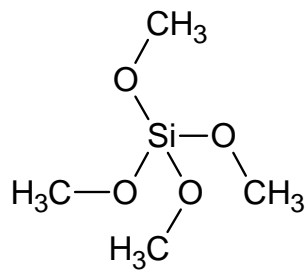

Figura 1: Estruturas moleculares do (A) TEOS e do (B) TMOS.

Os grupamentos metila e etila do TMOS e TEOS, respectivamente, têm um papel importante nestas reações, uma vez que as velocidades de reação de hidrólise/policondensação podem ser afetadas por fatores estéricos e indutivos. Estudos mostram que a hidrólise/policondensação do TMOS é bem mais rápida, portanto, embora os efeitos indutivos sejam importantes, os efeitos estéricos são preponderantes na determinação da cinética de um processo solge ${ }^{[13]}$.

As reações catalisadas por ácido ou base ocorrem por mecanismos distintos, como mostra a Figura $2^{[14,15]}$, que levam a sólidos com morfologias distintas (cadeias mais ou menos ramificadas, por exemplo) ${ }^{[16]}$. 
CATÁLISE ÁCIDA

Hidrólise

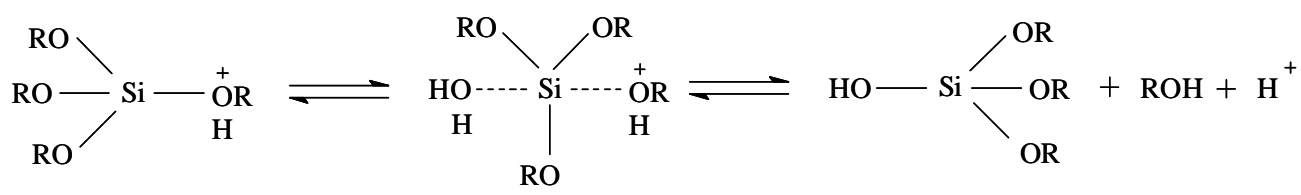

Condensação

$\mathrm{RO}-\mathrm{Si}(\mathrm{OH})_{3}+\mathrm{H}^{+} \stackrel{\text { rápida }}{\rightleftharpoons}$
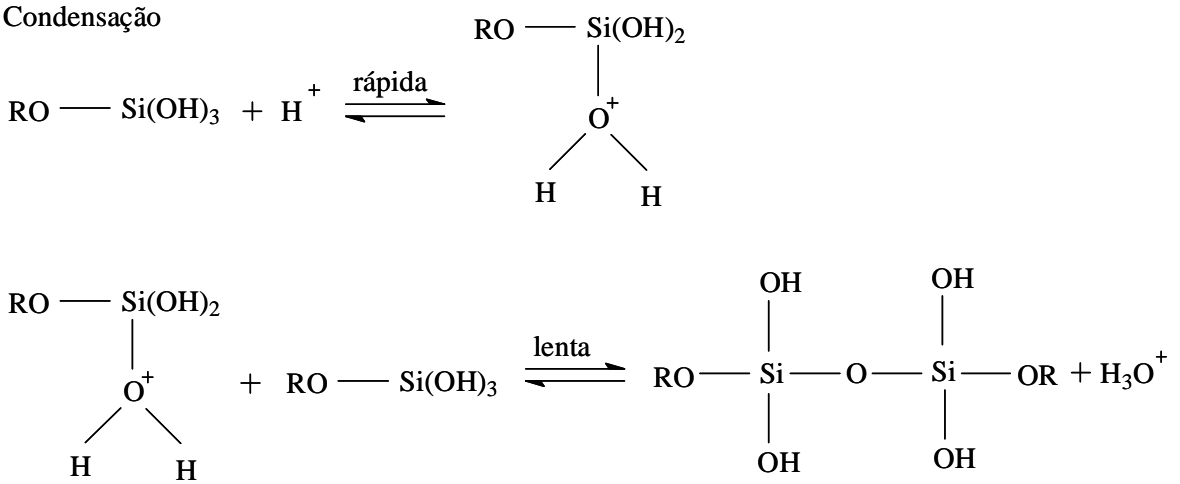

\section{CATÁLISE BÁSICA}

Hidrólise

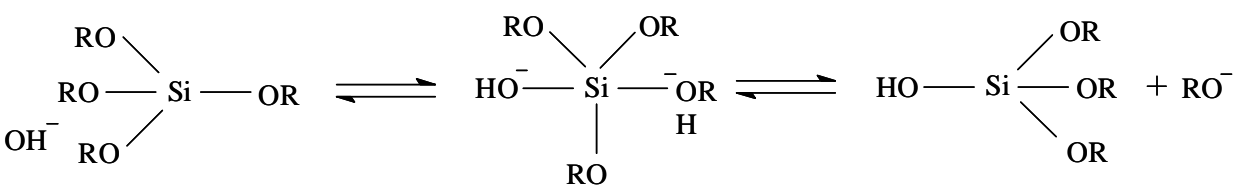

Condensação

$$
\begin{aligned}
& \mathrm{RO}-\mathrm{Si}(\mathrm{OH})_{3}+\mathrm{OH}^{-} \stackrel{\text { rápida }}{=} \mathrm{RO}-\mathrm{Si}(\mathrm{OH})_{2} \mathrm{O}^{-}+\mathrm{H}_{2} \mathrm{O} \\
& \mathrm{RO}-\mathrm{Si}(\mathrm{OH})_{3}+\mathrm{RO}-\mathrm{Si}(\mathrm{OH})_{2} \mathrm{O}^{-} \stackrel{\text { lenta }}{=} \mathrm{RO}-\mathrm{Si}(\mathrm{OH})_{2} \mathrm{O}-\mathrm{Si}(\mathrm{OH})_{2} \mathrm{OR}+\mathrm{OH}^{-}
\end{aligned}
$$

Figura 2: Mecanismos de reação de hidrólise/condensação catalisadas por ácido ou base ${ }^{[14,15]}$.

Certamente, os esquemas de reação da Figura 2 mostram, do ponto de vista químico, os mecanismos envolvidos na formação das partículas de sílica. Porém, há ricas discussões na literatura acerca dos mecanismos físicos envolvidos. 
Dois modelos foram propostos para elucidar os mecanismos físicos de crescimento da sílica: adição de monômeros ${ }^{[17,18]}$ e agregação controlada ${ }^{[19,20]}$, o que separa formação da sílica em dois eventos: nucleação e crescimento.

Os dois modelos usam diferentes abordagens para descrever o crescimento das partículas. O modelo de adição de monômeros, vai de encontro com o mecanismo de LaMer ${ }^{[21]}$ no qual, depois de uma nucleação inicial, o crescimento ocorre pela adição de monômeros hidrolisados à superfície da partícula. Por outro lado, o modelo de agregação controlada afirma que a nucleação ocorre continuamente no decorrer da reação, sendo que os primeiros núcleos se agregam uns com os outros.

Os trabalhos de Harris e van Blaaderen mostram que ambos os mecanismos são responsáveis pelo crescimento das partículas, sugerindo que a agregação controlada ocorre durante toda a reação, seguida pela adição de monômeros ${ }^{[22-24]}$. Estudos envolvendo ressonância magnética nuclear, espalhamento de raios $X$ de baixo ângulo e espalhamento de luz dinâmica, confirmam a hipótese de que ambos os mecanismos estão associados à formação das partículas. Além disso, outros autores chegam a afirmar que a competição entre os dois mecanismos é importante para se alcançar um tamanho ótimo de partículas ${ }^{[25]}$.

Há ainda na literatura, trabalhos que mostram a preparação de nanopartículas de sílica pelo método de Stöber, porém em microemulsões reversas ${ }^{[26]}$ e não em soluções alcoólicas, como é usualmente reportado. Neste tipo de preparação as micelas de surfactantes agem como meios confinados de reação e assume-se que o formato e o tamanho das partículas podem ser controlados variando-se alguns parâmetros da microemulsão, como por exemplo, a razão molar água/surfactante ou a sua natureza (surfactantes catiônicos, aniônicos, etc.) ${ }^{[27]}$. 


\section{3 - Corantes fluorescentes acridínicos e derivados (aspectos fotofísicos e fotoquímicos):}

Dentre as sondas utilizadas no desenvolvimento deste projeto, estão a safranina, auramina, 9-vinilantraceno, 9-aminoacridina e três derivados acridínicos, cujas estruturas moleculares estão mostradas no capítulo referente à parte experimental deste trabalho.

Os três últimos corantes citados merecem destaque, por terem sido preparados no Grupo de Fluorescência Molecular e por apresentarem uma fotofísica característica, que envolve processos de transferência de carga intramolecular.

A 9-aminoacridina é um corante altamente fluorescente, com rendimento quântico de fluorescência relativamente alto (0,69 em água, por exemplo) normalmente adquirido na forma de sal ${ }^{[28,29]}$. A Figura 3 mostra a estrutura molecular da 9-aminoacridina na forma protonada. A base livre é preparada pelo tratamento com hidróxido de amônio de uma solução do corante.

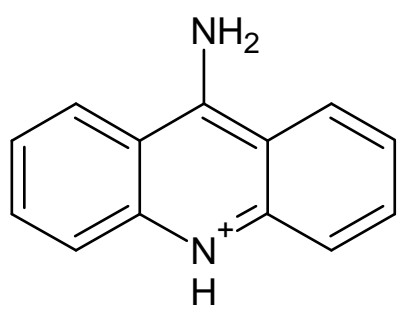

Figura 3: Estrutura molecular da 9-aminoacridina monoprotonada.

O corante 9-aminoacridina apresenta bandas estruturadas de absorção e emissão, que praticamente não sofrem alteração de perfil espectral, quando em diferentes solventes. 
O espectro de absorção apresenta bandas com máximos em 380, 400 e 428 nm. Já o espectro de emissão mostra máximos em 430, 455 e 480 nm. Em solução aquosa ou metanólica, a 9-aminoacridina apresenta uma dinâmica monoexponencial com tempo de vida da ordem de 15 ns. Espectros do corante solubilizado em metanol estão mostrados na Figura 4.
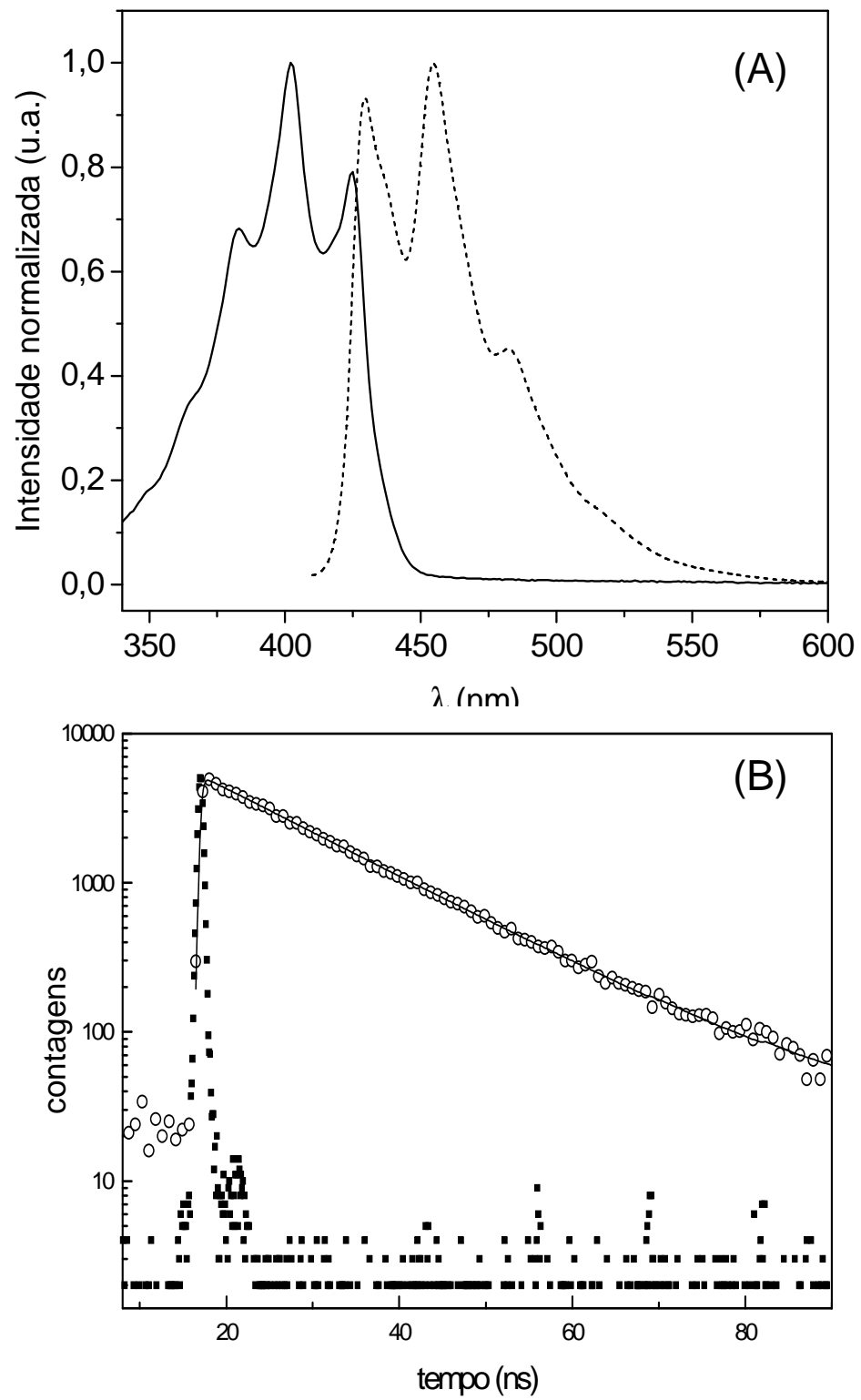

Figura 4: (A) Absorção, emissão estacionária e (B) curva de decaimento de fluorescência da 9aminoacridina, em metanol. 
Os compostos dietiletoximetilenomalonato, etil(etoximetileno)cianoacetato e etoximetilenomalonitrila (Figura 5) foram empregados na reação com 9aminoacridina para produzir derivados acridínicos com uma fotofísica diferenciada e característica $^{[30,31]}$.

\section{I}<smiles>CCO/C=C\C(=O)OCC</smiles>

II<smiles>CCO/C=C(\C#N)C(=O)OCC</smiles>

III<smiles>CCOC=C(C#N)C#N</smiles>

Figura 5: Estruturas moleculares de (I) dietiletoximetilenomalonato, (II) etil(etoximetileno)cianoacetato e (III) etoximetilenomalonitrila.

Os derivados de 9-aminoacridina com grupos retiradores de elétrons possuem uma cinética diferenciada no estado excitado, caracterizada pela emissão do cromóforo acridina nos seus estados excitados singlete localmente excitados (LE) e ainda uma emissão na região do vermelho de espécies formadas por transferência de carga intramolecular (ICT).

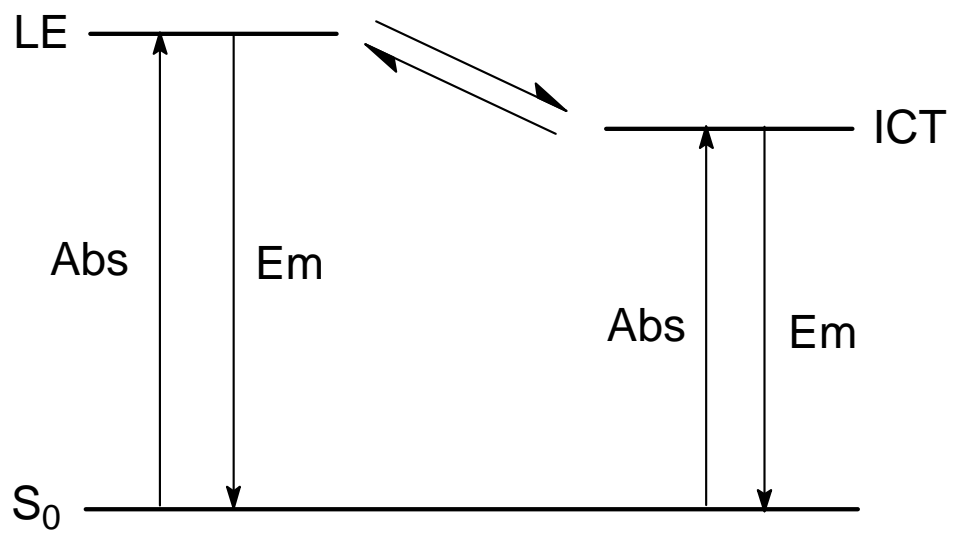

Figura 6: llustração do diagrama de energia envolvendo os estados excitados LE e ICT. 
Os derivados são sintetizados a partir do corante 9-aminoacridina e seus espectros eletrônicos são deslocados para o vermelho, quando comparados ao precursor. Além disso, os espectros perdem seu perfil estruturado e passam a apresentar uma banda larga, característica de processos de transferência de carga.
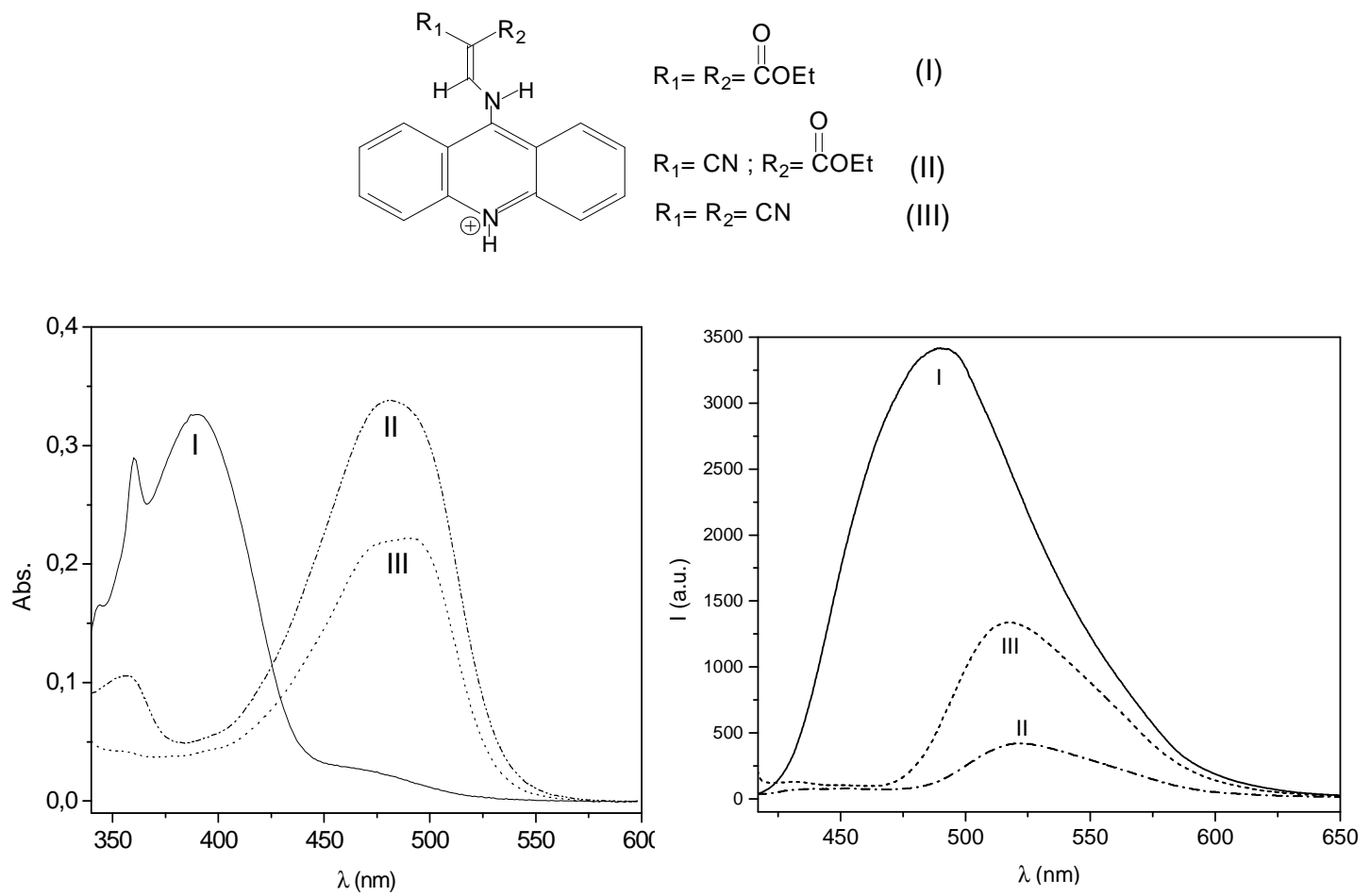

Figura 7: Espectros de absorção e emissão estacionária dos derivados acridínicos ${ }^{[19,20]}$.

O comportamento multiexponencial destes compostos confirma a presença da emissão dual. As análises resolvidas no tempo destes sistemas revelam dois componentes curtos com tempos na faixa de 160-350 ps e 1.1-3.0 ns, relacionados à formação e ao decaimento do estado ICT, mais um tempo de cerca de 9 ns, atribuído à emissão localizada do cromóforo acridina. 

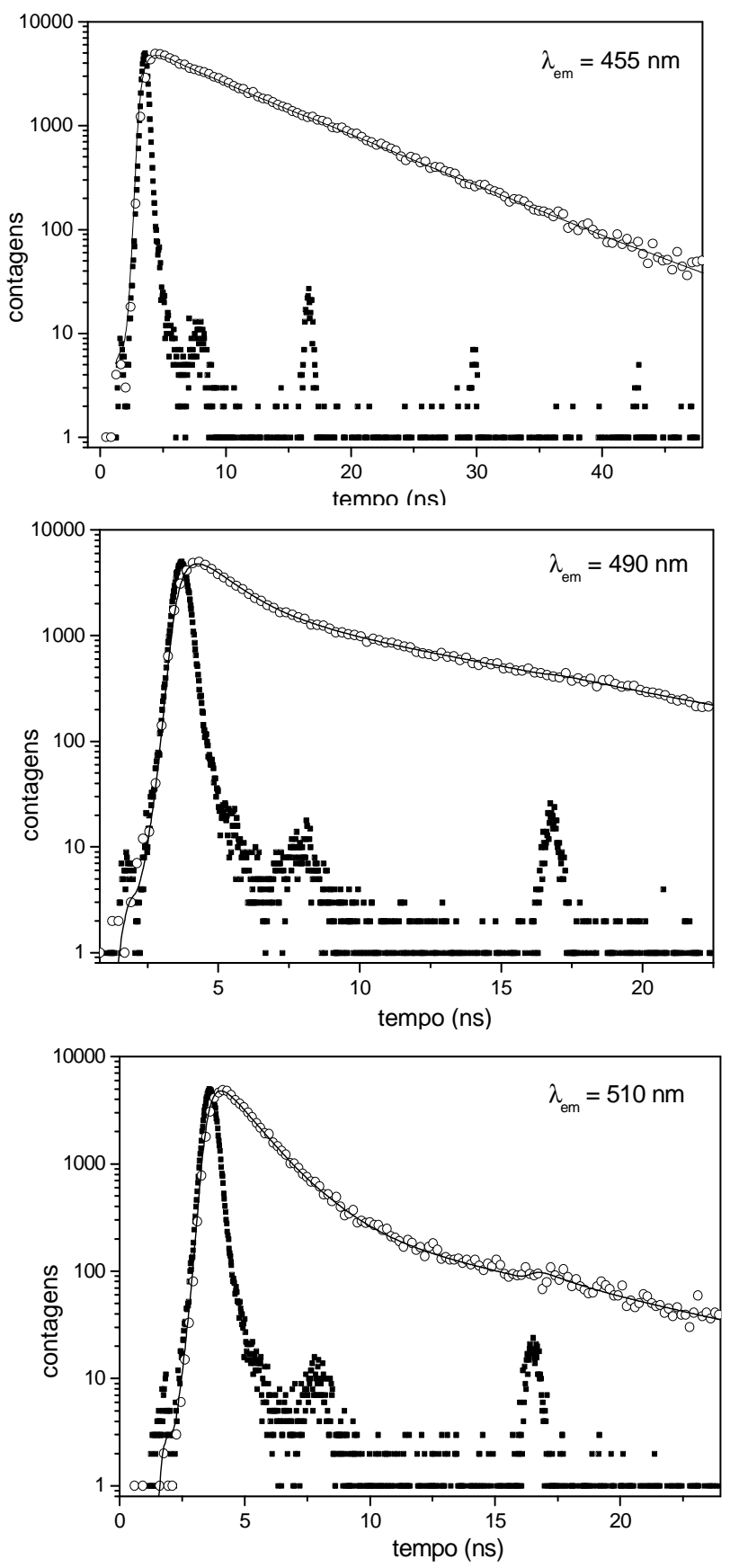

Figura 8: Exemplos de decaimentos de um dos derivados (composto II), em diferentes comprimentos de onda de emissão ${ }^{[30,31]}$.

Quando estes corantes modificados são ligados a cadeias de poli(ácido metacrílico), a dupla ligação vinílica é rompida, gerando a perda da conjugação do sistema $\pi$ e a transição óptica ICT não é mais possível. Quando ligados à cadeia 
polimérica, os derivados acridínicos apresentam comportamento fotofísico similar ao precursor 9AA, com espectros estacionários estruturados e caráter monoexponencial, com tempos de vida da ordem de $15 \mathrm{~ns}^{[32]}$.
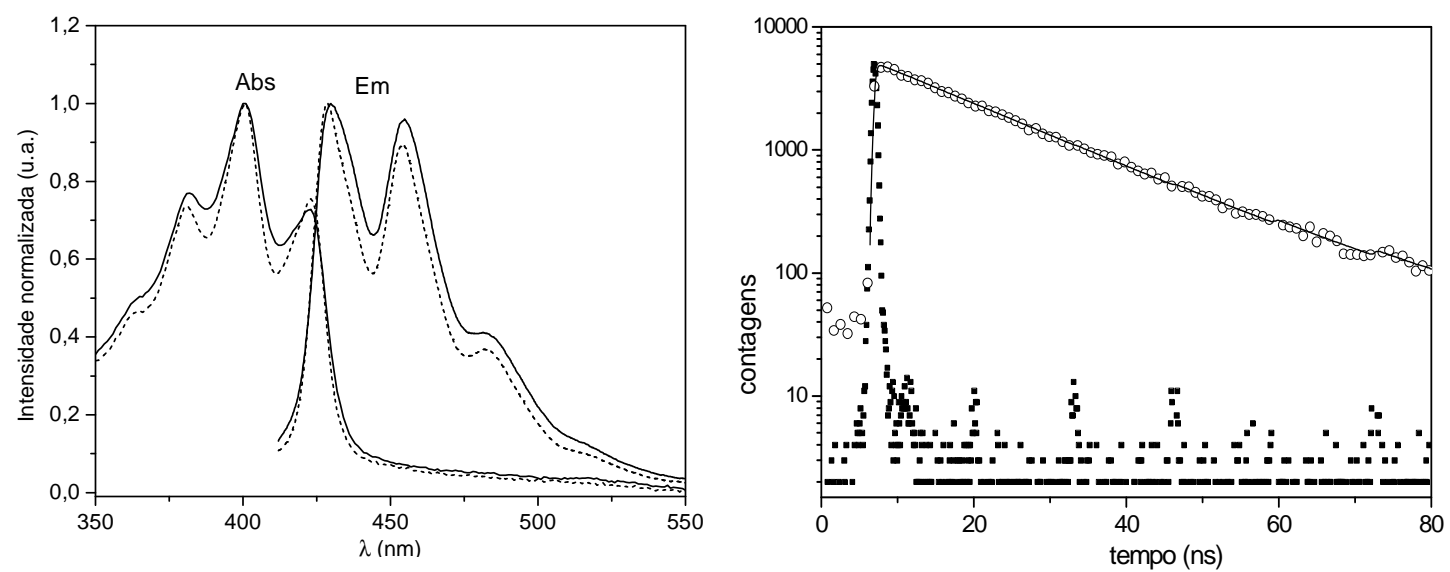

Figura 9: Absorção, emissão estacionária e decaimento de fluorescência do derivado acridínico II ligado à cadeia de poli(ácido metacrílico) ${ }^{[32]}$.

O comportamento dos derivados acridínicos em solução e ligados a cadeias poliméricas os torna bons candidatos a marcadores de nanopartículas, pois isto permitirá o estudo fotofísico de suas características em superfície, dando continuidade ao trabalho já realizado pelo grupo.

\section{4 - Sondas fluorescentes como marcadores em polímeros e nanopartículas:}

Sondas fluorescentes e cromóforos (corantes) são compostos de propriedades químicas e físicas que os tornam ferramentas úteis em técnicas 
analíticas e na realização de estudos através de medidas de absorção de luz e emissão de fluorescência ${ }^{[33-35]}$.

Compostos que não apresentam emissão de fluorescência intrínseca podem ser investigados, através de estudos de absorção e emissão, desde que sejam marcados com uma sonda.

Desta forma, características moleculares dos corantes podem ser obtidas com sucesso ao se observar suas propriedades fotofísicas em sistemas microheterogêneos tais como polímeros em solução, micelas, sistemas biológicos e partículas de sílica.

No caso de polímeros vinílicos e acrílicos, a marcação com uma sonda fluorescente tornou-se trivial, uma vez que pode ser realizada com relativa facilidade através da co-polimerização térmica dos monômeros com moléculas cromóforas que possuam uma ligação $\mathrm{C}=\mathrm{C}$.

A marcação de polímeros torna-se uma ferramenta útil no estudo de dinâmicas de polimerização e caracterização de sistemas poliméricos.

A ativação de poliolefinas através da introdução de anidrido maleico no polímero, por exemplo, trouxe a necessidade de se avaliar o grau de incorporação e distribuição destas moléculas. Pesquisas foram realizadas através de técnicas de RMN, porém se mostraram inconclusivas ${ }^{[36]}$, de modo que Zhang e colaboradores concluíram que estas propriedades deveriam ser avaliadas por uma técnica que permitisse medidas diretas. Para tal, os polímeros foram marcados com corantes que permitiram a determinação do grau de incorporação do anidrido maleico e sua distribuição ao longo da cadeia polimérica, por técnicas de fluorescência estacionária e resolvida no tempo ${ }^{[37]}$. 
A inclusão de sondas permite ainda o estudo da transição conformacional de cadeias poliméricas em diferentes meios ${ }^{[38]}$. A transição conformacional do poli(ácido metacrílico) foi estudada por anisotropia de fluorescência resolvida no tempo ${ }^{[39]}$, onde decaimentos de fluorescência do polímero marcado com derivados acridínicos foram registrados com polarização vertical (VV) e horizontal (VH).

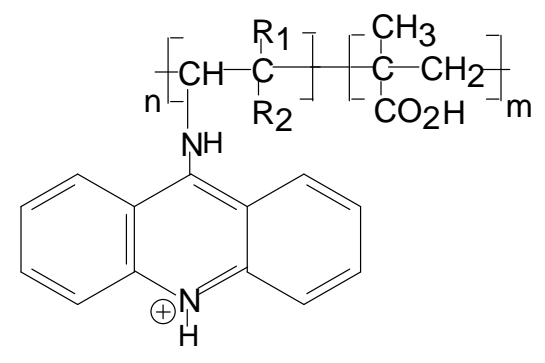

Figura 10: Representação da cadeia de poli(ácido metacrílico) marcado com derivado acridínico. $R_{1}=$ $\mathrm{CN}, \mathrm{R}_{2}=\mathrm{COOEt} ; m>n$.

Os diferentes tempos de relaxação rotacional permitem verificar se a cadeia polimérica em questão se encontra enovelada ou estendida, em diferentes valores de $\mathrm{pH}$, devido à interação dos grupos carboxilatos neutros ou carregados (em consequencia de sua dissociação) $^{[32]}$. Na Figura 11 é mostrado um exemplo, utilizando-se PAM marcado com 9-aminoacridinametilenocianoetilacetato. 


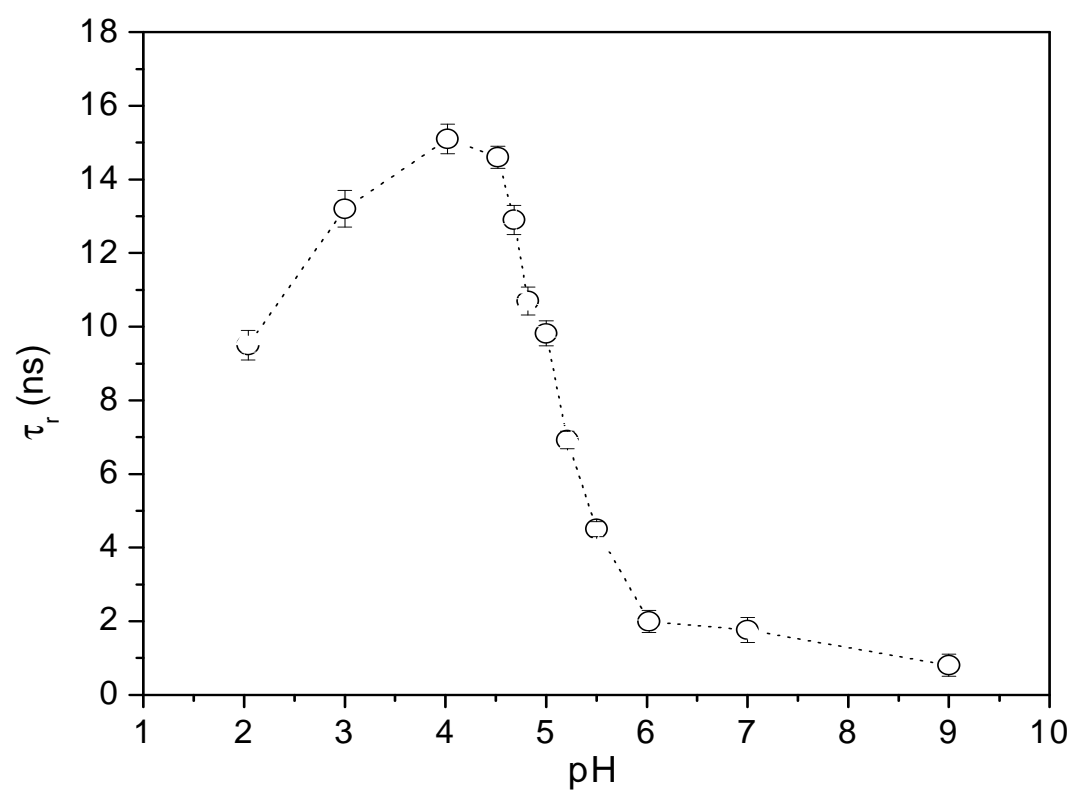

Figura 11: Variação no tempo de relaxação, indicando a transição conformacional de poli(ácido metacrílico) marcado com 9-aminoacridinametilenocianoetilacetato ${ }^{[32]}$.

Além de marcadores de sistemas poliméricos, compostos fluorescentes podem também ser estudados na presença de superfícies sólidas, como por exemplo, $\mathrm{TiO}_{2}, \mathrm{Al}_{2} \mathrm{O}_{3}, \mathrm{MgO}, \mathrm{SiO}_{2}$, nanopartículas de prata, entre outras.

Filmes, vidros ou partículas de sílica são considerados, em geral, materiais opticamente inertes, tornando-os boas matrizes ou suportes em estudos que envolvem fenômenos de absorção e emissão de luz ${ }^{[40,41]}$. Entretanto, esta afirmação deve ser observada com cautela já que, embora considerada espectroscopicamente inerte, a sílica apresenta luminescência, quando excitada na região do ultravioleta ${ }^{[42]}$. Assim, a escolha de sílica como matriz para estudos fotofísicos é acertada, quando a sonda que se deseja empregar não necessita de excitação em comprimentos de ondas na região ultravioleta.

O estudo do comportamento fotofísico de corantes na presença de sílica é, em geral, realizado com o corante apenas adsorvido ou encapsulado em meio à 
rede de sílica e comumente são utilizadas partículas de sílica de origem comercial[ ${ }^{[43-}$ 45].

Em meados de 1990, Matijevic e colaboradores reportaram trabalhos então inovadores, envolvendo a impregnação de uma série de corantes orgânicos em partículas de Ludox modificadas com alumina ou em nanoesferas preparadas a partir do tetraetoxiortosilicato. Corantes aniônicos, como Eozina Y, e catiônicos, como azul de metileno, foram impregnados em partículas de sílica e em outros diferentes sóis $\left(\mathrm{Al}(\mathrm{OH})_{3}, \mathrm{Zr}(\mathrm{OH})_{2} \mathrm{CO}_{3}, \mathrm{Cd}\left(\mathrm{PO}_{4}\right)_{2}\right.$, entre outros), determinando a importância de se conhecer a estrutura molecular do corante utilizado e a influência de fatores como valor de $\mathrm{pH}$. No caso do azul de metileno (Figura 12), por exemplo, a coordenação do átomo de enxofre com os grupos $\equiv \mathrm{SiO}^{-}$pode gerar uma forte interação, no entanto outros grupamentos na mesma molécula (como o nitrogênio heterocíclico) podem inibir tal interação ${ }^{[46,47]}$. Assim, é fundamental um cuidado especial na escolha dos marcadores.

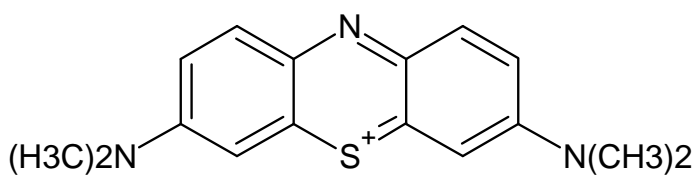

Figura 12: Estrutura molecular do corante catiônico azul de metileno, utilizado no estudo da adsorção em esferas de sílica ${ }^{[46]}$.

Compostos acridínicos são considerados boas sondas fluorescentes por possuírem rendimentos quânticos de fluorescência relativamente altos, como já foi dito anteriormente $\left(0,69\right.$ para 9-aminoacridina em água, por exemplo) ${ }^{[28,45]}$.

Negrón-Encarnación e colaboradores realizaram a caracterização de espécies acridínicas (AN) adsorvidas em diferentes matrizes, inclusive em $\mathrm{SiO}_{2}$, através das 
técnicas de refletância difusa, fluorescência estacionária e resolvida no tempo ${ }^{[45]}$. Em sílica, os espectros de absorção apresentam bandas que sugerem que no estado fundamental estão presentes espécies acridínicas protonadas $\left(\mathrm{ANH}^{+}\right)$, neutras (AN) e fazendo ligações de hidrogênio $(\mathrm{AN} \cdots \mathrm{HO})$. Ao menos que algum processo fotoquímico estivesse ocorrendo, estas deveriam ser as mesmas espécies observadas no estado excitado. No entanto, o espectro de emissão estacionária é característico da forma protonada do corante, o que sugere que podem estar ocorrendo reações de transferência de próton no estado excitado. O espectro de excitação é similar ao de absorção (refletância difusa) sugerindo que as espécies que emitem são $\mathrm{ANH}^{+}$, AN e AN...HO. Os resultados sugerem então que a pequena contribuição das espécies neutras é conseqüência de reações fotoprotolíticas. Tal suposição é confirmada pelas análises das curvas de decaimento que mostram

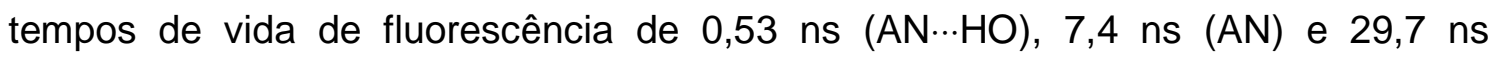
$\left(\mathrm{ANH}^{+}\right)^{[45]}$.

Alternativamente aos estudos de corantes adsorvidos ou encapsulados em partículas, no caso de partículas de sílica a introdução de um grupo trialcóxido diretamente à superfície permite a ligação covalente de corantes orgânicos ${ }^{[48]}$. $O$ processo envolve a imobilização de um grupo funcional orgânico, usando um organosilano como reagente intermediário ${ }^{[49-53]}$.

Processos de transferência de energia envolvendo fluoresceína, um corante já bem caracterizado fotofisicamente em diferentes meios, foram estudados em sílica preparada a partir de TEOS. A fluoresceína foi modificada com (3aminopropil)trietoxisilano, gerando um composto (Figura 13) passível de polimerização juntamente com o TEOS. Medidas espectroscópicas mostraram a banda de emissão estacionária característica da fluoresceína $\left(\lambda_{\max }=530 \mathrm{~nm}\right)$ e 
tempo de vida de fluorescência de 3,9 ns. As análises das medidas levaram à conclusão de que as moléculas de corante estão distribuídas de maneira não homogenia. Assim, em algumas regiões da rede de sílica, as moléculas de fluoresceína estão muito próximas, levando a um processo de auto-supressão de fluorescência. Porém, observam-se também regiões onde as moléculas de encontram próximas o suficiente para transferir energia, mas não tão próximas a ponto de gerar a auto-supressã $0^{[48]}$.

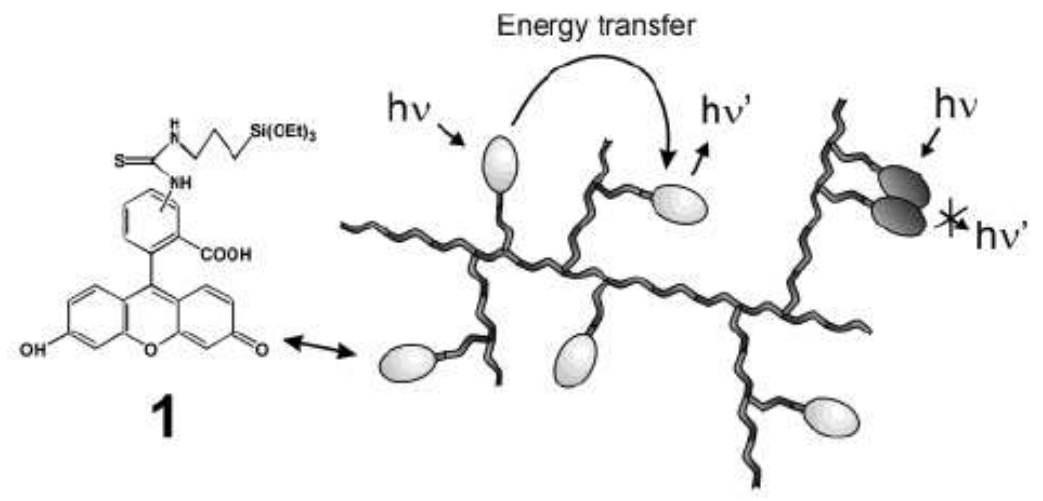

Figura 13: Representação dos processos fotofísicos que ocorrem nas nanopartículas marcadas com fluoresceína modificada (ligada covalentemente) ${ }^{[48]}$.

A literatura mostra que as partículas de sílica se apresentam como excelentes matrizes, já que sua preparação permite a encapsulação de sondas ou até mesmo a modificação de sua superfície com o objetivo de se ancorar moléculas de interesse. 


\section{2 - OBJETIVOS}




\section{2 - OBJETIVOS}

Este trabalho tem como objetivo:

> Preparar partículas de sílica marcadas com compostos fluorescentes, estudando sistemas com as seguintes características:

$\checkmark$ Partículas de sílica de origem comercial com diâmetro médio de $20 \mu \mathrm{m}$;

$\checkmark$ Nanopartículas de sílica preparadas pelo método de Stöber ou pela metodologia casca-caroço, em etanol ou 2-propanol, utilizando tetraetoxiortosilicato como precursor;

$\checkmark$ Utilizando 9-aminoacridina, 9-aminoacridinametilenodietilmalonato, 9aminoacridinametilenocianoetilacetato, 9-aminoacridinametilenomalonitrila, 9vinilantraceno, safranina $\mathrm{O}$ ou auramina como marcadores fluorescentes;

Investigar o comportamento fotofísico dos fluoróforos em nanopartículas por:

$\checkmark$ Emissão de fluorescência estacionária, avaliando possíveis alterações nos perfis espectrais dos marcadores, devido à encapsulação na matriz de sílica;

$\checkmark$ Emissão de fluorescência resolvida no tempo, visando a determinação dos tempos de vida de fluorescência dos compostos encapsulados;

Avaliar o processo de transferência de energia e supressão de fluorescência em nanopartículas de sílica contendo 9-aminoacridina e safranina $O$, por meio de medidas de emissão estacionária e decaimentos de fluorescência. 
3 - PARTE EXPERIMENTAL

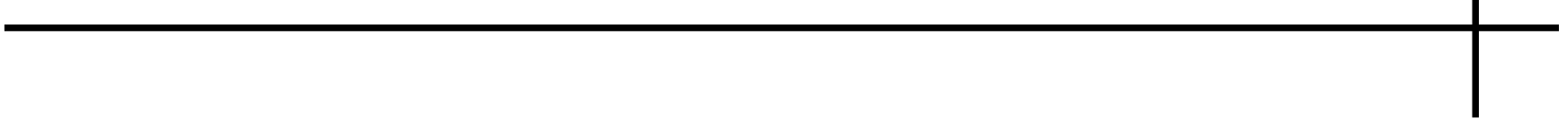




\section{3 - PARTE EXPERIMENTAL}

\section{1 - Reagentes e solventes:}

Os seguintes solventes foram empregados nas preparações ou nas medidas espectroscópicas: etanol (Quemis, 99 \%, grau P.A), metanol (J.T. Backer, grau HPLC), 2-propanol (J.T. Backer, grau HPLC), acetona (J.T. Backer, grau HPLC), tolueno (J.T. Backer, 99 \%) e tetrahidrofurano (Synth, $99 \%$ ).

Foram utilizados os seguintes reagentes no decorrer deste trabalho: sílica gel (Aldrich Chemical Company Inc., 1-20 $\mu \mathrm{m}$ ), 3-(trimetoxisilil) propilmetacrilato (Acros Organics, $98 \%$ ), peróxido de benzoíla (Synth, $98 \%$ ), metacrilato de metila (Aldrich Chemical Company Inc., 98 \%), tetraetilortosilicato (Fluka, 98 \%), hidróxido de amônio (Quemis, 28-30 \%), 9-aminoacridina (Aldrich Chemical Company Inc., 99\%), safranina $O$ (Aldrich Chemical Company Inc., $97 \%$ ), 9-vinilantraceno (Aldrich Chemical Company Inc., 97 \%) e auramina O (Merck, para microscopia).

As estruturas moleculares dos marcadores utilizados estão mostradas na Figura 14. 
<smiles>Cc1cc2nc3cc(C)c(N)cc3[n+](-c3ccccc3)c2cc1N</smiles>

Safranina $O$<smiles>Nc1c2ccccc2nc2ccccc12</smiles>

9-aminoacridina<smiles>[R7]C([R7])=CNc1c2ccccc2[nH+]c2ccccc12</smiles><smiles>[R]P=[R]C(=O)OCC</smiles>

9-aminoacridinametilenodietilmalonato (9AA I) 9-aminoacridinametilenocianoetilacetato (9AA II) 9-aminoacridinametilenomalonitrila (9AAIII)

Figura 14: Estruturas moleculares dos marcadores fluorescentes utilizados no decorrer do trabalho. 


\section{2 - Equipamentos e técnicas utilizadas:}

As nanopartículas de sílica foram caracterizadas, em relação à forma, grau de agregação e tamanho por microscopia eletrônica de varredura, em um equipamento LEO (modelo 440) com detector OXFORD, operando com feixe de elétrons de 20 $\mathrm{kV}$, corrente de 2,62 A e I probe de $150 \mathrm{pA}$. As amostras foram recobertas com $10 \mathrm{~nm}$ de ouro em um metalizador Coating System BAL-TEC MED 020 e mantidas em dessecador até o momento de análise.

Foram realizadas medidas de mobilidade para a determinação do potencial zeta das nanopartículas no equipamento Zeta PALS da Brookhaven Instruments corporation (Grupo de Físico-Química Orgânica do IQSC). As nanopartículas foram suspensas em água e condicionadas em cubetas de acrílico.

Para as medidas de absorção foi utilizado um espectrofotômetro Cary, modelo 5G, localizado na Central de Análises Químicas do IQSC.

Já as medidas de emissão estacionária de fluorescência foram realizadas em um espectrofluorímetro Hitachi, modelo F-4500, ou em um espectrômetro da Edinburgh Instruments, modelo CD-900.

Para as medidas espectroscópicas, as amostras foram condicionadas em cubetas de quartzo, com caminho óptico de $1 \mathrm{~cm}$, ou em lâminas suporte, no caso das medidas realizadas com as amostras no estado sólido, na configuração para excitação frontal (front-face), como mostra a Figura 15. 


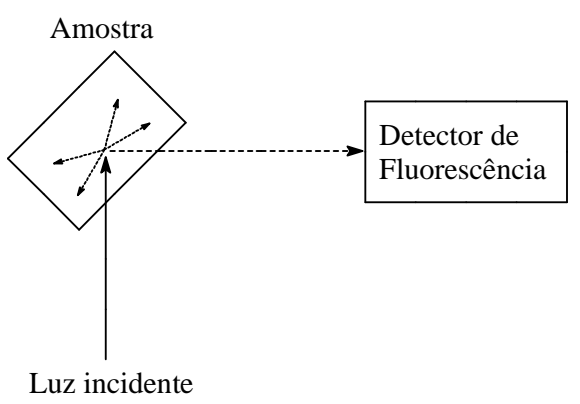

Figura 15: Configuração experimental das medidas realizadas com amostras no estado sólido.

As medidas de fluorescência resolvida no tempo (decaimentos de fluorescência) foram realizadas no espectrômetro equipado com polarizadores GlanLaser. Um esquema geral do equipamento no Laboratório de Fluorescência Molecular é mostrado na Figura 16. Como detector foi utilizado um sistema PMTMCP (R3809U-50, Hamamatsu), resfriado por um sistema Peltier. Os pulsos de excitação na região de 780-840 nm foram gerados por um sistema de laser de alta intensidade e pulsos ultracurtos. Este sistema é constituído de Laser Verdi/Coherent 5W bombeando um Ti-Safira (Coherent Mira Modelo XW) gerando pulsos de 200 fs. A utilização de um dobrador de freqüência para geração de segundo harmônico, resultou em pulsos para excitação em $400 \mathrm{~nm}$.

A medida dos tempos de vida é realizada excitando a amostra com uma fonte de luz pulsada, de forma que, a cada pulso de excitação, apenas um único fóton é detectado. Já o decaimento da intensidade de fluorescência é adquirido com o acúmulo do número de contagens.

Para calcular os tempos de vida de fluorescência é usada a análise de reconvolução. Este procedimento envolve a convolução do decaimento da amostra com a resposta instrumental (IRF - instrument response function). 

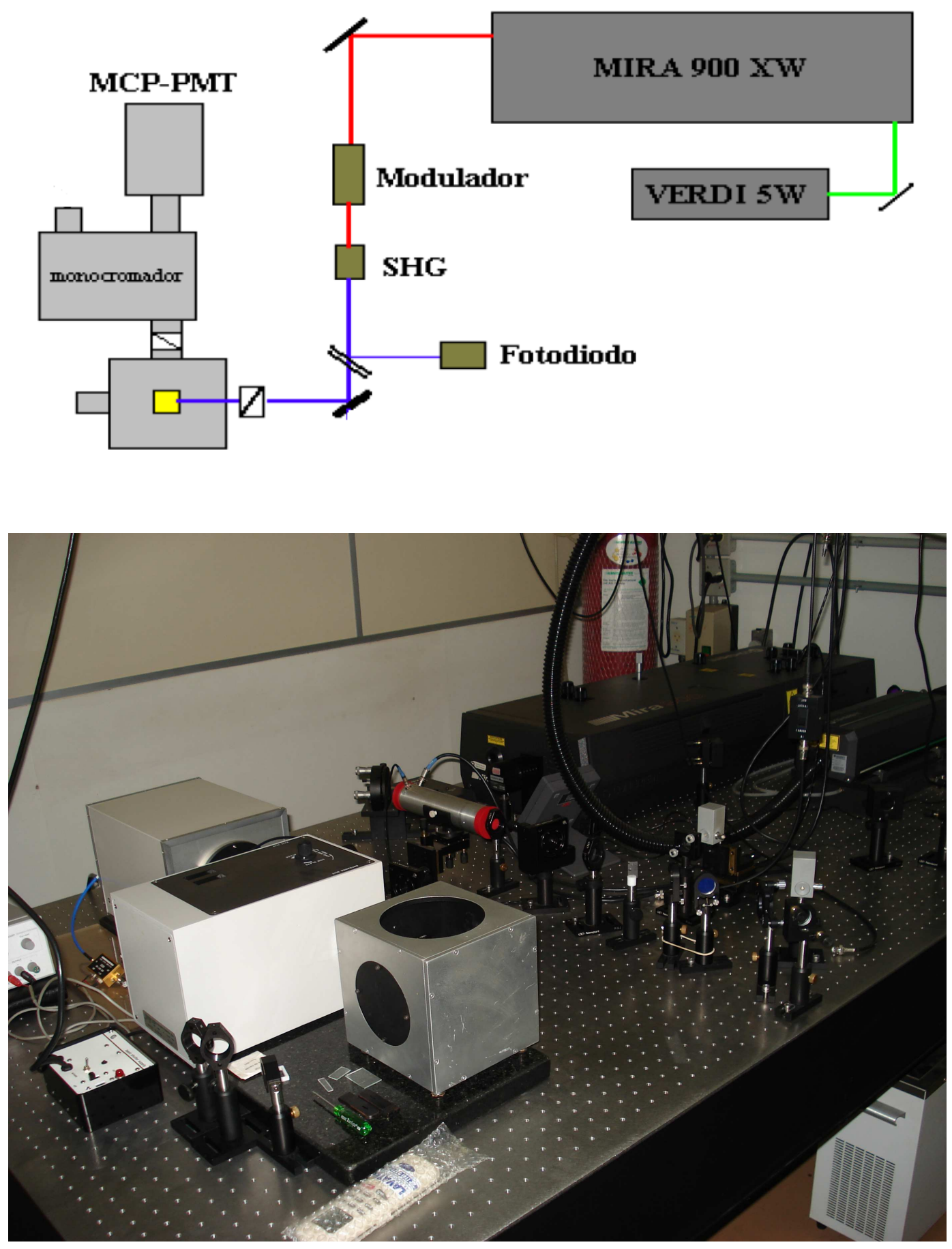

Figura 16: Sistema laser utilizado no Laboratório de Fluorescência Molecular. 


\section{3 - Preparação de sondas acridínicas modificadas:}

A derivatização do corante 9-aminoacridina foi realizada através da sua reação com:

- dietiletoximetilenomalonato, gerando o composto 9AA-I (9aminoacridinametilenodietilmalonato)

- etil(etoximetileno)cianoacetato, gerando o composto 9AA-II (9aminoacridinametilenocianoetilacetato)

- etoximetilenomalonitrila, gerando o composto 9AA-III (9aminoacridinametilenomalonitrila)

A 9-aminoacridina foi empregada na forma de base livre, preparada pela adição de hidróxido de amônio concentrado a uma solução do corante. Em um balão, reagiu-se 1,0 mmol da 9-aminoacridina com 1,3 mmol do composto vinílico, em etanol seco em peneira molecular. O sistema foi mantido sob aquecimento e refluxo por cerca de 6 horas. Na Figura 17 está mostrado o esquema de reação ${ }^{[19,20]}$. Após a remoção do solvente, o sólido obtido foi separado por cromatografia em coluna de vidro, com gradiente de concentração de hexano/acetato de etila. Os produtos finais foram secos e mantidos em dessecador.

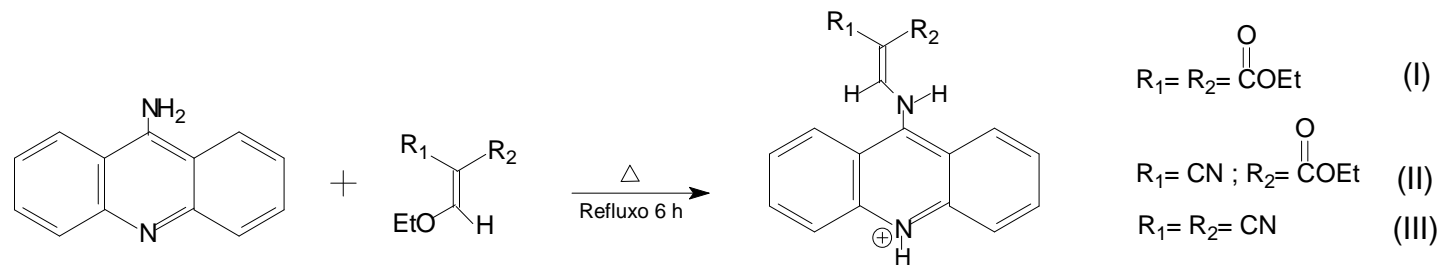

Figura 17: Reação de derivatização da 9-aminoacridina com compostos vinílicos. 


\section{4 - Inserção de compostos fluorescentes em polímero:}

Dentre outras sondas fluorescentes, o composto 9AA-III foi inserido ao poli(metacrilato de metila) $(\mathrm{PMMA})^{[54]}$.

O copolímero poli(MMA)-co-(9AA-III) foi preparado a partir da copolimerização térmica de metilmetacrilato com baixa concentração de 9AA-III $(0,5 \%$ em peso), utilizando-se peróxido de benzoíla como iniciador. O sistema foi submetido ao borbulhamento de nitrogênio, visando a eliminação de oxigênio, possível inibidor da copolimerização radicalar. O copolímero foi purificado via precipitação seletiva, utilizando-se os solventes tolueno e metanol, para retirada de substâncias que não reagiram. O produto final foi seco e mantido em dessecador.

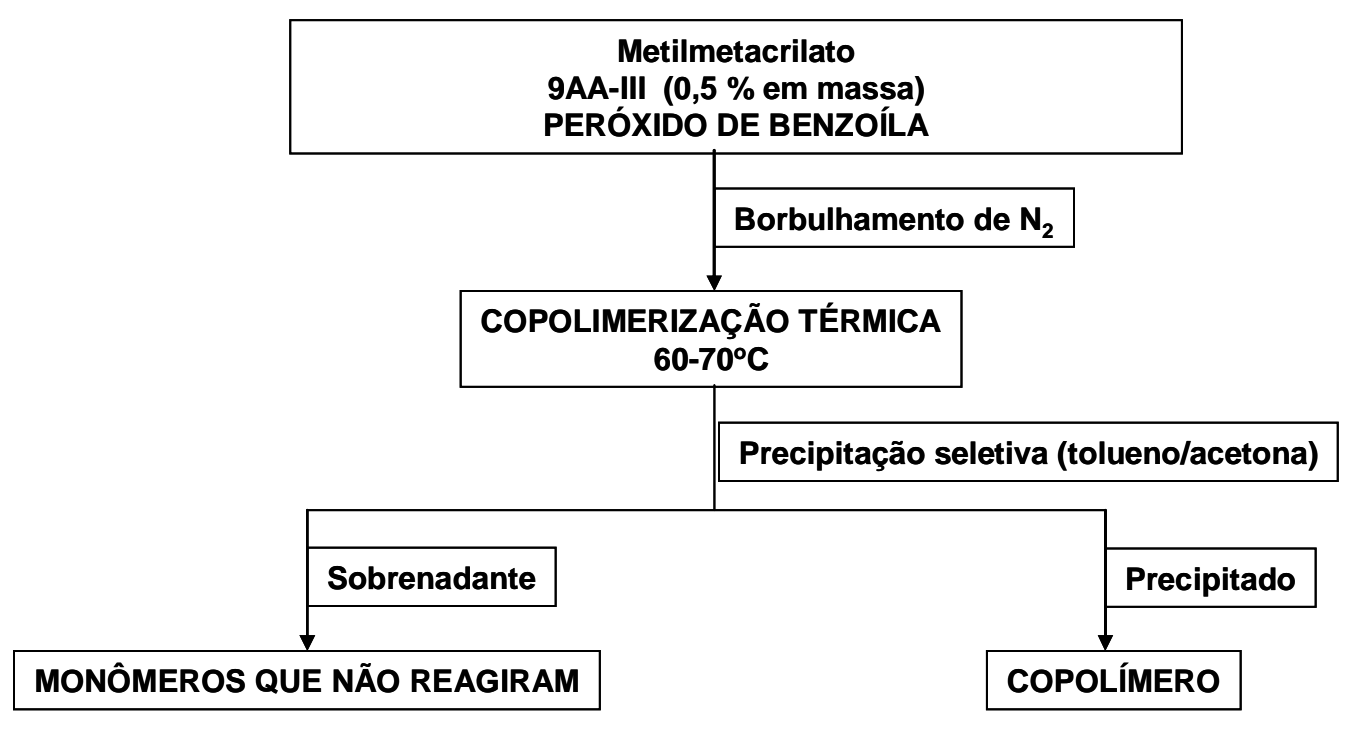

Figura 18: Esquema de copolimerização do metacrilato de metila com o 9AA-III. 


\section{5 - Funcionalização de partículas de sílica comercial e inclusão de sondas na superfície:}

Com o objetivo de se obter uma superfície passível de marcação, a foi realizada a modificação da superfície de sílica gel obtida comercialmente. As partículas de sílica gel, com tamanho entre $1-20 \mu \mathrm{m}$, foram ativadas por $4 \mathrm{~h}$ a $100^{\circ} \mathrm{C}$, sob vácuo. Foi realizada a reação de sililação ${ }^{[55]}$ da superfície pela adição do agente intermediário 3 - (trimetoxisilil) propilmetacrilato (TMSPM) a uma suspensão de sílica gel recentemente ativada, sob refluxo de tolueno e sob agitação por $6 \mathrm{~h}$. $\mathrm{O}$ sólido modificado foi lavado diversas vezes com tolueno, acetona, etanol e água gelados. Por fim, o material foi seco na estufa a vácuo, a $50^{\circ} \mathrm{C}$.

Um esquema das reações envolvidas nesta etapa é mostrado na Figura 19.

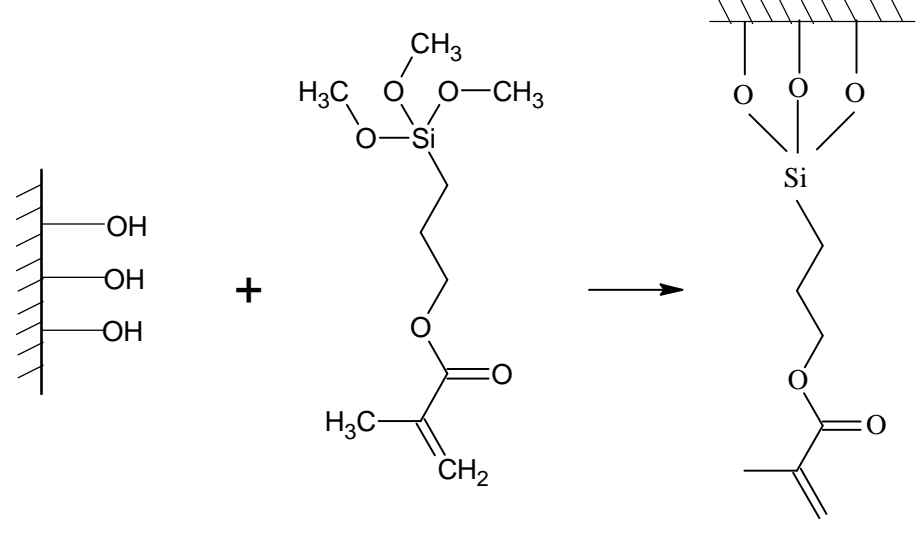

Figura 19: Esquema de sililação das partículas comerciais.

Uma vez que a superfície de sílica já se encontrava modificada, a etapa seguinte foi a inclusão das sondas fluorescentes de interesse. Para tal, foi realizada copolimerização térmica do marcador contendo uma dupla ligação vinílica com a sílica modificada, utilizando peróxido de benzoíla como iniciador da polimerização. 
Assim, uma solução do marcador em tolueno foi adicionada a uma suspensão da sílica modificada (no mesmo solvente), sob agitação constante. Este sistema foi mantido sob refluxo, por 3 horas e a $70{ }^{\circ} \mathrm{C}$. Um esquema reacional da inclusão de derivados acridínicos à superfície é mostrado na Figura 20. O produto final foi lavado com solventes de diferentes polaridades, para garantir a retirada de compostos que não reagiram. Posteriormente, a sílica modificada e com os marcadores incorporados foi seca em estufa a vácuo a $50^{\circ} \mathrm{C}$.

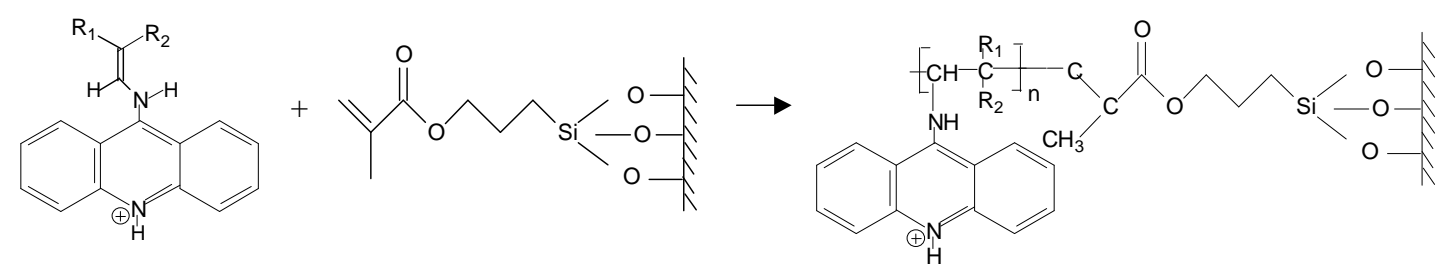

Figura 20: Incorporação dos derivados acridínicos à superfície de sílica.

\section{6 - Preparação de nanopartículas de sílica pelo método de Stöber:}

As nanopartículas de sílica foram preparadas pelo método de Stöber ${ }^{[12]}$, no qual ocorre a hidrólise/policondensação do precursor. Em todos os casos o tetraetoxiortosilicato (TEOS, Figura 21) foi usado como precursor. 


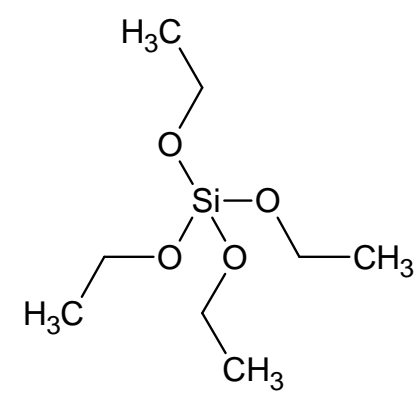

Figura 21: Estrutura molecular do TEOS.

Com o objetivo de se obter nanopartículas uniformes, com baixo grau de agregação e monodispersividade em relação à forma e tamanho, alguns parâmetros de ração foram variados, como por exemplo, o solvente (etanol ou 2-propanol), o catalisador (ácido ou básico) e a temperatura (temperatura ambiente ou $40{ }^{\circ} \mathrm{C}$ ).

Em geral, a reação foi realizada solubilizando-se sob agitação constante, o precursor TEOS, água, o catalisador e a solução do marcador que se desejava encapsular. A concentração de marcador utilizada foi da ordem de $10^{-6}-10^{-4} \mathrm{~mol} . \mathrm{L}^{-1}$ no meio reacional. Depois de alguns minutos de agitação para homogeneizar o meio, foi adicionada água e o sistema foi deixado reagir por 1 hora, quando o sistema foi colocado em banho de gelo para garantir que a reação cessasse. Depois de completada a reação, as nanopartículas foram isoladas por centrifugação $\left(40 \mathrm{~min} / 17^{\circ} \mathrm{C} / 8000 \mathrm{rpm}\right)$, secas em estufa a vácuo e mantidas em dessecador.

Como já foi dito acima, alguns dos parâmetros de reação foram variados, inclusive as razões molares entre os reagentes e catalisador. A Tabela 1, resume a série de diferentes preparações realizadas e identifica o marcador utilizado em cada uma delas. 
Tabela 1: Siglas utilizadas para denotar cada sistema e principais parâmetros de suas preparações

\begin{tabular}{|c|c|c|c|c|c|}
\hline Sistema & $\begin{array}{l}\text { método de } \\
\text { preparação }\end{array}$ & $\begin{array}{c}\text { razão } \\
\text { molar } \\
\text { TEOS: } \\
\text { H2O: } \\
\text { catalisador }\end{array}$ & solvente & catalisador & marcador ${ }^{*}$ \\
\hline 1_Si9VA ${ }^{a}$ & Stöber & $1: 21: 14$ & etanol & $\mathrm{NH}_{3}$ aquosa & $9 \mathrm{VA}$ \\
\hline 1_Si9VA/TMSPM ${ }^{a, b}$ & Stöber & $1: 21: 14$ & etanol & $\mathrm{NH}_{3}$ aquosa & $9 \mathrm{VA}$ \\
\hline 1_Si9AAII ${ }^{a}$ & Stöber & $1: 21: 14$ & etanol & $\mathrm{CH}_{3} \mathrm{COOH}$ & 9AAII \\
\hline 1_SiSf ${ }^{a}$ & Stöber & $1: 21: 14$ & etanol & $\mathrm{CH}_{3} \mathrm{COOH}$ & Safranina $\mathrm{O}$ \\
\hline 2_Si9AAII ${ }^{c}$ & Stöber & $1: 21: 0,5$ & 2-propanol & $\mathrm{NH}_{3}$ aquosa & 9AAII \\
\hline 2_SiSf ${ }^{c}$ & Stöber & $1: 21: 0,5$ & 2-propanol & $\mathrm{NH}_{3}$ aquosa & Safranina $\mathrm{O}$ \\
\hline 2_Si9AA ${ }^{c}$ & Stöber & $1: 21: 0,5$ & 2-propanol & $\mathrm{NH}_{3}$ aquosa & 9AA \\
\hline$C S_{-} S f^{c}$ & casca-caroço & $1: 21: 0,5$ & 2-propanol & $\mathrm{NH}_{3}$ aquosa & Safranina $\mathrm{O}$ \\
\hline$C S_{-} 9 A A^{c}$ & casca-caroço & $1: 21: 0,5$ & 2-propanol & $\mathrm{NH}_{3}$ aquosa & 9AA \\
\hline$C S_{-} 9 A A I I^{c}$ & casca-caroço & $1: 21: 0,5$ & 2-propanol & $\mathrm{NH}_{3}$ aquosa & 9AAII \\
\hline$C S_{-} A u^{c}$ & casca-caroço & $1: 21: 0,5$ & 2-propanol & $\mathrm{NH}_{3}$ aquosa & Auramina \\
\hline$C S_{-} P M M A-9 A A I I I^{c}$ & casca-caroço & $1: 21: 0,5$ & 2-propanol & $\mathrm{NH}_{3}$ aquosa & $\begin{array}{l}\text { PMMA- } \\
\text { 9AAIII }\end{array}$ \\
\hline$C S \_S f \_9 A A^{c}$ & casca-caroço & $1: 21: 0,5$ & 2-propanol & $\mathrm{NH}_{3}$ aquosa & $\begin{array}{c}\text { Safranina } \mathrm{O} \\
\text { e 9AA }\end{array}$ \\
\hline
\end{tabular}
(a) reação realizada a temperatura ambiente
(b) adição de 3 - (trimetoxisilil) propil metacrilato.
(c) reação realizada a $\mathrm{T}=40^{\circ} \mathrm{C}$.
* ver estruturas moleculares na página 37

\section{7 - Preparação de nanopartículas de sílica do tipo casca-caroço (core-chell - CS):}

A preparação das nanopartículas CS, assim como o método de Stöber, baseia-se na hidrólise/condensação do precursor silano, mas a preparação é 
dividida em duas etapas: a formação inicial de um caroço rico em marcador e a posterior formação da casca de sílica branca.

As diferentes preparações realizadas pelo método de Stöber geraram produtos que foram caracterizados na seqüência. Deste modo, foi possível avaliar quais os parâmetros ideais para obtenção dos melhores sistemas. Isso posto, as preparações posteriores foram realizadas seguindo a mesma razão molar entre TEOS, água e catalisador (1: $21: 0,5)$ e em 2-propanol.

Em um primeiro passo, a reação é realizada da mesma forma que a anterior (método de Stöber convencional). Esta fase é necessária para que se forme um núcleo de sílica com corante incorporado. Porém, apenas uma fração da quantidade total de TEOS a ser utilizada na preparação foi adicionada nesta fase. O sistema reagiu por 12 horas e na seqüência foram adicionadas alíquotas de TEOS em intervalos de tempo de 15 minutos, sempre com agitação constante. Um esquema ilustrativo está mostrado na Figura 22. O meio reacional foi mantido reagindo por mais 1 hora. Os procedimentos posteriores, como isolamento por centrifugação, foram realizados da mesma maneira que para os sistemas anteriores.

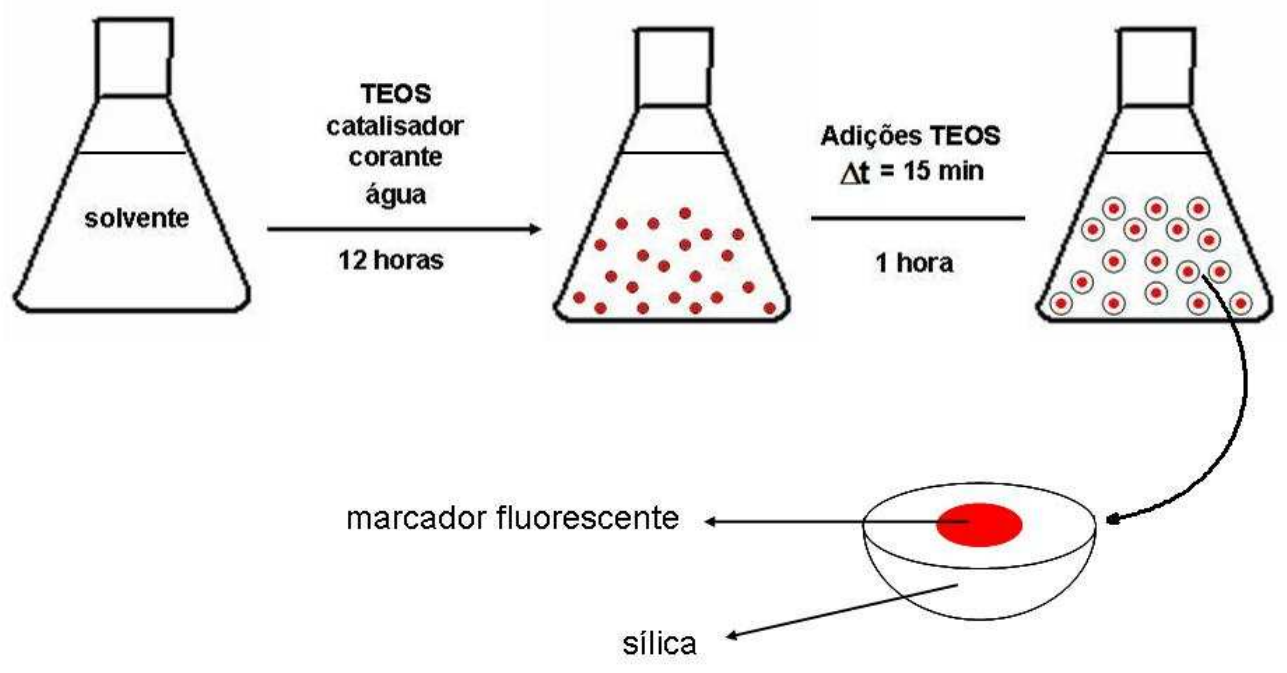

Figura 22: Esquema ilustrativo da preparação das partículas do tipo casca-caroço. 
4 - RESULTADOS E DISCUSSÃO 


\section{4 - RESULTADOS E DISCUSSÃO}

\section{1 - Partículas de sílica comerciais:}

Os derivados acridínicos 9-aminoacridina-metilenodietilmalonato (9AA I) e 9aminoacridina-metilenocianoetilacetato (9AA II) foram incorporados a partículas de sílica obtidas comercialmente, utilizando-se o 3 - (trimetoxisilil) propil metacrilato (TMSPM) como agente intermediário (veja Figura 19, no capítulo 3).

Como já discutido brevemente na introdução, os derivados de 9aminoacridina com grupos retiradores de elétrons possuem uma cinética complexa no estado excitado, caracterizada pela emissão do cromóforo acridina nos seus estados excitados singlete localmente excitados e ainda uma emissão na região do vermelho de espécies formadas por transferência de carga intramolecular (ICT). Os derivados são sintetizados a partir do corante 9-aminoacridina e seus espectros eletrônicos são deslocados para o vermelho, quando comparados ao precursor. O comportamento multiexponencial destes compostos confirma a presença da emissão dual. As análises resolvidas no tempo destes sistemas revelam dois componentes curtos com tempos na faixa de $160-350$ ps e 1.1-3.0 ns, relacionados à formação e ao decaimento do estado ICT, mais um tempo de cerca de 9 ns, atribuído à emissão localizada do cromóforo acridina ${ }^{[30,31]}$.

Quando estes corantes modificados são ligados a cadeias de poli(ácido metacrílico), a dupla ligação vinílica deixa de existir, gerando a perda da conjugação do sistema $\pi$ e a transição óptica ICT não é mais possível. Quando ligados à cadeia 
polimérica, 9AA I e 9AA II apresentam comportamento fotofísico similar ao precursor 9AA, com espectros estacionários estruturados e caráter monoexponencial, com tempos de vida da ordem de $15 \mathrm{~ns}^{[32]}$.

De posse destas informações, a emissão de fluorescência estacionária tornase uma ferramenta útil na confirmação da incorporação dos marcadores às superfícies. Para isso, foi preparada uma amostra de sílica obtida comercialmente, porém com 9AA I apenas adsorvido à superfície. Os perfis espectrais do 9AA I ligado e adsorvido são distintos, como pode ser observado na Figura 23.

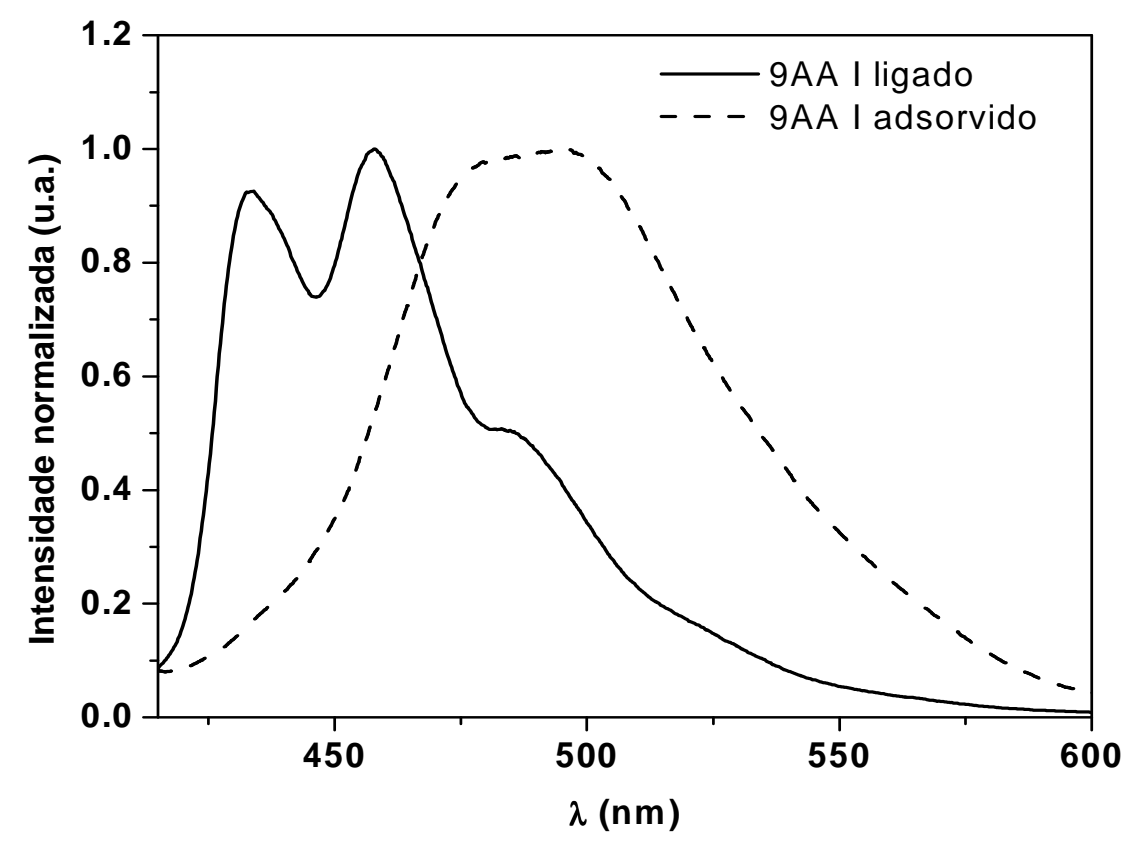

Figura 23: Emissão de fluorescência estacionária do 9AA I ligado e adsorvido à sílica; $\lambda_{\text {exc }}=400 \mathrm{~nm}$

Como se observa na Figura 23, a banda larga centrada em torno de $500 \mathrm{~nm}$ (característica do processo ICT do corante isolado) apenas é observada quando 9AA I está adsorvido à sílica. Após a reação com a sílica modificada, o corante apresenta emissão estruturada, com picos em 435, 456 e $485 \mathrm{~nm}$, de onde se pode inferir que 
ele se encontra covalentemente ligado. Perfis similares foram obtidos para 9AA II. O comportamento fotofísico destes sistemas foi também estudado por fluorescência resolvida no tempo ${ }^{[56]}$.

O corante 9AA I ligado à superfície de sílica, apresenta comportamento triexponencial. O tempo de vida mais longo $\left(\tau_{1}=15,4 \mathrm{~ns}\right)$ pode ser relacionado a uma fração de desativação do próprio cromóforo acridina, enquanto que os tempos de vida mais curtos ( $\tau_{2}=1,36 \mathrm{~ns}$ e $\tau_{3}=5,11 \mathrm{~ns}$ ) podem ser atribuídos à dinâmica no estado excitado de espécies monoméricas e diméricas.

Do ponto de vista das propriedades de fluorescência, um corante pode apresentar grandes diferenças de comportamento quando em superfície ou em solução. Interações específicas do corante com a superfície, movimento restrito, auto-agregação são alguns dos efeitos responsáveis pelas propriedades únicas encontradas em sólidos.

A formação de agregados (ou dímeros de corantes) pode ser observada pelas variações nos espectros de absorção e emissão, uma vez que eles usualmente apresentam propriedades fotofísicas diferentes das características do monômero do corante em questão. Estas modificações nos espectros eletrônicos são relativas a dois tipos clássicos de agregados: $\mathrm{J}$ ou $\mathrm{H}$. No caso dos agregados $\mathrm{J}$, o máximo de absorção é deslocado para região do vermelho no espectro, em relação à banda do monômero, e geralmente são observados picos estreitos. Já os agregados $H$, mostram a banda deslocada para a região do azul e frequentemente são caracterizados pela presença de bandas largas ${ }^{[57]}$.

O corante 9AA II, quando ligado à superfície de sílica, apresenta duas componentes de decaimento relativamente rápidas (3,08 e 4,83 ns), o que indica um processo de supressão em conseqüência da provável auto-agregação do derivado 
acridínico $^{[58,59]}$, uma vez que dímeros de 9-aminoacridina em meio micro-heterogênio (na região pré-micelar) são dímeros do tipo $\mathrm{H}$, nos quais as transições entre dipolos estão fora de fase ${ }^{[11,57]}$. Trata-se de supressores ativos, designados por "dímeros escuros", por não apresentarem transição de momento de dipolo para o estado fundamental. Estes dímeros agem como centros de supressão, gerando um trapping de energia. A presença de dímeros, atuando como supressores, é esperada quando corantes planares estão dispersos em sólidos ou filmes, pelo fato da configuração em paralelo ser favorecida, ou seja, os dímeros são formados por moléculas de corante com momentos de dipolo orientados paralelamente ${ }^{[60]}$.

A Figura 24 mostra as curvas de decaimento de ambos os sistemas.
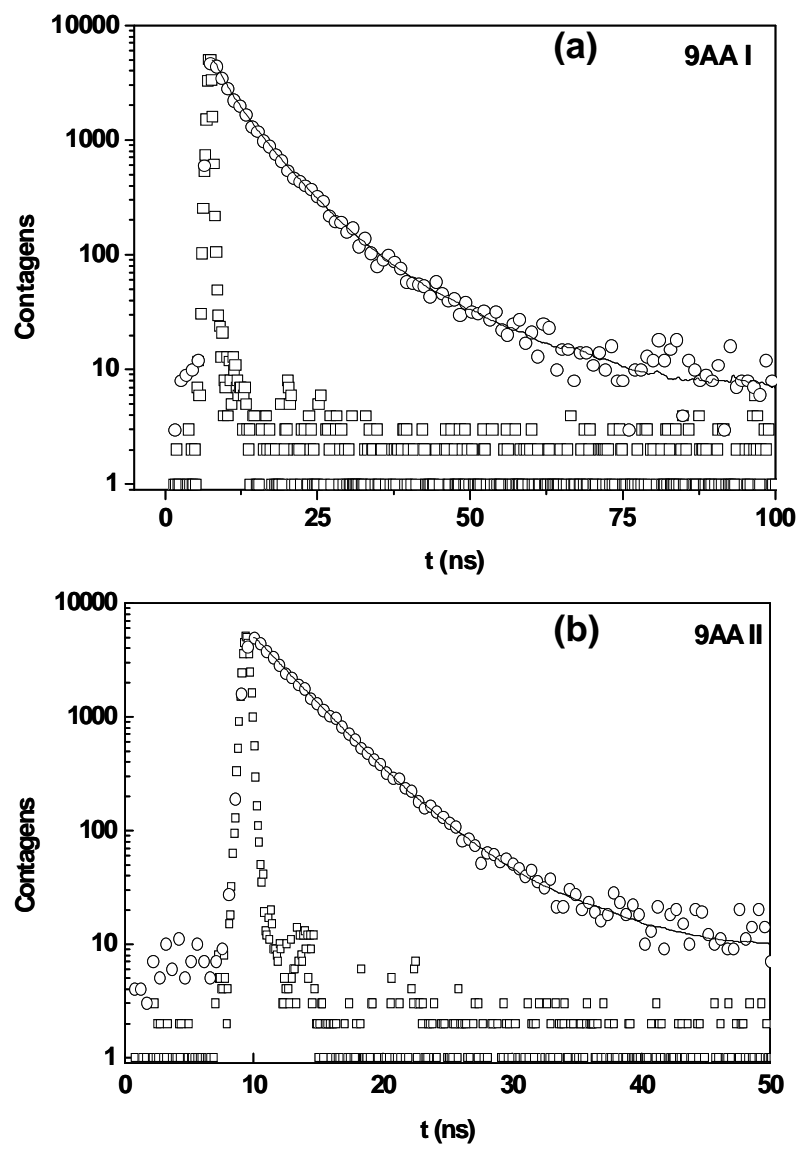

Figura 24: Decaimentos de fluorescência de partículas de sílica marcadas com 9AA I (a) e 9AA II (b); $\lambda_{\mathrm{exc}}=400 \mathrm{~nm}$ 
Imagens das partículas comerciais utilizadas foram obtidas por microscopia eletrônica de varredura (MEV). Como pode ser observado na Figura 25, trata-se de partículas com morfologia irregular (tamanho e forma).

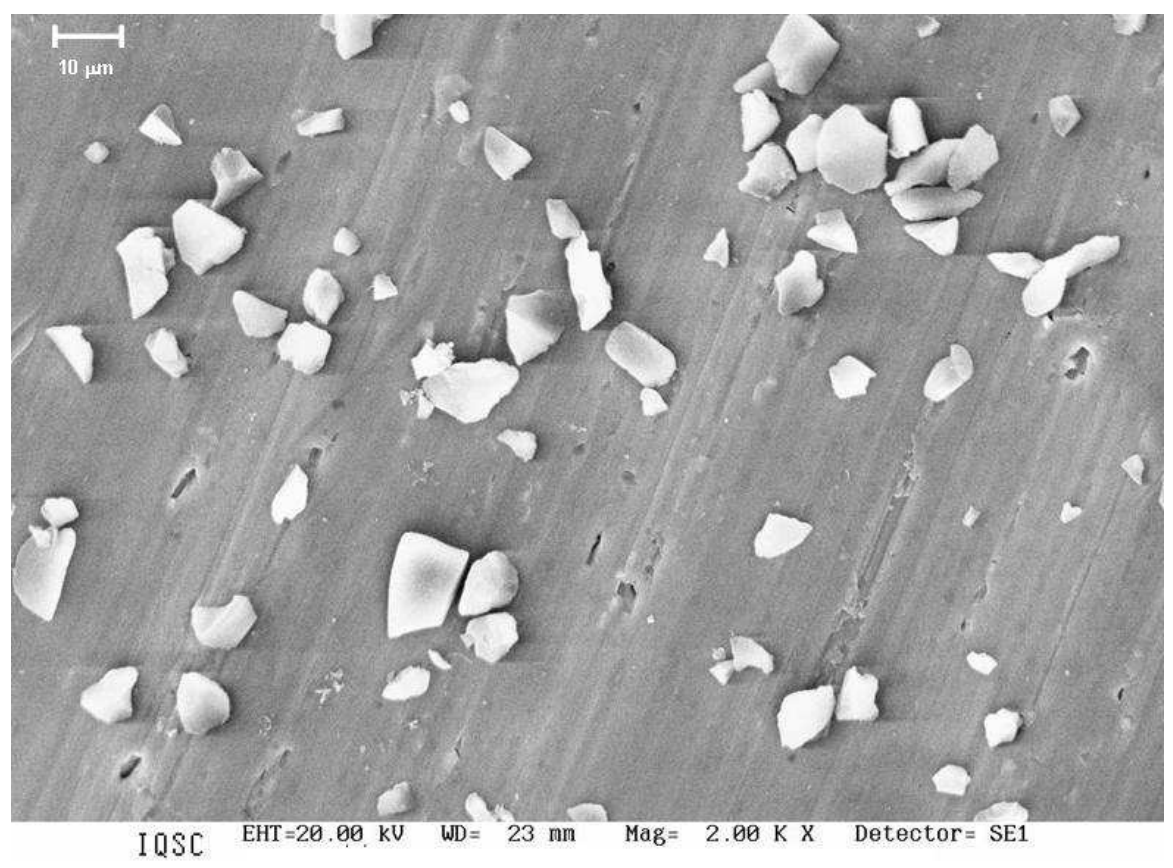

Figura 25: Imagem de MEV das partículas comerciais.

Um grande número de moléculas de corantes pode estar distribuído de maneira totalmente aleatória em tais partículas, possibilitando uma série de processos após a absorção de luz.

Assim, fez-se necessário optar por um novo tipo de matriz, de maneira a tornar viável o estudo do comportamento fotofísico dos corantes em superfície ou em seu interior. 


\section{2 - Nanopartículas preparadas pelo método de Stöber: morfologia e emissão de fluorescência estacionária}

\subsection{1 - Sistemas preparados em etanol}

Visando a obtenção de nanopartículas com morfologia mais homogenia, foram realizadas preparações, de acordo com o método de Stöber, utilizando-se etanol como solvente, com catálise básica $\left(\mathrm{NH}_{3}-14\right.$ mol.L-1 $)$, TEOS como precursor (1 mol...-1) e água (21 mol...-1), em temperatura ambiente e sob agitação por uma hora.

Uma série de sistemas foi preparada, utilizando como marcadores os $\begin{array}{llll}\text { seguintes } & \text { compostos: } & \text { 9-vinilantraceno } & \text { (9VA), }\end{array}$ aminoacridinametilenocianoetilacetato (9AA II) e safranina $\mathrm{O}(\mathrm{Sf})$.

\section{Meio reacional: etanol / catalisador básico / marcador: 9VA}

As primeiras partículas preparadas pelo método de Stöber foram preparadas em etanol, com TEOS, água e amônia aquosa na razão molar 1:14:21, marcadas com 9-vinilantraceno. Estas partículas serão denotadas por 1_SigVA. Numa segunda preparação, foi adicionada também uma alíquota de 3 - (trimetoxisilil) propil metacrilato, permitindo que as moléculas do marcador ficassem covalentemente ligadas à superfície (1_SigVA/TMSPM). A adição do TMSPM foi realizada 20 minutos após a adição do TEOS. Este tempo de intervalo é necessário porque a reação de policondensação do TMSPM é mais rápida que a do TEOS, assim, este 
procedimento evita que os grupos funcionais fiquem localizados apenas no interior da rede de sílica ${ }^{[26]}$.

Em ambos os casos, foi adicionada uma solução de 9VA de modo que sua concentração no meio reacional ficou na ordem de $1.10^{-6} \mathrm{~mol} . \mathrm{L}^{-1}$. Na preparação da amostra com TMSPM, uma pequena quantidade de peróxido de benzoíla foi adicionada como iniciador da polimerização térmica, que se deu a $70^{\circ} \mathrm{C}$ por 4 horas.

Os espectros de emissão de fluorescência estacionária da 1_SigVA e da 1_SigVA/TMSPM não apresentam grandes diferenças entre si, a não ser um leve deslocamento no comprimento de onda referente aos máximos de emissão.

É possível notar, quando os espectros estacionários do 9VA em solução e Sílica/9VA são comparados, que também não se observam grandes variações nos perfis espectrais.

No entanto, uma análise mais atenta leva à observação de que quando o corante é ligado à superfície da sílica há um deslocamento de $5 \mathrm{~nm}$ para o vermelho no caso da 1_SigVA e 13 nm no caso da 1_SigVA/TMSPM, no espectro de emissão. A sobreposição dos espectros de emissão do 9-vinilantraceno em solução e dos sólidos marcados é mostrada na Figura 26. 


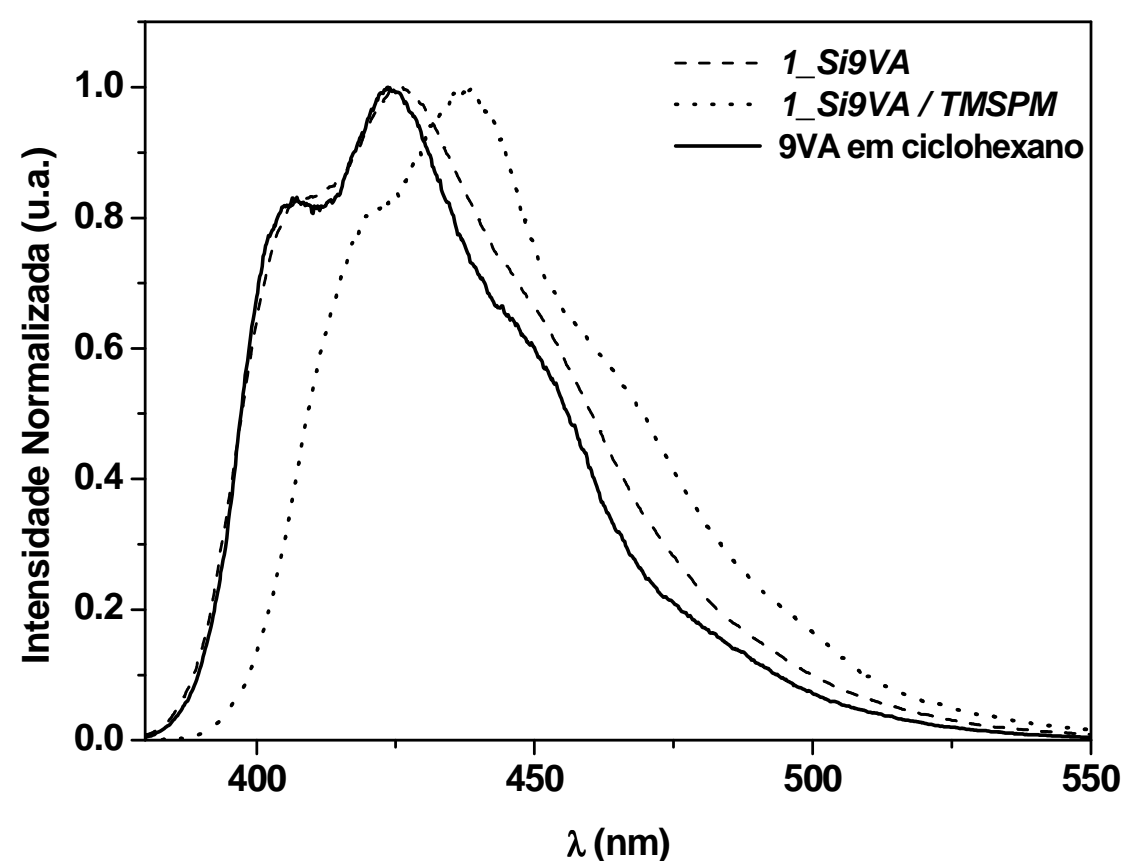

Figura 26: Emissão de fluorescência estacionária do 9VA em ciclohexano e dos sistemas 1_SigVA e 1_SigVA/TMSPM suspensos no mesmo solvente; $\lambda_{\text {exc }}=360 \mathrm{~nm}$.

Ambos os sistemas marcados com 9VA foram submetidos a estudos resolvidos no tempo. Os valores de tempos de vida e suas contribuições estão sumarizados na Tabela 2. Os perfis dos decaimentos de fluorescência estão mostrados na Figura 27.

Tabela 2: Tempos de vida, e suas contribuições, das partículas de sílicas marcadas com 9VA

$\tau_{1}$

(\% relativa)

$1,95 \mathrm{~ns}$

1_Si9VA

1_Si9VA / TMSPM
(5)

1,16 ns

(39) $\tau_{2}$

(\% relativa)

$11,2 \mathrm{~ns}$

6,85 ns

(61) 


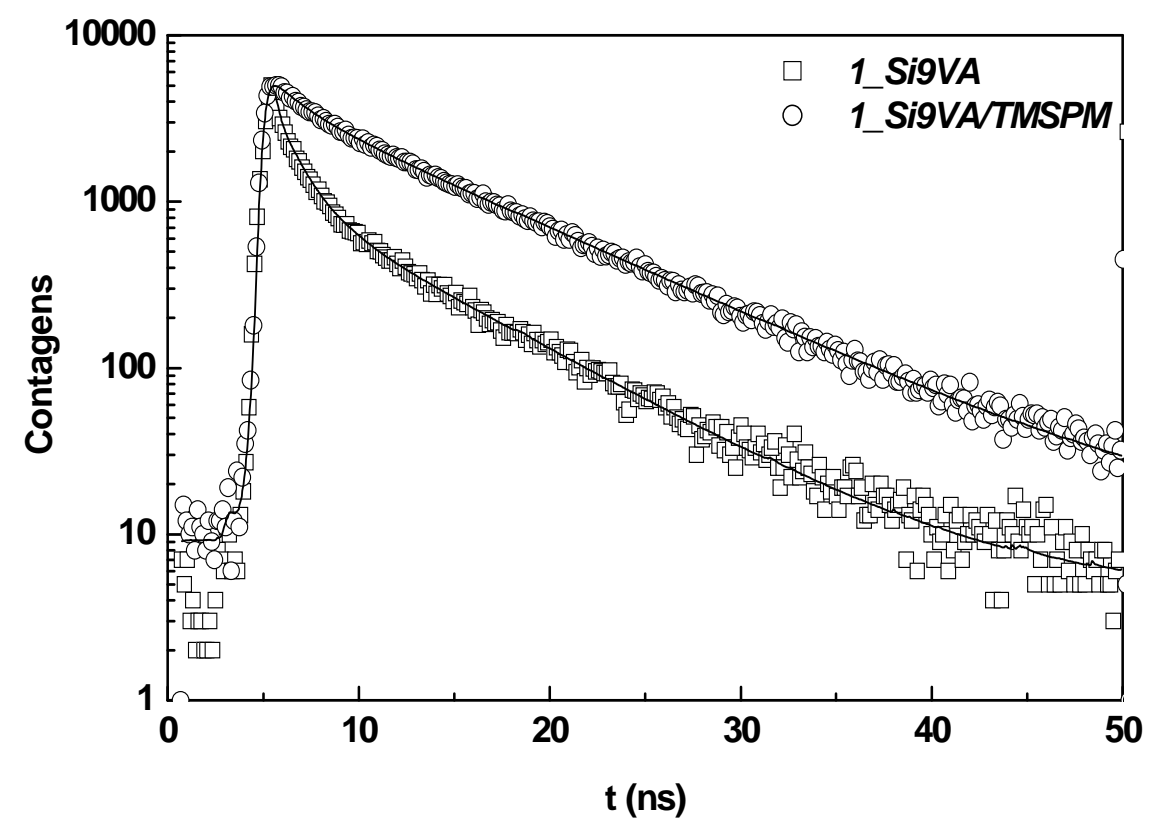

Figura 27: Decaimentos de fluorescência dos sistemas 1-SigVA e 1-SigVA/TMSPM ; $\left(\lambda_{\mathrm{exc}}=400 \mathrm{~nm}\right.$ e $\lambda_{\text {em }}=445 \mathrm{~nm}$ ).

Tanto a 1-SigVA quanto a 1-SigVA/TMSPM apresentaram comportamento biexponencial com maior contribuição do tempo de vida mais longo. Porém, comparativamente, o tempo de vida curto teve maior contribuição no sistema preparado com a adição do TMSPM.

Tanto o sistema 1-SigVA quanto o 1-SigVA/TMSPM apresentaram tamanhos menores que as partículas obtidas comercialmente. No entanto, foi observado um alto grau de aglomeração entre as partículas e uma falta de uniformidade em relação ao seu tamanho e à sua forma. 


\section{Meio reacional: etanol / catalisador ácido / marcador: 9AA II ou Sf}

Com a observação de que a preparação em etanol com catálise básica resultou em partículas pequenas, porém não uniformes, foi necessário alterar o meio reacional, realizando novas preparações na tentativa de se obter nanométricas, uniformes e sem aglomeração.

Assim, foi realizada uma nova preparação, seguindo o mesmo método em etanol, mas agora utilizando ácido acético como catalisador.

São descritos na literatura preparações de nanopartículas de sílica pelo método de Stöber tanto com catálise básica quanto com catálise ácida. A escolha pela utilização de um catalisador ácido nesta preparação foi com o objetivo de se obter partículas mais regulares que as obtidas anteriormente.

Utilizando ácido acético como catalisador, foram preparadas partículas marcadas com 9AA II e com safranina O. Estes marcadores foram escolhidos por possuírem altos rendimentos quânticos de fluorescência ${ }^{[30,61,62]}$, considerando a possibilidade de estes sistemas serem usados futuramente para estudos de correlação de fluorescência. A concentração de 9AA II e Sf no meio reacional foi da

ordem de $10^{-4} \mathrm{~mol} . \mathrm{L}^{-1}$ e os sistemas foram denotados como 1_SigAAll e 1_SiSf, respectivamente.

As partículas contendo o derivado acridínico (1_SigAAll) se mostraram altamente fluorescentes e com uma coloração amarelada, como pode ser observado nas Figuras 28 e 29 . 
(A)

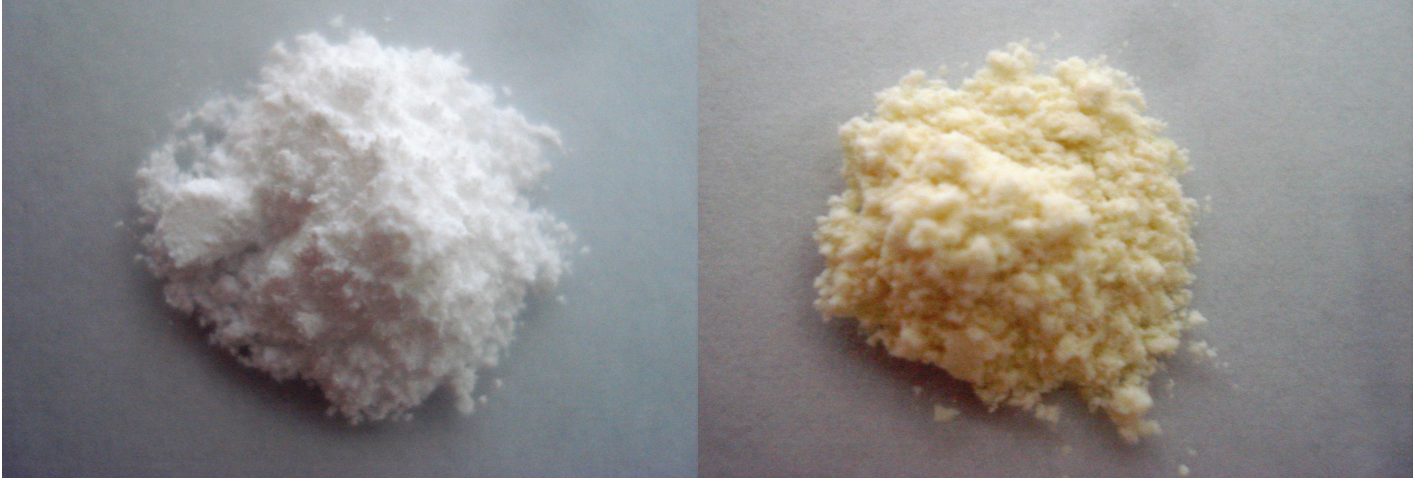

Figura 28: Fotos da sílica sem marcador (A) e do sistema 1_SigAAll, sólido amarelado (direita).

O espectro de fluorescência estacionária (Figura 29) mostra bandas de emissão posicionadas nos mesmos comprimentos de onda que este fluoróforo em solução metanólica (413 e 434 nm).

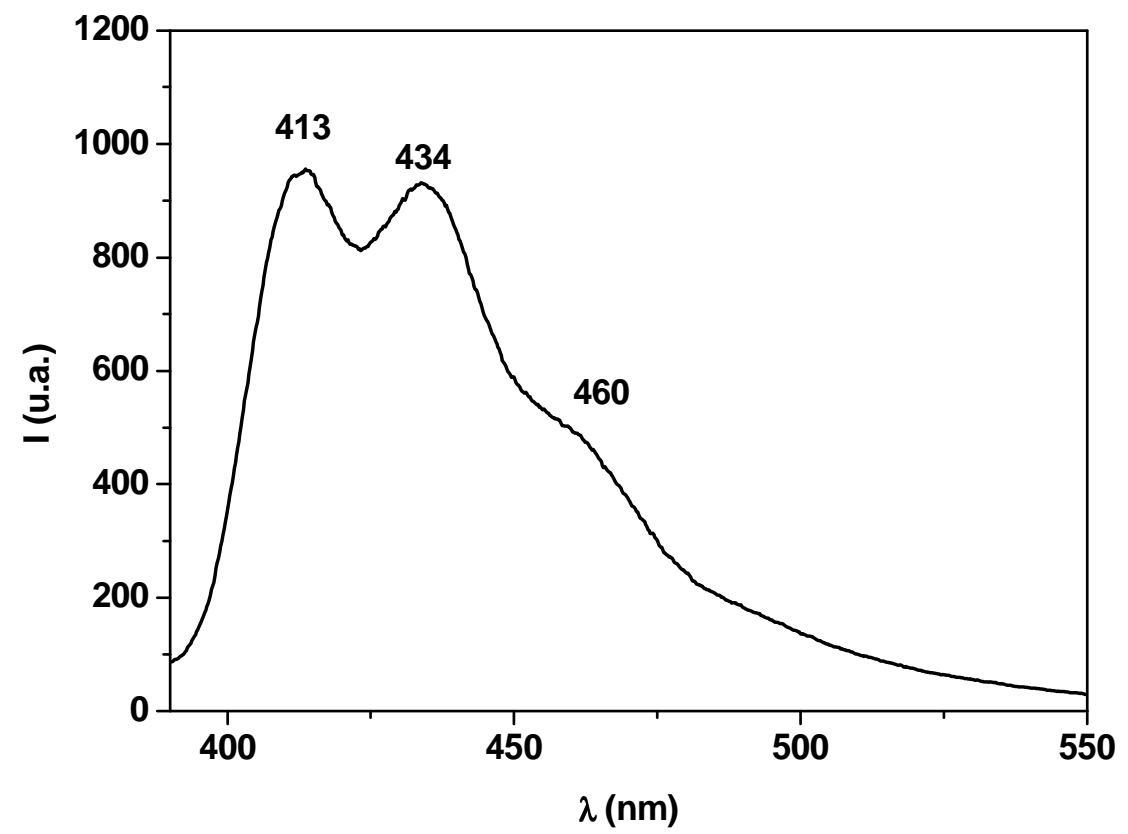

Figura 29: Emissão de fluorescência estacionária do sistema 1_SigAAll; $\lambda_{\mathrm{exc}}=400 \mathrm{~nm} ; \lambda_{\text {máx em }}=413$, 434 e $460 \mathrm{~nm}$.

Já o sistema contendo safranina O (1_SiSf)) apresentou uma intensa coloração rósea, como mostra a foto da Figura 30. 


\section{(A)}
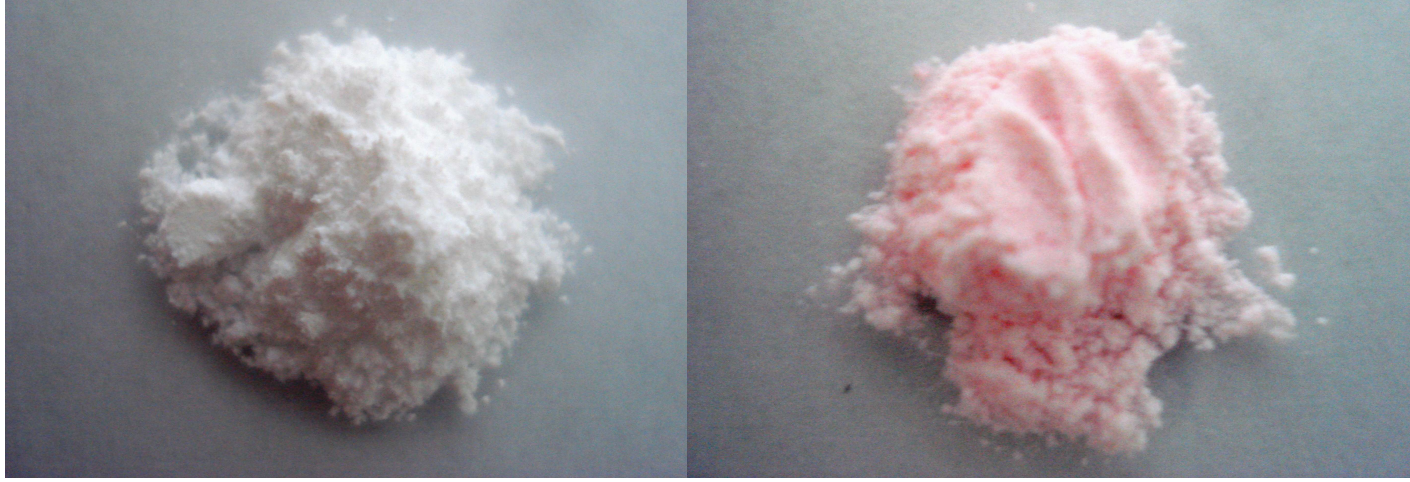

Figura 30: Fotos da sílica sem marcador (A) e do sistema 1_SiSf, sólido rosa (B).

A emissão de fluorescência estacionária da 1_SiSf manteve o mesmo perfil espectral da safranina $O$ em solução, como é mostrado na Figura 31. É observada uma banda larga centrada em $560 \mathrm{~nm}$.

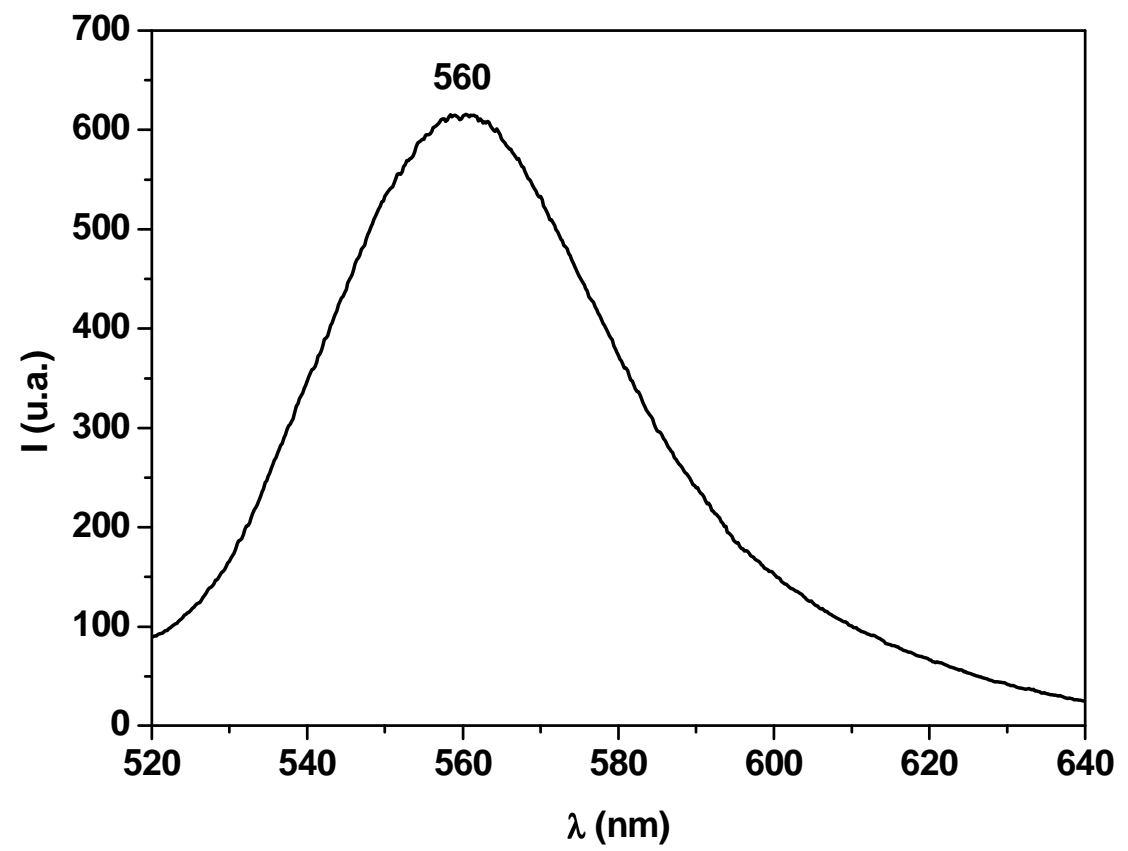

Figura 31: Emissão de fluorescência estacionária do sistema 1_SiSf; $\lambda_{\text {exc }}=532 \mathrm{~nm} ; \lambda_{\text {máx em }}=560 \mathrm{~nm}$. 
As partículas 1_SigAAll e 1_SiSf preparadas com catalisador ácido mostraram uma considerável incorporação de marcador, tanto para 9AA II quanto para safranina $\mathrm{O}$, porém a imagem obtida por microscopia eletrônica de varredura mostrou que esta tentativa não obteve sucesso em seu objetivo de obter superfícies regulares. A aglomeração, polidispersividade e irregularidade (Figura 32) tornam os sistemas inviáveis para o estudo das propriedades fotofísicas das sondas.

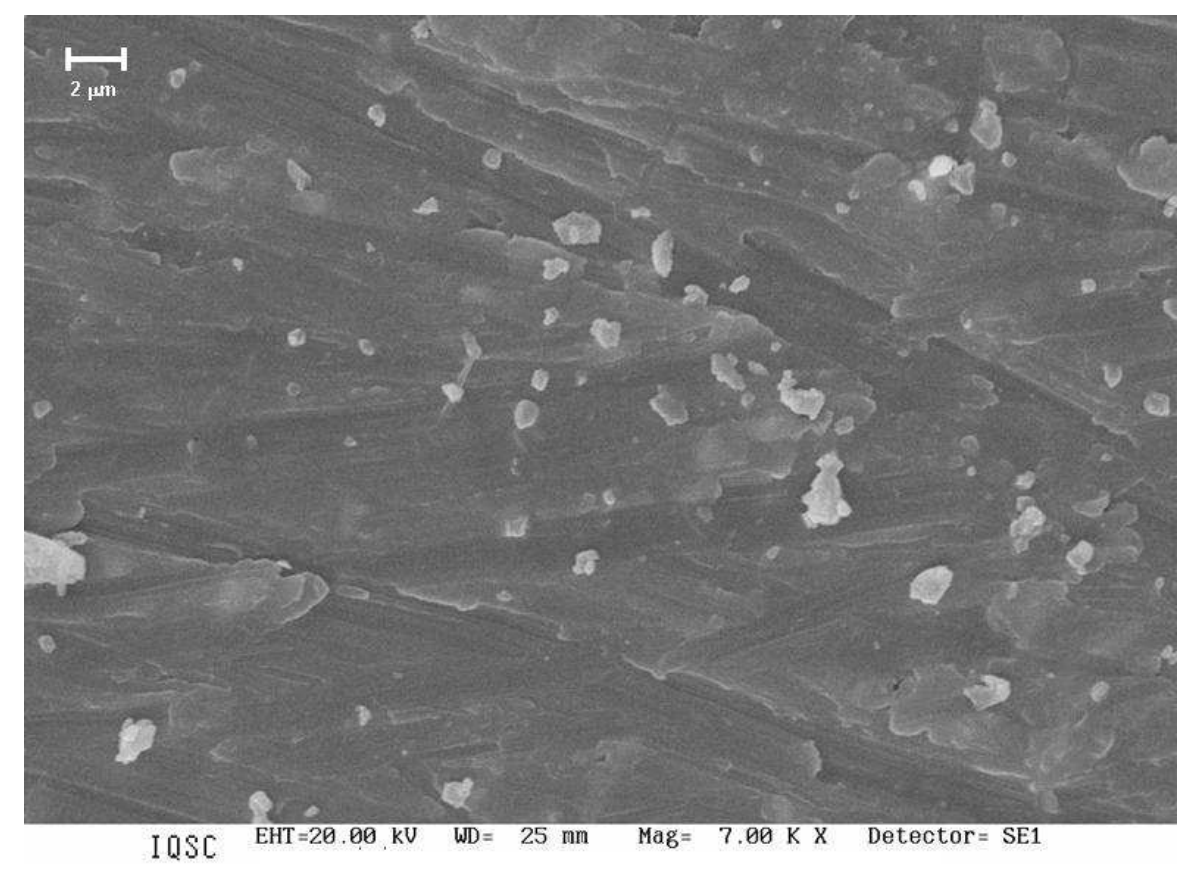

Figura 32: Imagem de MEV da 1_SigAAIl, preparada com ácido acético como catalisador.

Buscando contornar a questão da morfologia das superfícies obtidas, novos procedimentos foram realizados variando-se a razão molar de TEOS, água e catalisador e o solvente utilizado. 


\subsection{2 - Sistemas preparados em 2-propanol}

Após uma série de preparações concluiu-se que o melhor resultado foi obtido quando a síntese foi feita em um solvente de baixa constante dielétrica, com uma alta concentração de água, catalisador a concentrações mais baixas, leve aquecimento ( $\mathrm{T}=40^{\circ} \mathrm{C}$ ) e agitação magnética por uma hora ${ }^{[63]}$.

Assim, foram preparadas novas nanopartículas utilizando-se 2-propanol como solvente e o sistema reacional foi mantido a $40{ }^{\circ} \mathrm{C}$, sob agitação constante. $\mathrm{O}$ precursor TEOS, água e o catalisador amônia aquosa foram empregados na razão molar 1:21:0,5, respectivamente. Após o tempo necessário para a hidrólise/policondensação do TEOS o sistema foi submetido a um banho de gelo. A solução turva formada foi centrifugada e as partículas isoladas foram secas em estufa e mantidas em dessecador.

As nanopartículas foram preparadas sem a presença de sondas ou marcadores, apenas com o objetivo de checar se a alteração do solvente e das razões molares resultaria em partículas nanométricas esféricas.

A imagem de microscopia na Figura 33 mostra que as partículas obtidas na preparação acima descrita são monodispersas, com diâmetro médio de 100 nm e com baixo grau de aglomeração, quando comparadas às partículas obtidas anteriormente. 


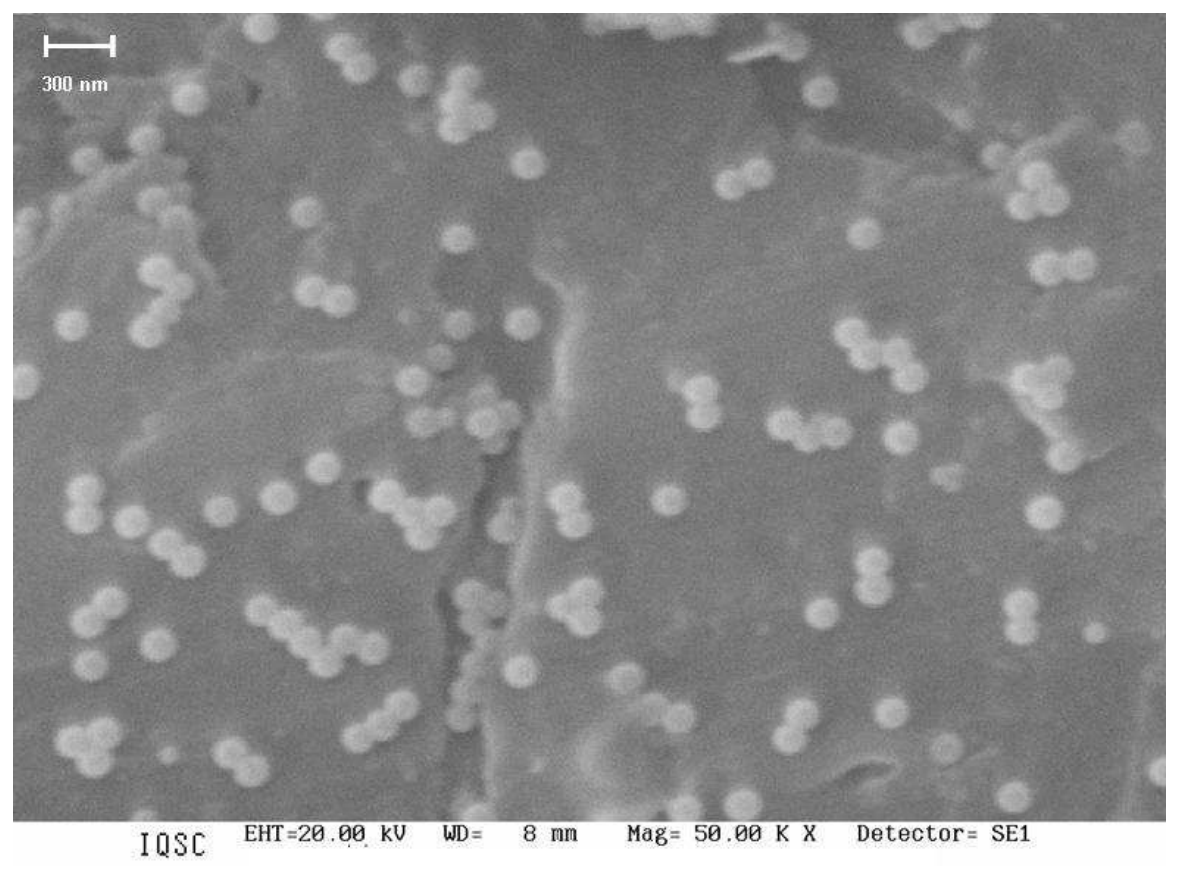

Figura 33: Imagem de MEV das nanopartículas de sílica preparadas em 2-propanol, sem adição de marcadores fluorescentes, com diâmetro médio de $100 \mathrm{~nm}$.

Uma vez otimizado o método de preparação de nanopartículas esféricas com tamanhos regulares e pouca aglomeração, deu-se inicio à preparação das partículas marcadas com sondas fluorescentes.

Meio reacional: 2-propanol / catalisador básico / marcador: 9AAIl ou Sf

Seguindo o objetivo de se obter nanopartículas altamente fluorescentes, as sondas 9AA II e safranina $O$ foram utilizadas nas preparações seguintes. Estes marcadores foram escolhidos nestas preparações por já terem sido utilizadas nos sistemas anteriores e por seus altos rendimentos quânticos de fluorescência.

Na preparação do sistema denotado por 2_SigAA/l foi utilizado 9AA II a uma concentração de $3,17.10^{-6}$ mol.L ${ }^{-1}$. A safranina $O$ foi adicionada ao sistema 2_SiSf, de modo que sua concentração no meio reacional foi de $8,42 \cdot 10^{-6}$ mol. $\mathrm{L}^{-1}$. A adição 
de uma alíquota de marcador foi realizada após a completa homogeneização do precursor TEOS e do catalisador no solvente.

Os espectros de emissão estacionária mostraram que em ambos os casos foram obtidas nanopartículas fluorescentes, como pode ser observado nas Figuras 34 e 35, para 2_SigAAll e 2_SiSt, repectivamente. Para o sistema 2_SigAAll a localização dos máximos de emissão não se diferenciou em relação à sonda em solução e ficaram localizados em 427, 453 e 485 nm. Além disso, observa-se uma banda de pequena intensidade em $525 \mathrm{~nm}$ que pode ser referente a uma fração residual de transferência de carga ocorrendo em moléculas de 9AA II, ou apenas uma progressão vibrônica do próprio corante. Já no caso das nanopartículas com safranina $\mathrm{O}$, foi observado o máximo de emissão em $565 \mathrm{~nm}$.

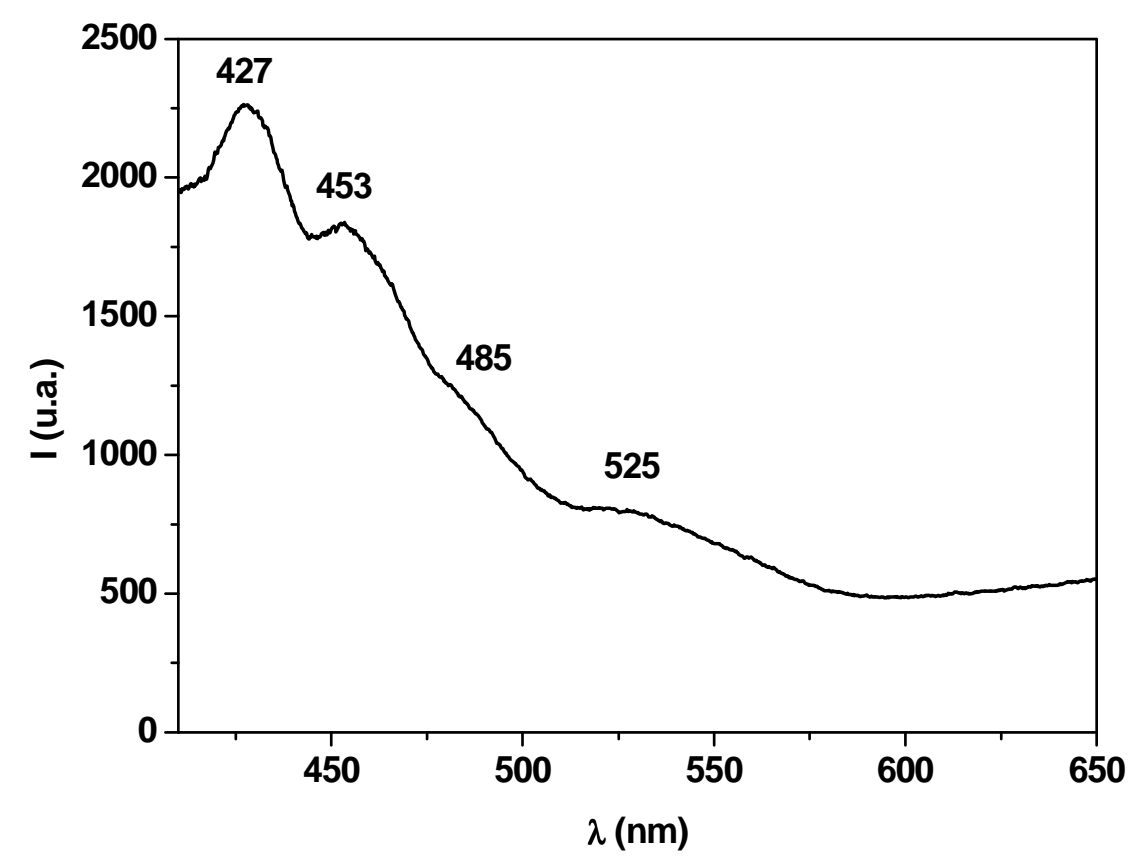

Figura 34: Emissão estacionária de 2_SigAAII $\left(\lambda_{\mathrm{exc}}=400 \mathrm{~nm} ; \lambda_{\text {máx em }}=427,453\right.$ e $\left.485 \mathrm{~nm}\right)$ 


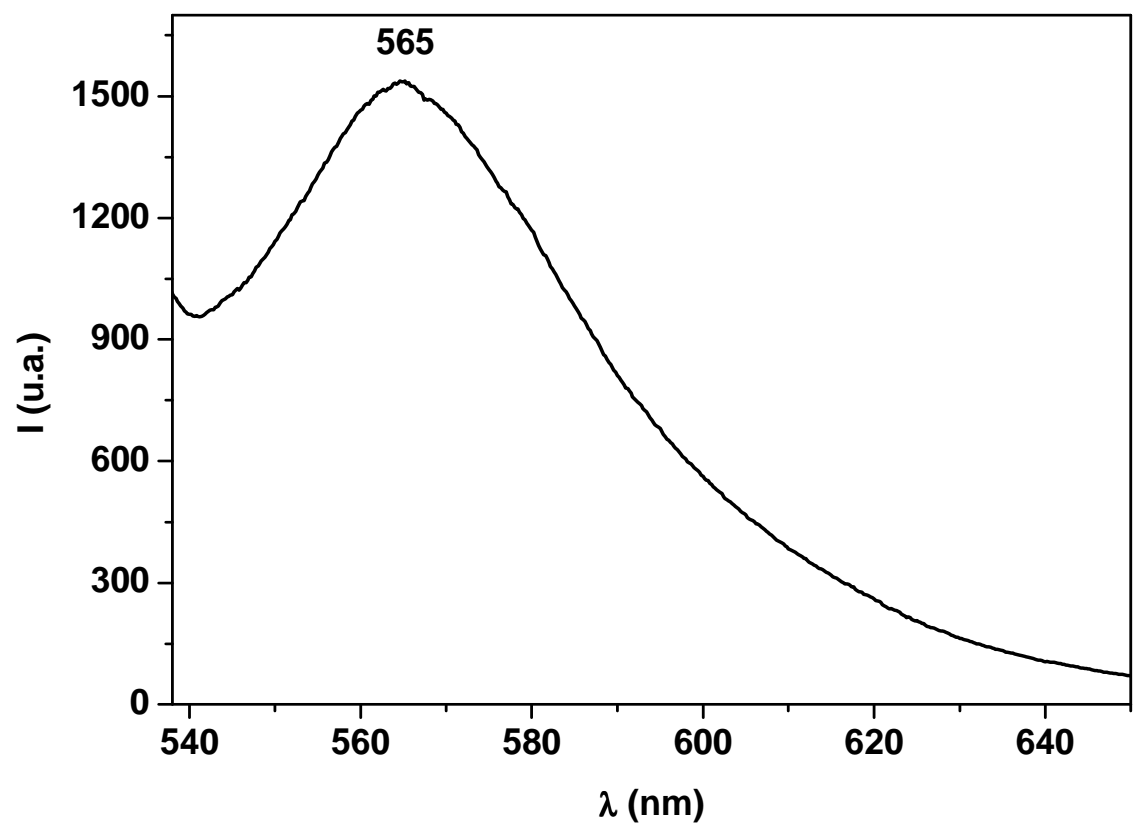

Figura 35: Emissão estacionária de 2_SiSf $\left(\lambda_{\mathrm{exc}}=532 \mathrm{~nm} ; \lambda_{\text {máx em }}=565 \mathrm{~nm}\right)$.

Pode-se perceber que a inclusão das sondas resultou em partículas com considerável emissão de fluorescência e a presença dos fluoróforos no meio reacional não influenciou na forma das nanopartículas. Pelas imagens de MEV (Figura 36) nota-se que as nanopartículas continuam com pouca aglomeração e com diâmetros médios de $100 \mathrm{~nm}$. 


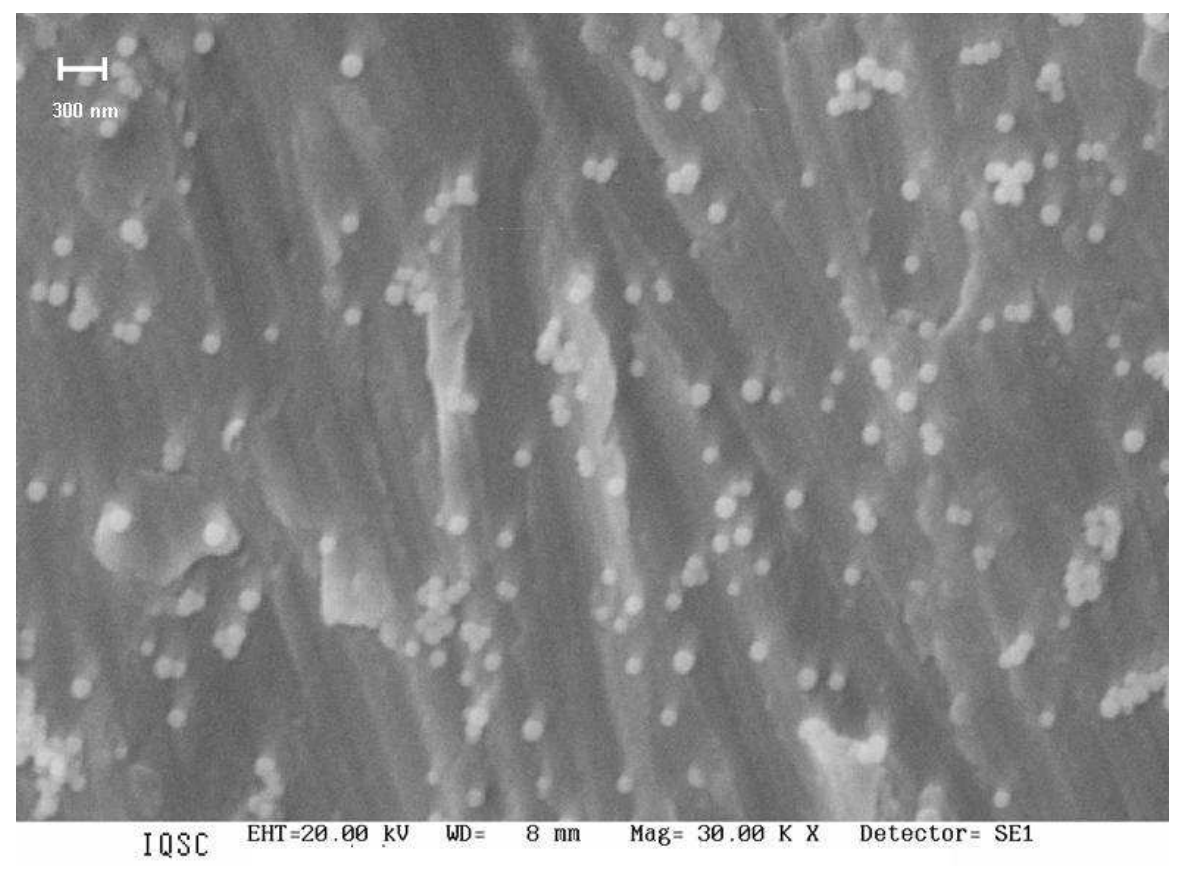

Figura 36: Imagem de MEV das nanopartículas preparadas em 2-propanol, com safranina $\mathrm{O}$, com diâmetro médio de $100 \mathrm{~nm}$.

\section{Meio reacional: 2-propanol / catalisador básico / marcador: 9AA}

Foram também preparadas nanopartículas de sílica marcadas com 9aminoacridina. Como já foi mencionado, este corante é o precursor do composto utilizado na marcação dos sistemas anteriores e já foi bastante estudado pelo nosso grupo em solução, micelas e polímeros.

O sistema marcado com 9AA, denotado por 2_SigAA, foi preparado seguindo a mesma metodologia e razões molares de reagentes (preparação em 2-propanol). A adição de uma alíquota de marcador foi realizada após a completa homogeneização do precursor TEOS e do catalisador no solvente, de modo que a concentração de 9AA no meio reacional ficasse em $1 \cdot 10^{-4} \mathrm{~mol} \cdot \mathrm{L}^{-1}$.

Na Figura 37 está mostrado o espectro de emissão estacionária das nanopartículas marcadas com 9AA. O sistema apresentou alta intensidade de 
emissão com perfil espectral similar ao corante em solução, com máximos em 427, 450 e $480 \mathrm{~nm}$

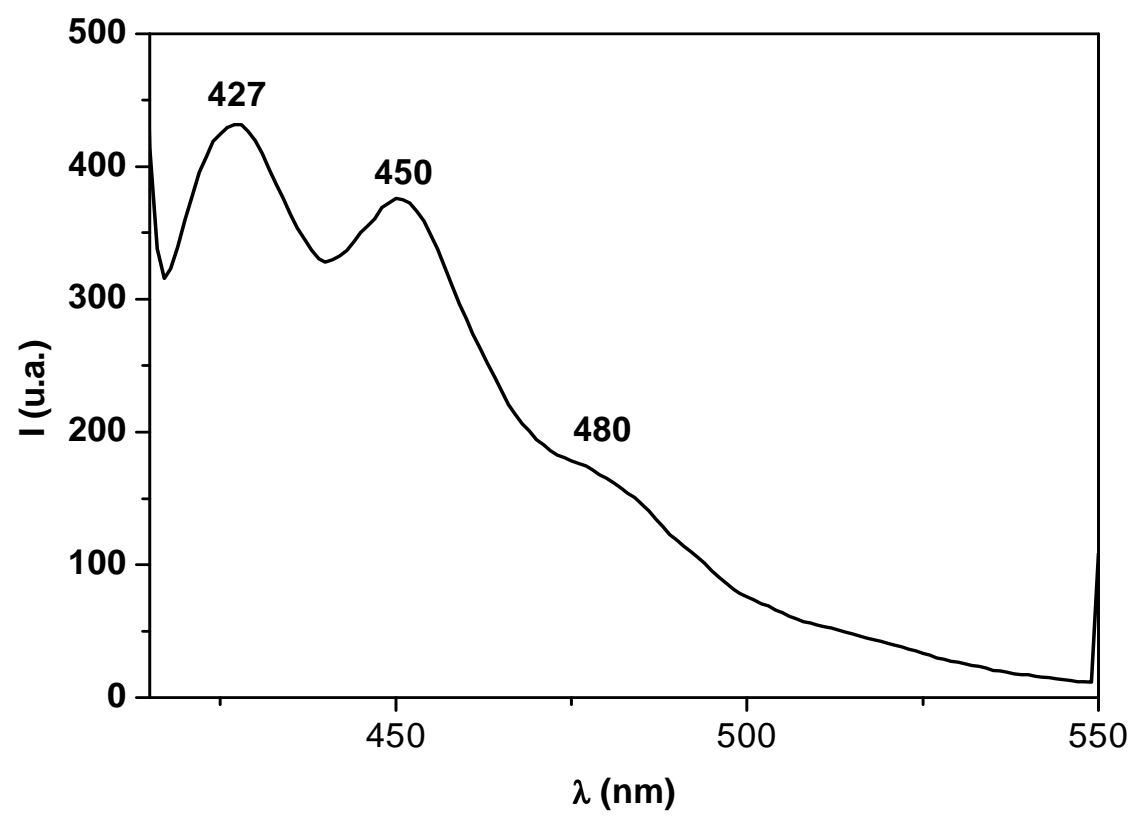

Figura 37: Emissão estacionária das partículas 2_SigAA; $\lambda_{\text {exc }}=400 \mathrm{~nm} ; \lambda_{\text {máx em }}=427,450$ e $480 \mathrm{~nm}$.

Assim como para o sistema 2_SigAAll, a participação da 9AA na reação não interferiu na morfologia das partículas, sendo formadas nanoesferas altamente fluorescentes, com pouca aglomeração e diâmetro médio de 100 nm, como se pode observar na Figura 38. 


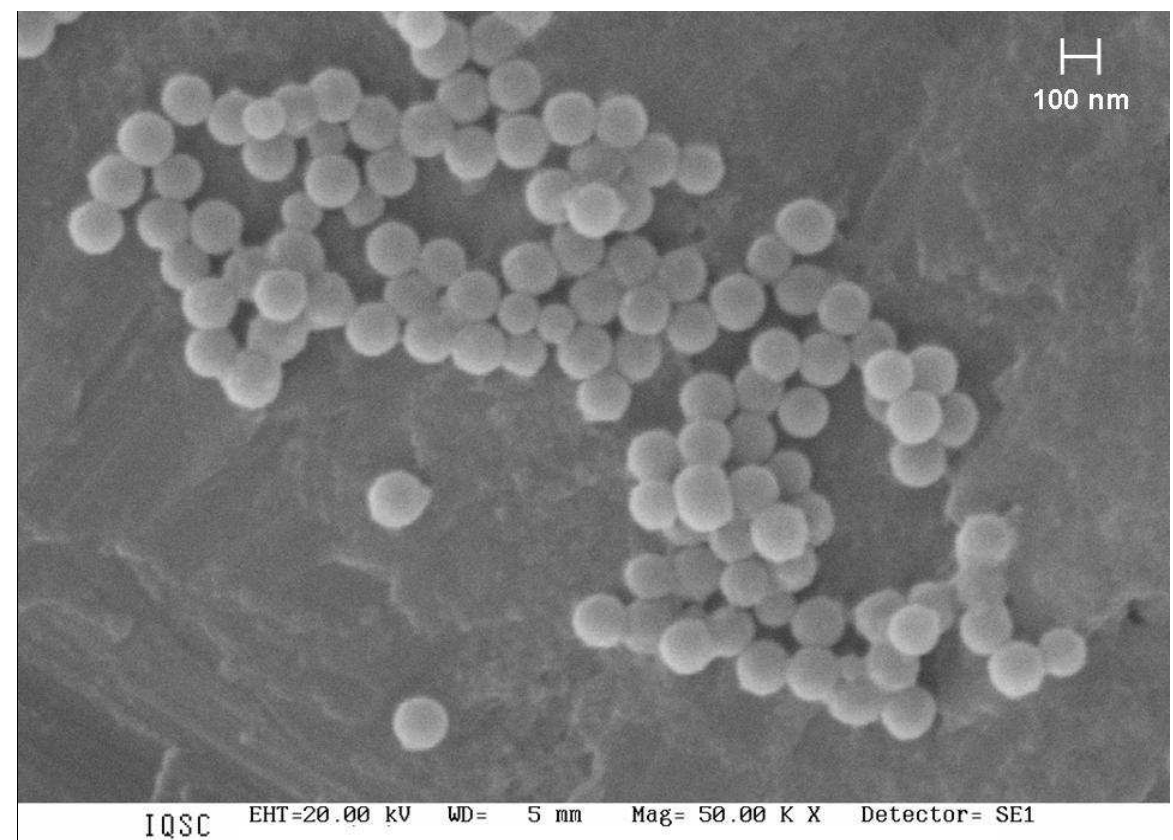

Figura 38: Imagem de MEV das nanopartículas preparadas em 2-propanol, marcadas com 9aminoacridina, com diâmetro médio de $100 \mathrm{~nm}$.

Todas as partículas preparadas pelo método de Stöber, utilizando 2-propanol como solvente, apresentaram-se fluorescentes, esféricas e monodispersas em relação ao tamanho. Contudo, devido à sua morfologia, estas partículas porosas quando dispersas em solução permitem a difusão do fluoróforo. Para evitar este efeito, fez-se necessário preparar as partículas de maneira a evitar a difusão do fluoróforo para o solvente, para que os sistemas permanecessem estáveis por um maior período de tempo.

\section{3 - Partículas de sílica do tipo casca-caroço:}

Outros métodos de preparação têm sido desenvolvidos para se aperfeiçoar o método de Stöber com objetivo de se obter partículas marcadas com corantes. 
Recentemente, as nanopartículas mais estudadas são as chamadas nanopartículas core-shell (partículas CS - veja Figura 39). O termo em inglês core-shell, refere-se a partículas formadas por uma estrutura do tipo "casca-caroço", composta por um caroço rico em corante e uma casca formada por poli(silanos). As partículas preparadas desta maneira oferecem vantagens em trabalhos envolvendo marcadores: maior fotoestabilidade quando submetidas à excitação e maiores sinais de fluorescência, resultado do grande número de moléculas fluorescentes encapsuladas neste tipo de matriz, já que a casca age como uma barreira que evita a difusão dos marcadores para fora da partícula ${ }^{[64]}$.

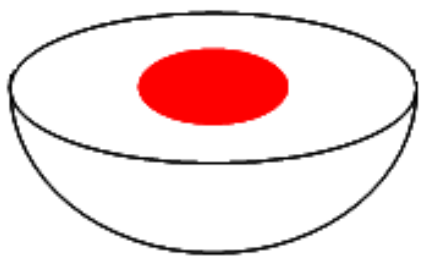

Figura 39: llustração idealizada de partículas do tipo CS.

A preparação das partículas CS foi baseada nos trabalhos de Webb ${ }^{[65,66]} \mathrm{e}$ colaboradores que, assim como o método de Stöber, baseia-se na hidrólise/condensação do precursor silano, mas a preparação é dividida em duas etapas: a formação inicial do caroço rico em marcador e a posterior formação da casca.

Para se testar o encapsulamento de um dos corantes já utilizados, foram preparadas partículas CS marcadas com safranina O (CS_Sf). O solvente, a razão molar precursor/catalisador/água e a concentração de safranina $O$ foram exatamente 
os mesmos empregados na preparação das partículas 2_SiSf, preparadas pelo método de Stöber convencional e marcadas com safranina $O$.

O ponto chave neste caso é que, inicialmente, foi colocado no meio de preparação um terço da quantidade total de TEOS a ser utilizada. Deixou-se o sistema reagir por aproximadamente 12 horas e o restante de TEOS foi adicionado em alíquotas de $50 \mu \mathrm{L}$ em intervalos de 15 minutos. Os procedimentos posteriores, como isolamento por centrifugação, foram realizados da mesma maneira que para os demais sistemas.

Na Figura 40 é mostrada uma imagem do sistema CS_Sf, obtida por MEV. Nota-se que foram obtidas nanoesferas com diâmetro médio de $250 \mathrm{~nm}$, ou seja, maiores que as nanopartículas preparadas pelo método de Stöber convencional.

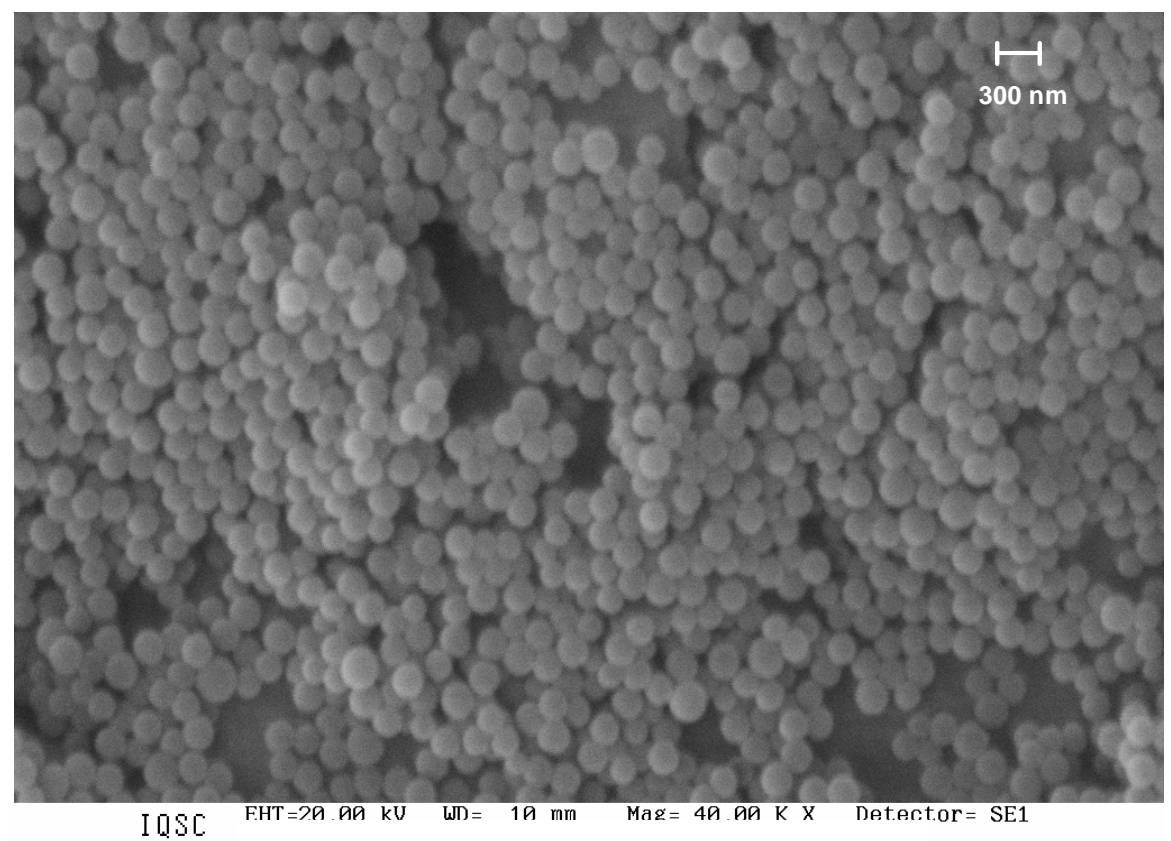

Figura 40: Imagem de MEV das partículas CS, marcadas com safranina O (CS_Sf), com diâmetro médio de $250 \mathrm{~nm}$. 
Pela imagem é possível observar uma grande quantidade de partículas, em comparação com as imagens de MEV mostradas anteriormente. No entanto, não se trata de um efeito de concentração e sim, provavelmente, da maneira como o suporte para análise foi recoberto, de modo que houve um acúmulo das partículas em uma determinada região da placa suporte.

Tendo em mãos dois sistemas preparados usando diferentes metodologias, mas com o mesmo marcador, foi realizado um estudo para estimar o grau de incorporação de safranina $O$ nas partículas preparadas pelo método de Stöber convencional e pela metodologia core-shell.

Para tal, foram utilizados os espectros de absorção da solução restante após a centrifugação para isolar as partículas, a concentração inicial de safranina 0 utilizada no meio reacional e o coeficiente de extinção molar $(\varepsilon)$ deste corante, em 2propanol.

O coeficiente de extinção molar da safranina $\mathrm{O}$ em 2-propanol foi determinado como $\varepsilon=32.840 \mathrm{~mol}^{-1}$.L.cm ${ }^{-1}$. Na Figura 41 é mostrado o gráfico dos valores obtidos para absorção em função da concentração do corante.

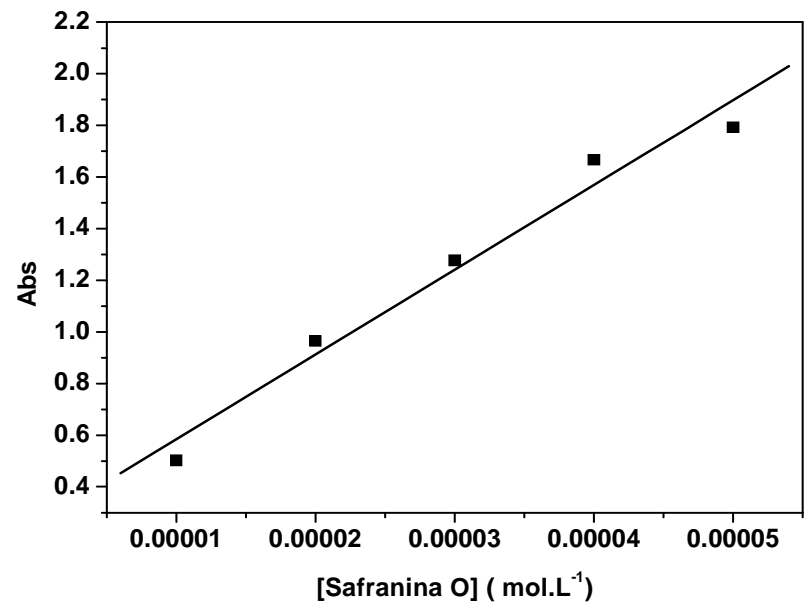

Figura 41: Intensidade de absorção versus concentração de safranina $O$. 
Juntamente com o espectro de absorção da solução correspondente ao meio reacional (com a concentração inicial de safranina O), o espectro de absorção do sobrenadante obtido na centrifugação do sistema foi utilizado para estimar o grau de incorporação de safranina O. A Figura 42 mostra a diferença de intensidade de absorção das duas soluções.

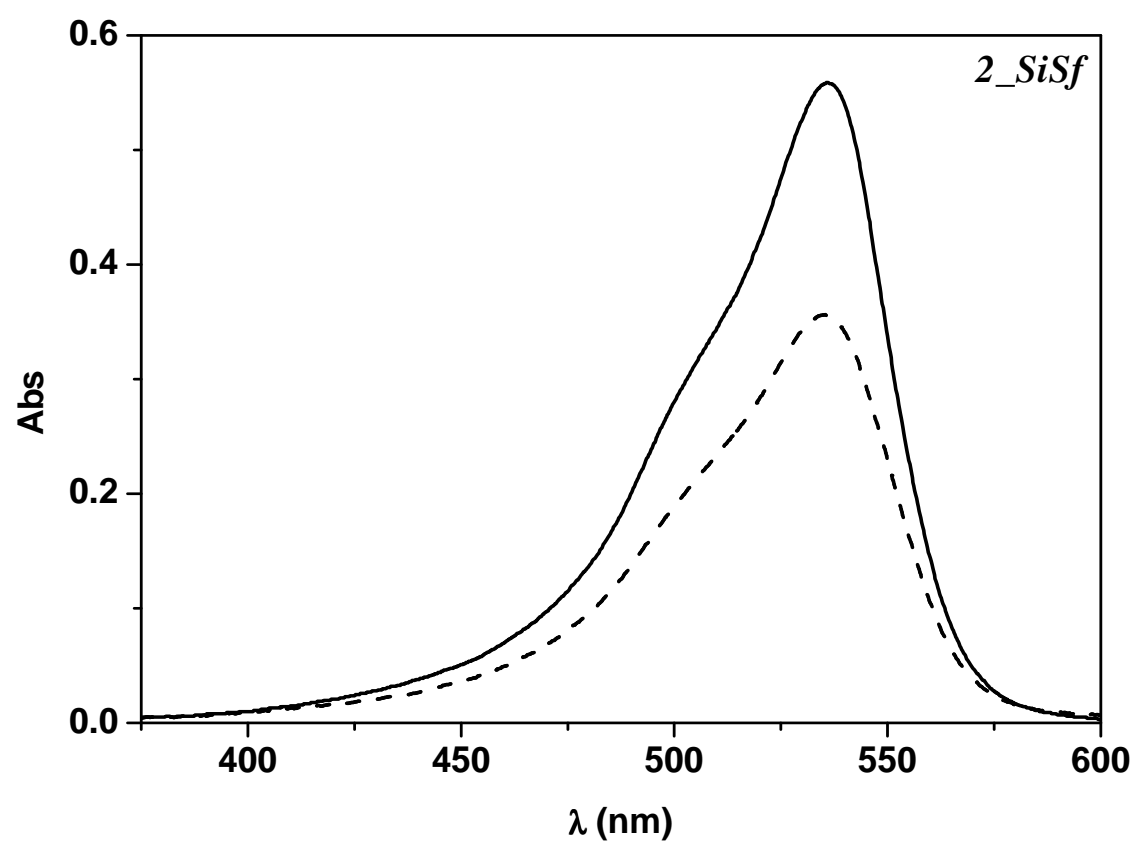

Figura 42: Absorção de solução de safranina $\mathrm{O}(-)$ no meio reacional e (---) no sobrenadante da preparação do sistema 2_SiSf

De acordo com os dados obtidos no sistema 2_SiSf, estima-se que o grau de incorporação de safranina O foi de $36 \%$.

Uma análise similar foi realizada com o sobrenadante do sistema preparado pela metodologia CS. Os espectros de absorção da safranina $\mathrm{O}$ no meio reacional e no sobrenadante restante da preparação CS_Sf estão mostrados na Figura 43. 


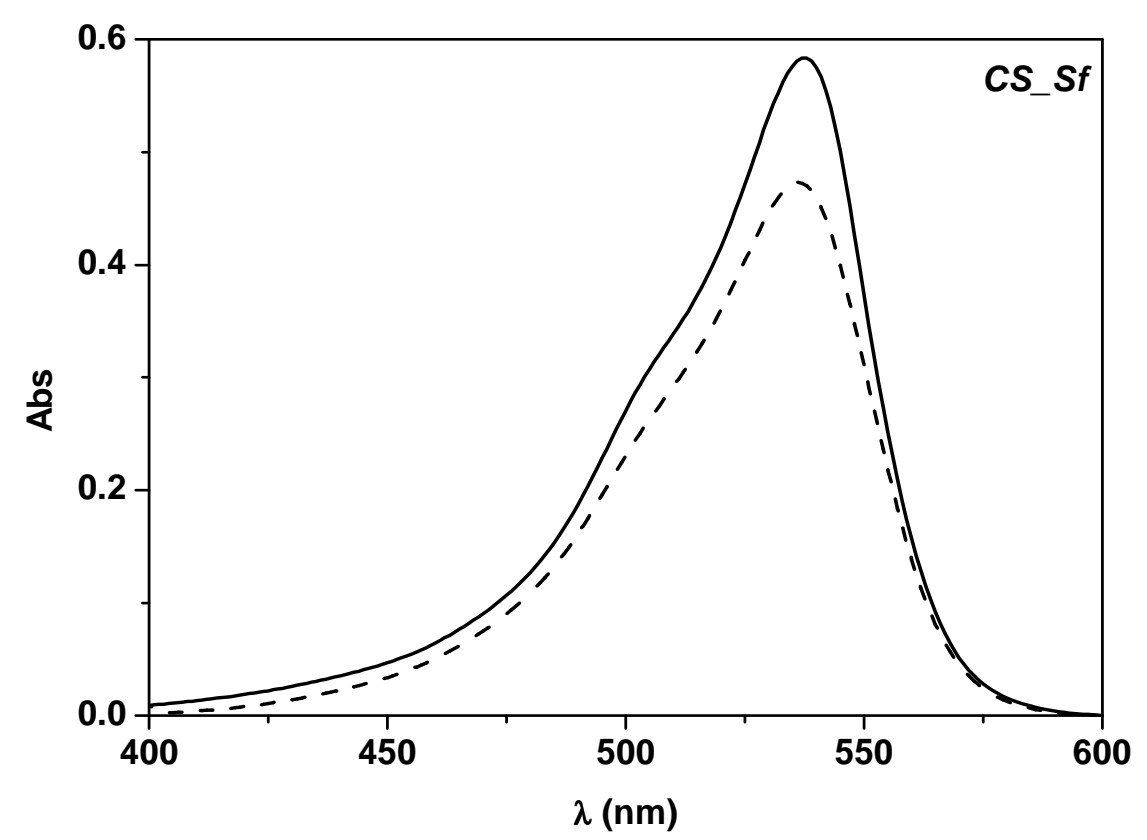

Figura 43: Absorção de solução de safranina $\mathrm{O}(-)$ no meio reacional e (---) no sobrenadante da preparação do sistema CS_Sf.

O cálculo do grau de incorporação da safranina O nas nanopartículas CS_Sf também foi realizado utilizando-se os espectros de absorção da solução correspondente ao meio reacional e da solução sobrenadante obtida após a centrifugação e separação do sólido final. Foi estimado que o grau de incorporação do marcador na CS_Sf foi de $18 \%$.

A Figura 44 mostra os espectros de emissão estacionária dos dois sistemas preparados com safranina $O$ (pelo método de Stöber convencional e pela metodologia de preparação CS). 


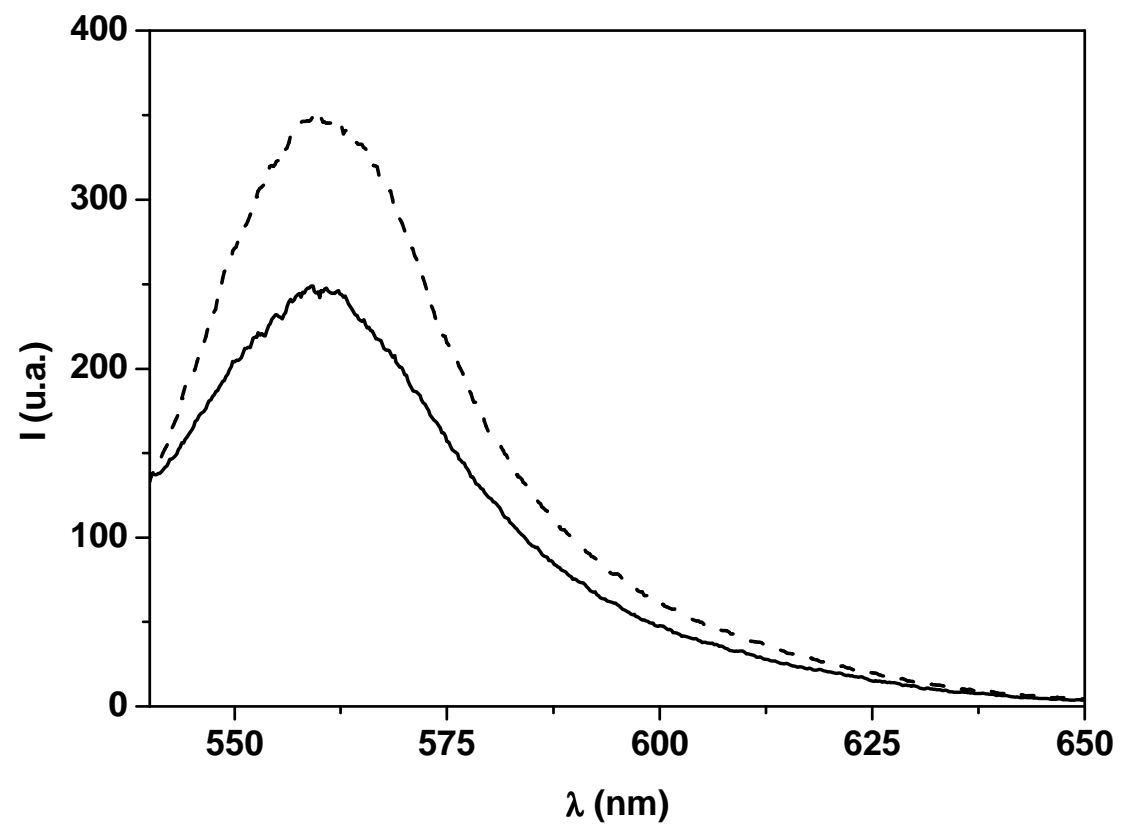

Figura 44: Emissão estacionária das partículas 2_SiSf (---) e CS_Sf (一), em 2-propanol.

Os espectros da Figura 44 foram obtidos nas mesmas condições de amostra (6 mg de amostra em $5 \mathrm{~mL}$ de solvente) e equipamento (fluorímetro operando com as mesmas aberturas de fendas). Assim, é possível comparar as intensidades de emissão, concluindo que a metodologia de preparação CS alcançou seu objetivo no que diz respeito à obtenção de nanopartículas fluorescentes, porém a preparação realizada pelo método de Stöber alcançou uma maior incorporação de marcador.

Deve-se destacar que, mesmo as partículas CS tendo apresentado um grau de incorporação de fluoróforo de $18 \%$, elas são consideradas a melhor opção para se estudar o comportamento fotofísico dos fluoróforos, pois a casca de sílica os envolve evitando que eles migrem para a solução.

Com o objetivo de preservar a estabilidade das nanopartículas em solução, as preparações seguintes envolvem a metodologia CS, empregando 9AA, 9AAll e auramina, já utilizados anteriormente. 


\section{Nanopartículas CS marcadas com 9AA e 9AAII}

Dando continuidade ao trabalho, foram preparadas pela metodologia CS nanopartículas com os marcadores já utilizados anteriormente (9AA e 9AAll) para realização de novas medidas fotofísicas.

Na Figura 45 é mostrado o espectro de emissão estacionária das partículas CS marcadas com 9-aminoacridina (CS_9AA), na qual se pode perceber uma alta intensidade de emissão, com máximos localizados em 428, 450 e 480 nm.

O espectro estacionário das partículas CS_9AA mostra máximos de emissão nos mesmos comprimentos de onda das partículas preparadas pelo método de Stöber. Em ambos os casos, a emissão estruturada se dá na mesma região espectral da 9-aminoacridina em metanol, no entanto, o segundo pico vibrônico domina e emissão no caso das nanopartículas CS_9AA, um indicativo de que a estrutura da sílica está perturbando o acoplamento do estado excitado com o estado fundamental[ ${ }^{[11]}$.

Assim, como no caso da CS_Sf, a adição da solução de 9AA ao meio reacional não interferiu na morfologia das partículas. Neste sentido, foram obtidas nanoesferas com diâmetro médio de 200 nm, monodispersas e sem agregação, como pode ser percebido na Figura 46. 


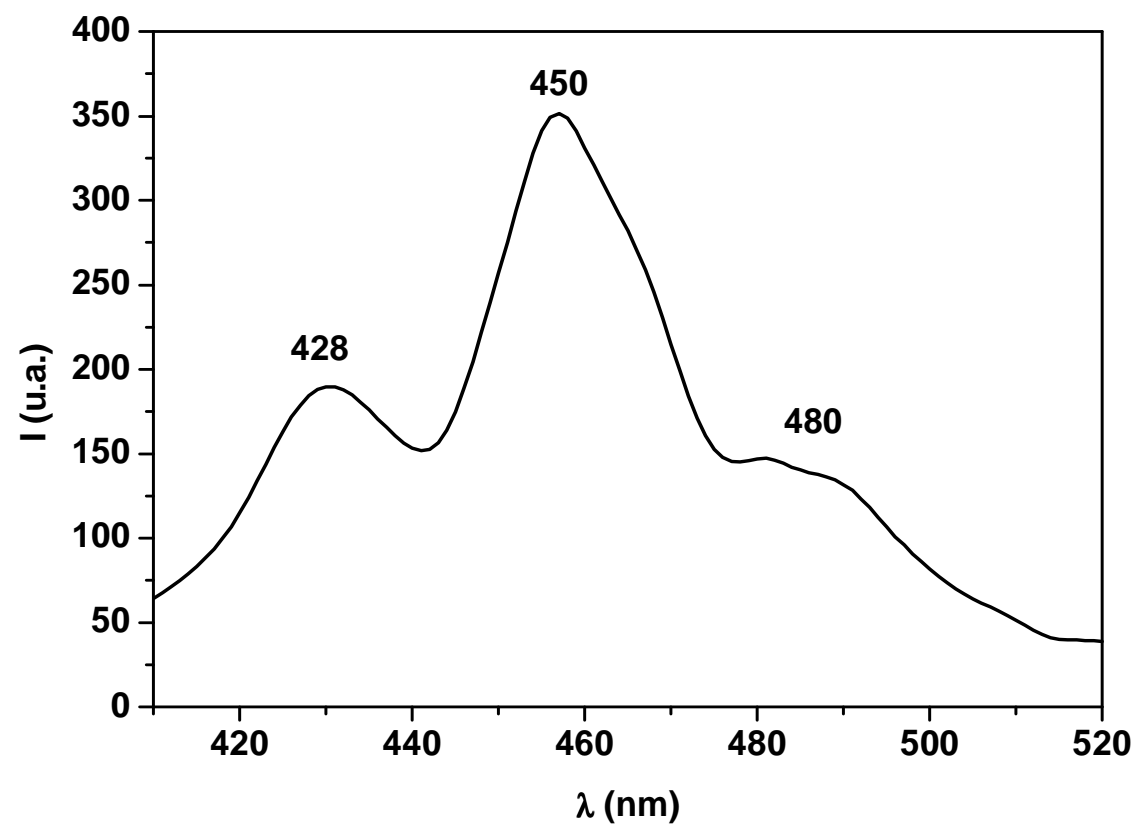

Figura 45: Emissão estacionária das partículas $\operatorname{CS} 9 A A ; \lambda_{\text {exc }}=400 \mathrm{~nm} ; \lambda_{\text {máx em }}=428,450$ e $480 \mathrm{~nm}$.

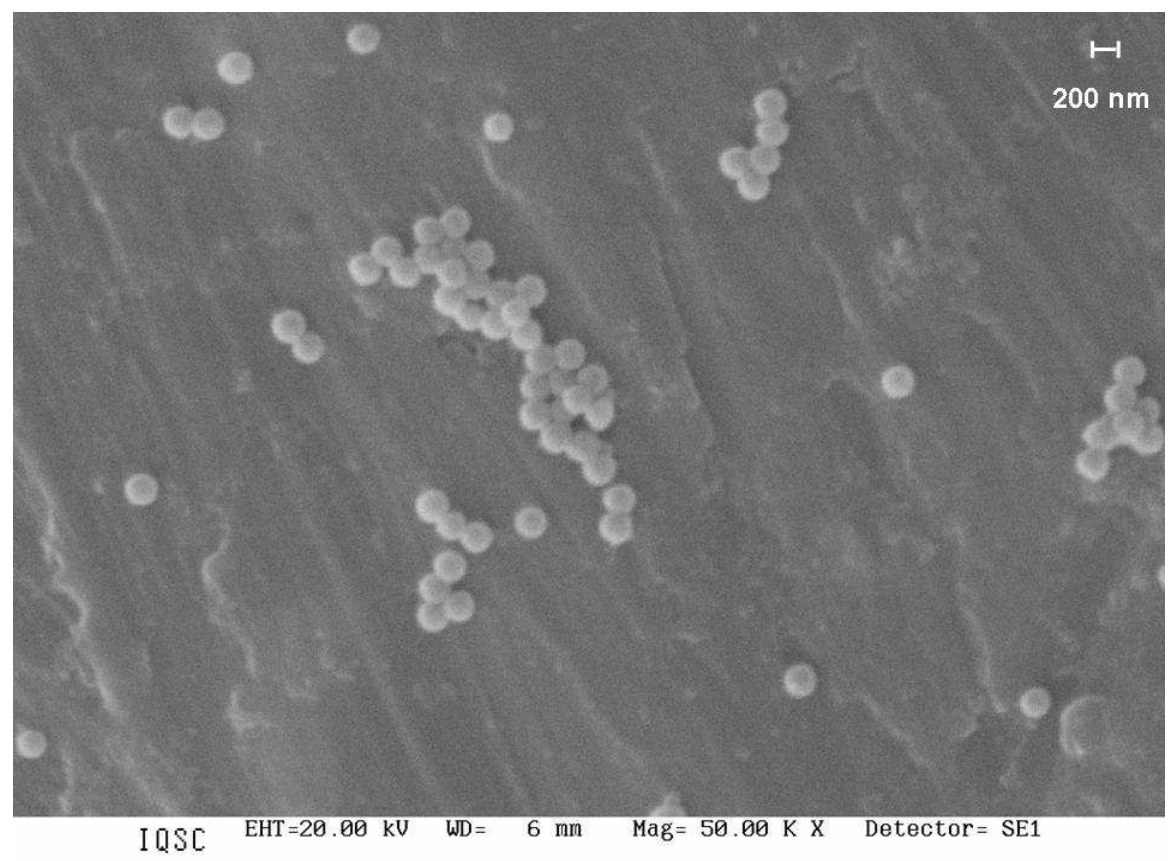

Figura 46: Imagem de MEV das partículas CS, marcadas com 9AA, com diâmetro médio de $200 \mathrm{~nm}$.

O sistema preparado pela metodologia CS marcado com 9AAll apresentou significativa emissão de fluorescência, como mostra a Figura 47. Tanto o perfil 
espectral quanto os máximos de emissão (426, 450 e 480 nm) são similares ao sistema 9AAll em nanopartículas de Stöber.

Em ambos os casos, pode-se observar na região do vermelho do espectro uma banda em $530 \mathrm{~nm}$ com baixa intensidade em relação às demais. Esperava-se que com a inclusão do derivado acridínico 9AAll nas nanopartículas, o estado excitado referente à transferência de carga intramolecular (ICT) fosse totalmente extinguido. Porém, a presença da banda em 530 nm (embora com baixa intensidade) sugere a presença de estados excitados relacionados à transferência de carga intramolecular, mesmo que com pequena contribuição.

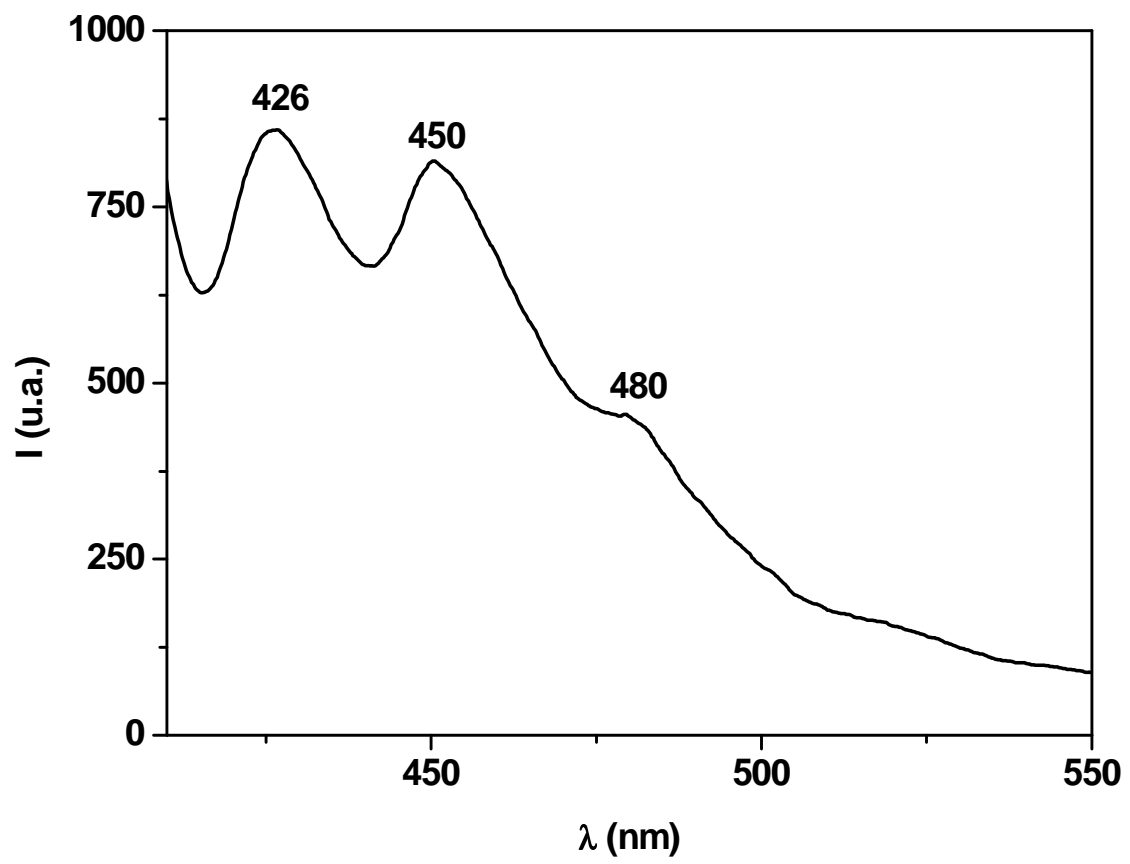

Figura 47: Emissão estacionária das partículas CS9AAll; $\lambda_{\text {exc }}=400 \mathrm{~nm}$; $\lambda_{\text {máx em }}=426,450$ e $480 \mathrm{~nm}$.

Da mesma maneira que os sistemas anteriores, a preparação gerou nanoesferas com diâmetro médio de 200 nm, com pouca aglomeração, como pode ser visto na Figura 48. 


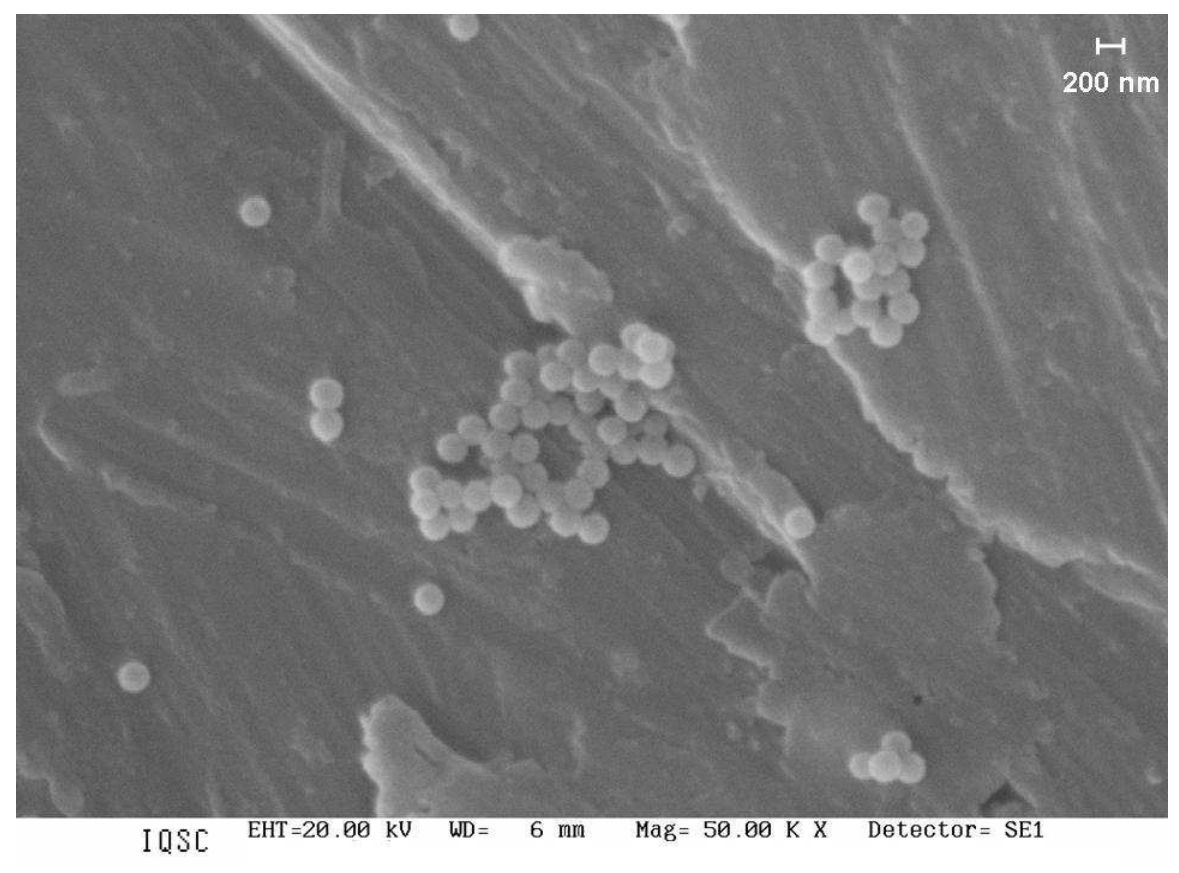

Figura 48: Imagem de MEV das partículas CS, marcadas 9AAll, com diâmetro médio de 200 nm.

\section{Nanopartículas CS marcadas com Auramina (Au)}

A auramina é um composto que apresenta emissão de fluorescência muito baixa em solventes como água e etanol (rendimento quântico de fluorescência em água: 0,003$)^{[57]}$. O processo não radiativo responsável pela supressão da fluorescência da auramina está relacionado com a formação de um estado escuro que sofre relaxação, voltando para o estado fundamental. A fraca emissão é atribuída à livre rotação dos anéis fenílicos presentes na molécula de auramina, o que já foi estudado por diferentes técnicas em vários meios (solventes viscosos, matrizes sólidas, etc. ${ }^{[11,67,68]}$, inclusive por técnicas espectroscópicas ultra-rápidas de fluorescência (up-conversion) ${ }^{[69]}$.

Devido ao comportamento da auramina, este composto se torna uma opção interessante como marcador para nanopartículas de sílica. 
A imagem de MEV da Figura 49 mostra as nanoesferas de sílica marcadas com auramina, com morfologia e tamanho coerentes com os sistemas preparados pela metodologia CS.

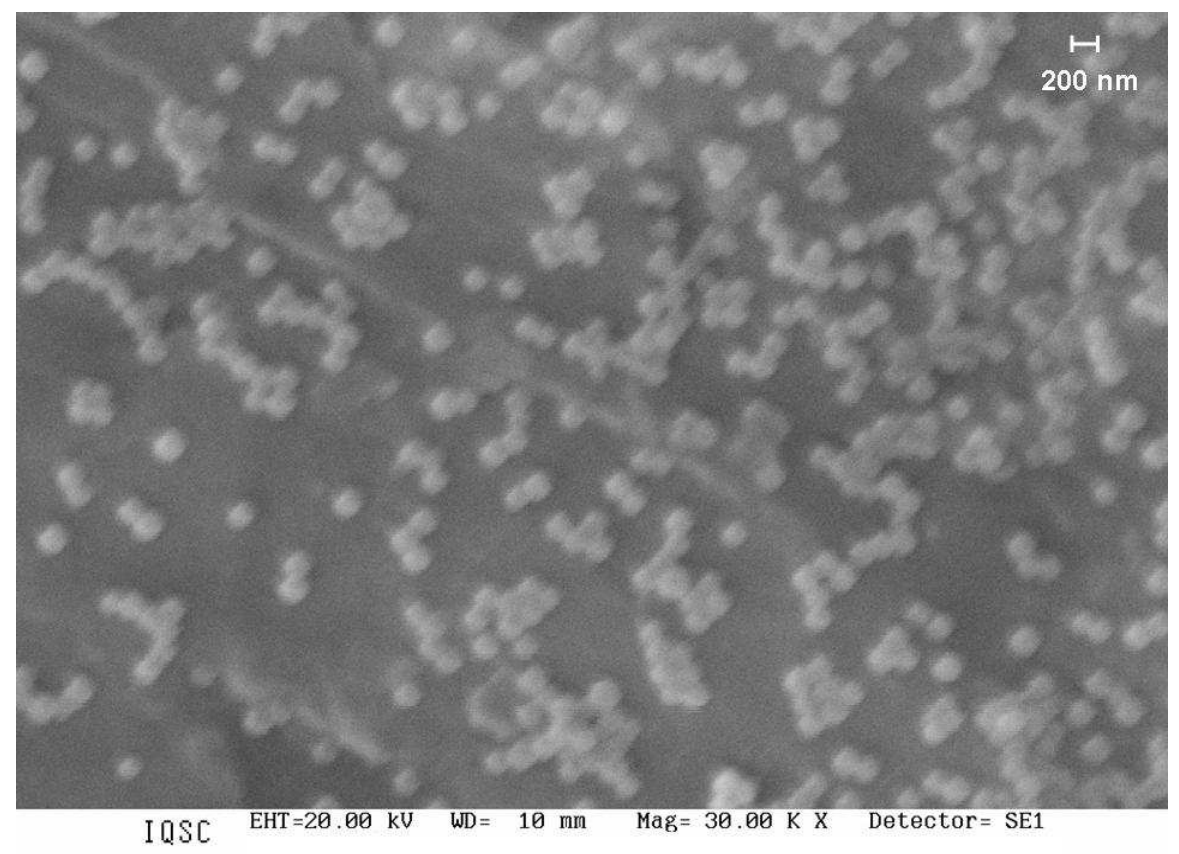

Figura 49: Imagem de MEV das partículas CS, marcadas auramina, com diâmetro médio de $200 \mathrm{~nm}$.

O sistema CS_Au, preparado pela metodologia CS e usando auramina como marcador, apresentou comportamentos diferentes, em relação à emissão em alguns solventes e no estado sólido.

As medidas de emissão estacionária realizadas com CS_Au no estado sólido (Figura 50) mostram que a inclusão da auramina na sílica proporcionou uma maior rigidez à molécula, diminuindo a livre rotação dos anéis fenílicos e gerando alto sinal de emissão, com a banda de emissão característica do composto ( $\lambda_{\text {máx }}=423 \mathrm{~nm}$ ). 


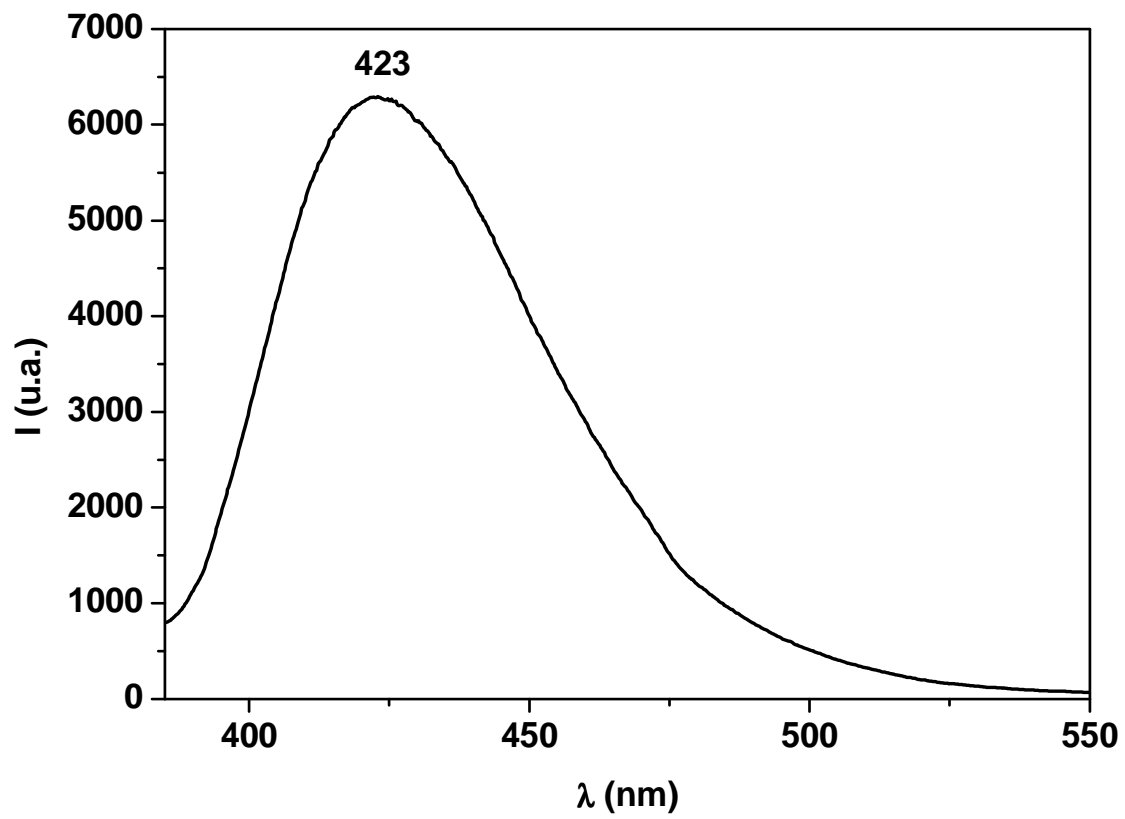

Figura 50: Emissão estacionária das partículas CS_Au, no estado sólido; $\lambda_{\text {exc }}=380 \mathrm{~nm} ; \lambda_{\text {máx em }}=423$ $\mathrm{nm}$.

\section{4 - Estudos de interação polímero/nanopartículas de sílica:}

O copolímero poli(MMA)-co-(9AAIII) (PMMA-9AAIII - Figura 51), preparado a partir da copolimerização térmica de metacrilato de metila com 9AA-III foi utilizado nestes estudos.

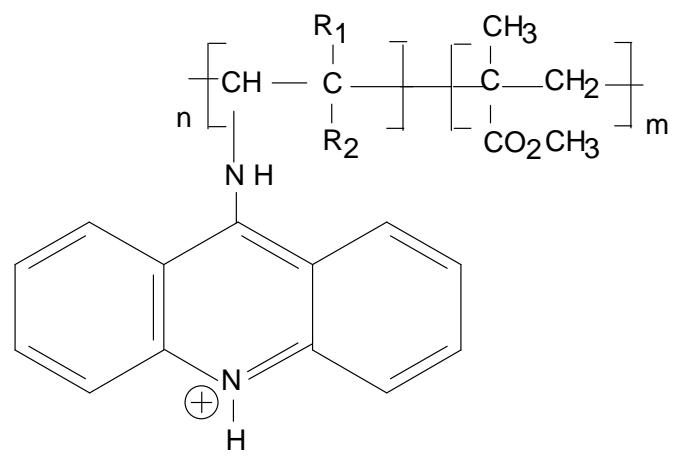

Figura 51: Representação da cadeia de poli(metacrilato de metila) marcado com derivado acridínico. $\mathrm{R}_{1}=\mathrm{R}_{2}=\mathrm{CN} ; m>>n$. 
O espectro de emissão estacionária do PMMA-9AAllI apresenta uma banda larga centrada em $480 \mathrm{~nm}$, atribuída à emissão proveniente do estado de transferência de carga, em direção aos grupos retiradores de elétrons $\mathrm{CN}$. O rendimento quântico de fluorescência deste material é praticamente independente do solvente, com valor médio de $0.035^{[54]}$. As análises de decaimento de fluorescência revelam o comportamento triexponencial do polímero, com tempos de vida de 1,52 ns, 3,70 ns e 12,7 ns, em clorofórmio.

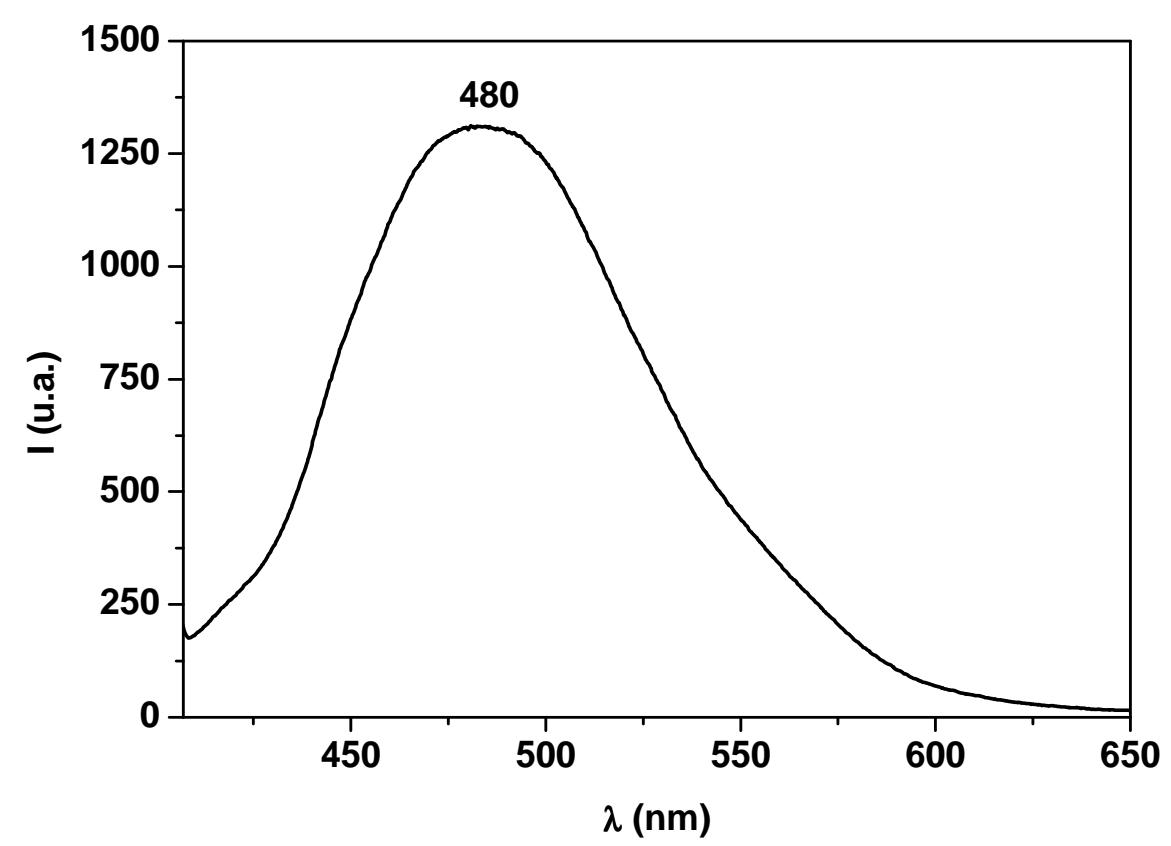

Figura 52: Espectro de emissão estacionária do PMMA-9AAIII.; $\lambda_{\text {exc }}=400 \mathrm{~nm} ; \lambda_{\text {máx em }}=480 \mathrm{~nm}^{[54]}$

Com o intuito de se observar o comportamento do polímero marcado na presença de nanopartículas de sílica, foi preparada uma solução de PMMA-9AAllI na concentração de 2 g. $\mathrm{L}^{-1}$ e nela foi suspenso $1 \mathrm{mg}$ de sílica (branca, sem marcador). A suspensão primeiramente sonicada, e mantida sob constante agitação, foi 
submetida a medidas de emissão estacionária de fluorescência em intervalos de tempo determinados, até que se completassem 20 horas.

A primeira medida realizada logo após a preparação da suspensão apresentou a banda larga, similar àquela mostrada na Figura 52, referente ao polímero marcado. A segunda medida, realizada apenas 5 minutos depois, já mostrou um perfil espectral totalmente distinto. Além de se observar a clara estruturação da emissão, foi observado um deslocamento no comprimento de onda máximo de $480 \mathrm{~nm}$ para $458 \mathrm{~nm}$, como se pode notar na Figura 53, e este perfil espectral foi mantido pelas 20 horas seguintes.

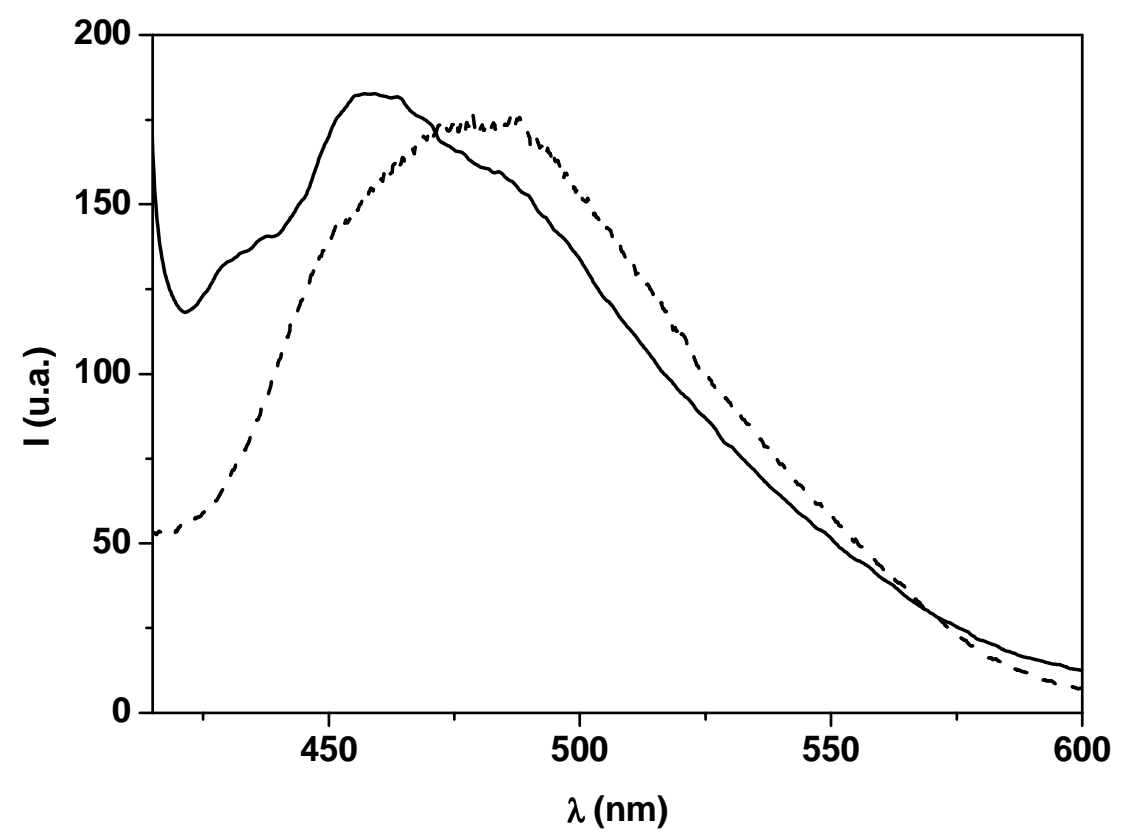

Figura 53: Espectros de emissão estacionária de (---) PMMA-9AAlll e (-) do sistema sílica/PMMA9AAIII. $\lambda_{\text {exc }}=400 \mathrm{~nm}$

A transferência de carga entre grupos doadores e receptores de elétrons na mesma molécula é responsável pela formação do estado ICT. No entanto, a 
conjugação estendida desde o grupo $\mathrm{CN}$ até os anéis acridínicos é imprescindível para que isto ocorra.

Os grupos Si-OH remanescentes na superfície da sílica podem interagir com os grupamentos N-H do corante, formando ligações de hidrogênio, por exemplo. Se ocorrer uma interação deste tipo, especialmente no nitrogênio exocíclico, a conjugação pode ser afetada, levando a uma diminuição na taxa de formação do estado excitado de transferência de carga, o que causaria a estruturação de banda observada na Figura 53.

Ainda envolvendo os sistemas poliméricos, foi feita uma nova síntese de nanopartículas, pela metodologia casca-caroço.

Desta vez, porém, ao invés de se adicionar uma solução de corante ao meio reacional, foi adicionada uma solução do polímero marcado com 9AAll. A concentração de polímero corresponde a $5 \%$ (em massa) do total de TEOS usado na preparação. Assim a nanopartícula é composta por um núcleo de sílica/polímero e uma casa de sílica branca. Este sistema será denotado por CS_PMMA-9AAIII.

As imagens de microscopia eletrônica de varredura das partículas CS preparadas até então mostraram que a inclusão de uma solução de corante no início da preparação não alterava a morfologia dos sólidos obtidos, sendo que as partículas se mantinham esféricas, monodispersas e com pouca agregação.

Por outro lado, a adição de uma solução polimérica ao meio reacional interferiu significantemente nas partículas finais.

Como pode ser observado na Figura 54, na parte inferior, foram obtidas nanopartículas com cerca de 200 nm de diâmetro. No entanto, a imagem na parte superior da Figura 54, realizada com um aumento de 15000 vezes, revela o alto grau de aglomeração deste sistema. 

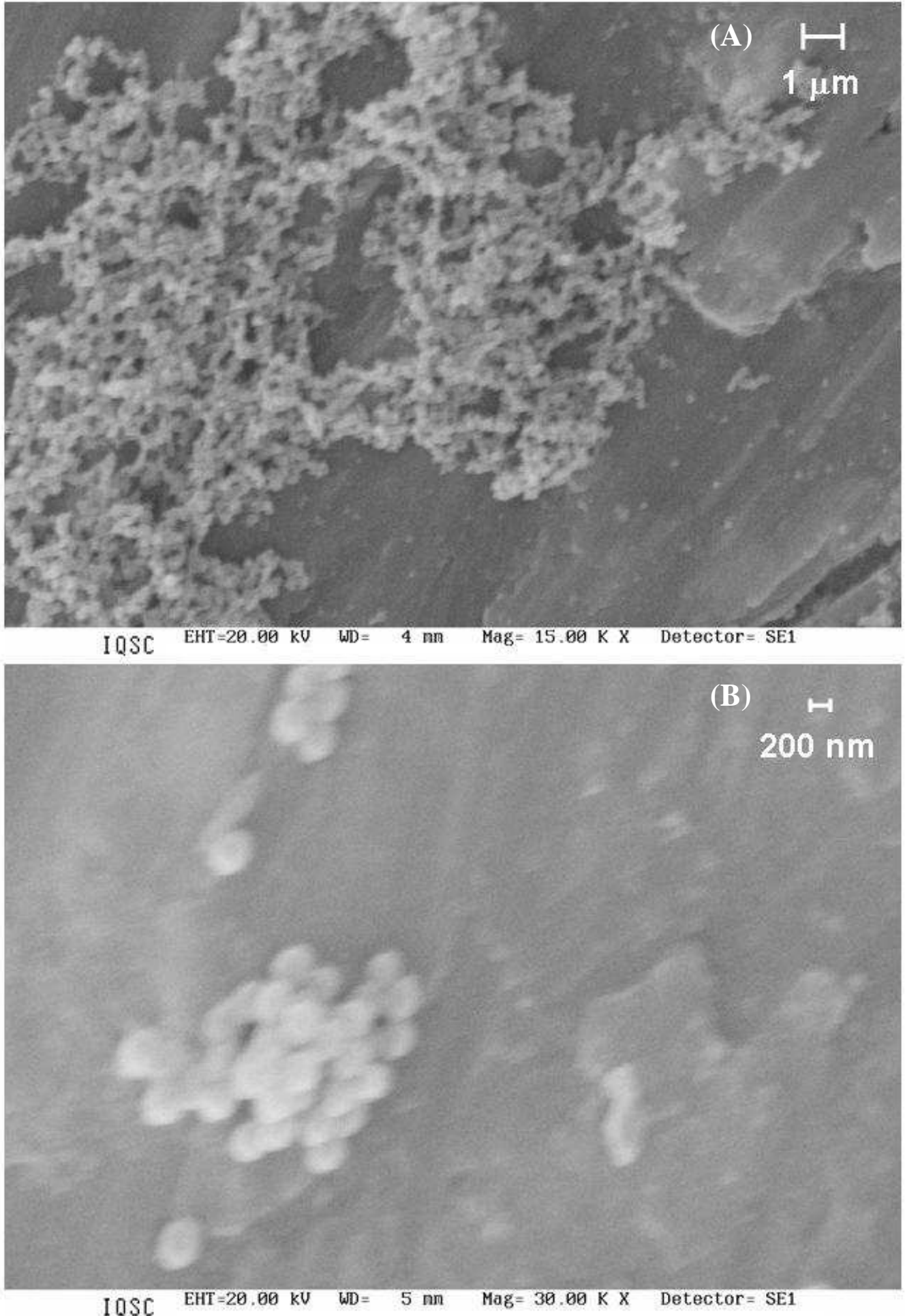

Figura 54: Imagem de MEV das partículas CS_PMMA-9AAIII, com aumento de (A) 15000 vezes e (B) 30000 vezes. Partículas com diâmetro médio de $200 \mathrm{~nm}$. 
Sabe-se que as taxas de hidrólise/condensação nos processos sol-gel sofrem grandes influências de fatores como, concentração dos reagentes, temperatura e solventes utilizados, o que interfere grandemente na morfologia do produto final. Assim, a presença de um polímero no meio reacional, mesmo em baixa quantidade (5\% em massa, em relação ao TEOS), certamente interferiu no processo de formação do caroço rico em marcador.

De uma maneira geral, o desequilíbrio causado pela presença do polímero na reação levou a uma distribuição aleatória de marcador e à formação de nanopartículas isoladas e outras unidas (com formação de chamados "pescoços", veja Figura 55). Em 2-propanol infere-se que a cadeia polimérica se encontre enovelada, podendo ser incorporada no interior das partículas, porém dependendo do grau de enovelamento, porções parcialmente estendidas das cadeias podem estar unindo duas ou mais partículas.

As nanopartículas de sílica preparadas pela metodologia sol-gel, usando base para catalisar a reação, possuem carga superficial negativa, parcialmente responsável por sua estabilidade em solução. Foram realizadas medidas de mobilidade iônica das nanopartículas preparadas pela metodologia casca-caroço, em suspensão aquosa e o valor de potencial zeta destas nanopartículas, obtido a partir das medidas de mobilidade, foi de $-32 \mathrm{mV}$. Portanto, aglomeração observada nas imagens de MEV pode ser atribuída a cadeias poliméricas enoveladas localizadas na superfície externa das nanopartículas (o que levaria à formação de pescoços) ou ao fato das nanopartículas terem sido formadas ao longo de uma mesma cadeia parcialmente estendida. 


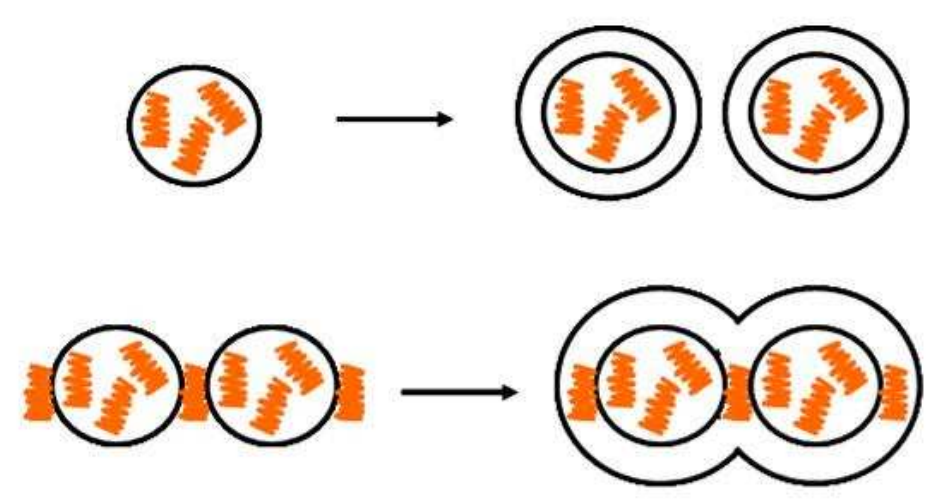

Figura 55: llustração da formação das nanopartículas CS_PMMA-9AAIII.

Para avaliar o comportamento fotofísico do sistema CS_PMMA-9AAIII foram realizadas medidas de excitação e emissão estacionária de fluorescência das nanopartículas suspensas em clorofórmio (Figura 56).

Como já mencionado, o $\lambda_{\text {máx }}$ de emissão para a solução polimérica é de 480 nm (veja Figura 52). O espectro de emissão do CS_PMMA-9AAIII mostrou uma estruturação da banda de emissão e seu deslocamento para regiões de maior energia do espectro $\left(\lambda_{\operatorname{máx}}=416 \mathrm{~nm}\right)$, assim como foi visto no caso do polímero na presença de sílica branca $\left(\lambda_{\operatorname{máx}}=458 \mathrm{~nm}\right)$, discutida anteriormente. Ambos os sistemas (sílica branca suspensa na solução polimérica e polímero encapsulado na sílica) apresentaram o deslocamento da banda de emissão, mas suas estruturas vibrônicas são distintas.

Buscando aumentar o sinal de emissão foram realizadas novas medidas, agora com o sistema no estado sólido. Ao contrário do que se esperava, o espectro mostrou a banda ainda na região de baixos comprimentos de onda, porém sem estruturação.

Os espectros de excitação e emissão do CS_PMMA-9AAIII suspenso em clorofórmio e no estado sólido estão mostrados na Figura 56. As curvas estão 
normalizadas, como o intuito de melhor se comparar os perfis espectrais nas duas situações.

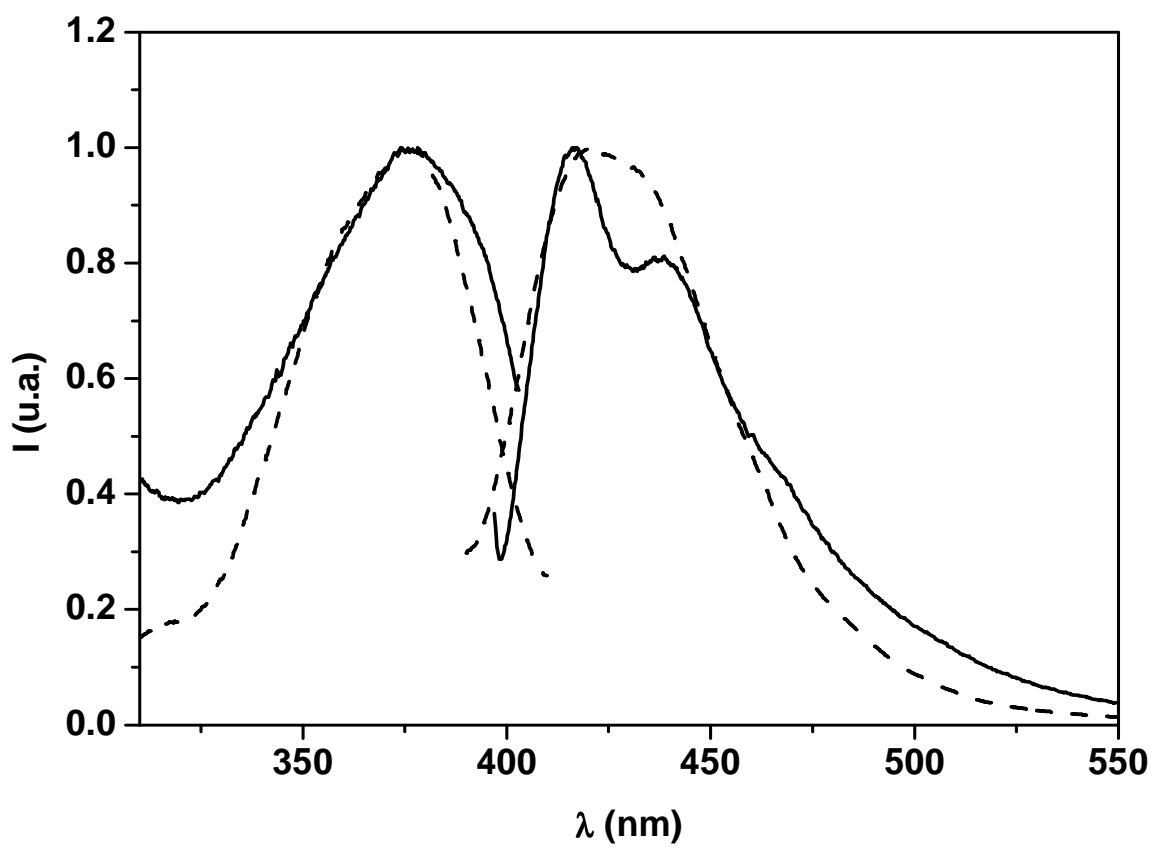

Figura 56: Espectros de excitação e emissão estacionária do sistema CS_PMMA-9AAIII (-) em clorofórmio e (---) no estado sólido; $\left(\lambda_{\mathrm{exc}}=380 \mathrm{~nm} ; \lambda_{\mathrm{em}}=420 \mathrm{~nm}\right)$.

As curvas de emissão apresentam máximo de intensidade na mesma região do espectro, porém possuem perfis distintos. O aparente alargamento da banda, quando a medida é realizada no estado sólido, deve-se ao fato de a sonda experimentar um microambiente rígido e desordenado, onde as moléculas cromóforas estão solvatadas devido à interpenetração do clorofórmio nos poros da sílica.

Sendo assim, fica claro que o intervalo energético entre $S_{0}$ e $S_{1}$ é menor quando a amostra é suspensa em clorofórmio do que no caso do sólido. Na Figura 57 está representada a ilustração do diagrama de energia do sistema CS_PMMA9AAIII, em clorofórmio e no estado sólido. Através dos espectros apresentados na 
Figura 56, foi possível a determinação do $\mathrm{E}_{0,0}$ para as nanopartículas suspensas em solvente e no estado sólido, com valores de 3,12 eV e 3,07 eV, respectivamente.

CS_PMMA-9AAIII

(clorofórmio)

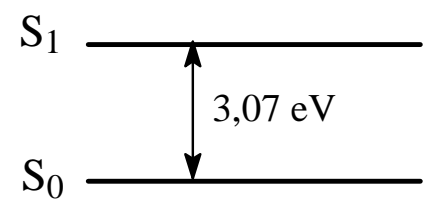

CS_PMMA-9AAIII (sólido)

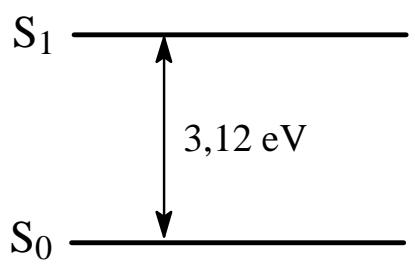

Figura 57: llustração do diagrama de energia do sistema CS_PMMA-9AAIII, em clorofórmio e no estado sólido.

\section{5 - Nanopartículas de sílica casca-caroço contendo dois corantes: estudos de transferência de energia e supressão de fluorescência}

Uma vez bem estabelecido o método de preparação de nanopartículas com corantes encapsulados, deu-se início à preparação de novas partículas, contendo dois tipos de marcadores, para estudar possíveis processos como transferência de energia e supressão de fluorescência.

No processo de transferência de energia eletrônica um fóton emitido pelo doador (D) no estado excitado é absorvido pelo receptor (A):

$$
\begin{gathered}
D+h v \rightarrow D^{*} \\
D^{*}+A \rightarrow D+A^{*}
\end{gathered}
$$


Para tal, a energia transferida deve corresponder a uma freqüência comum aos espectros de emissão do doador e absorção do receptor, ou seja, os espectros devem se sobrepor para que a transferência de energia seja eficiente ${ }^{[35,48,70,71]}$.

Desta forma, os corantes 9-aminoacridina e safranina $O$ foram escolhidos, devido sobreposição das curvas de absorção da safranina e emissão da 9AA. A Figura 58 mostra os espectros dos dois compostos em solução metanólica.

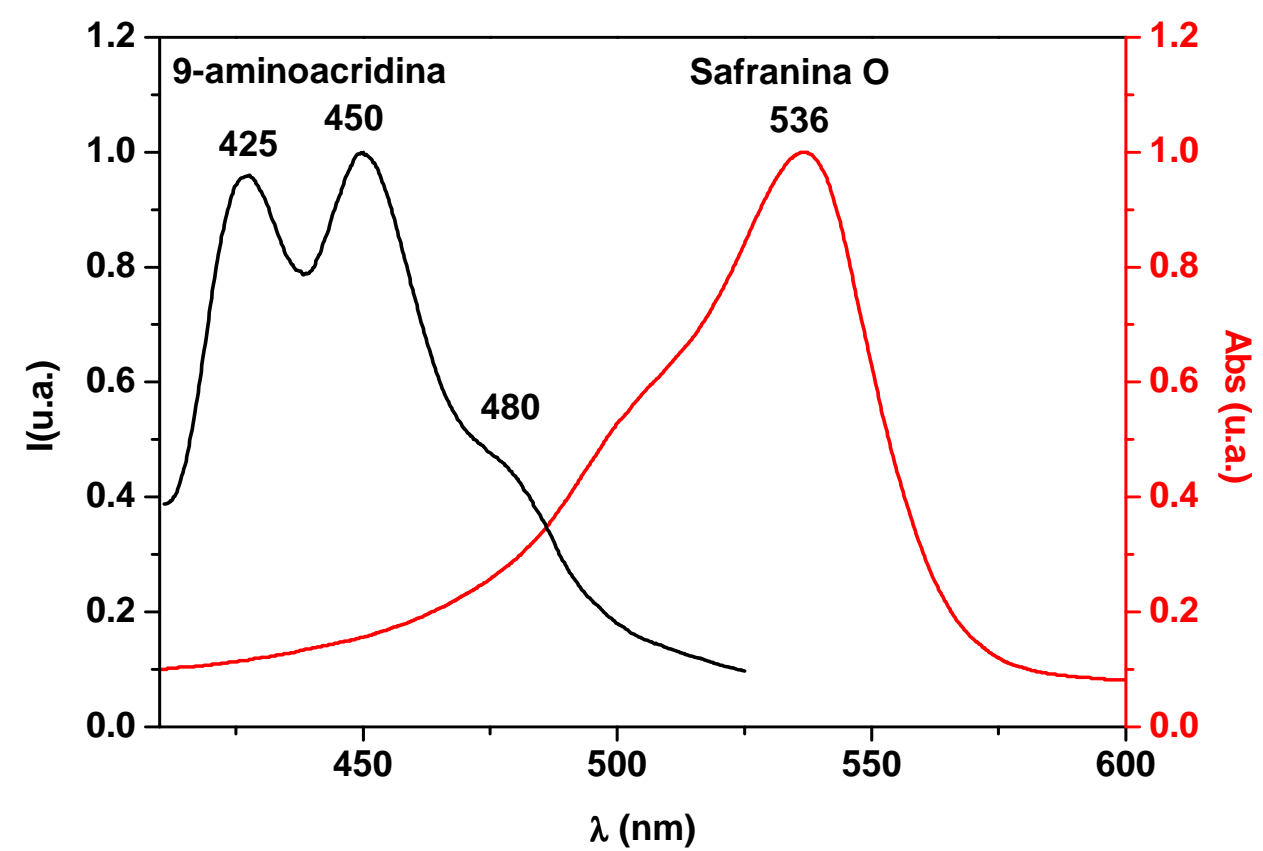

Figura 58: Espectros de emissão estacionária da 9AA $\left(\lambda_{\mathrm{exc}}=400 \mathrm{~nm}\right)$ e absorção da safranina O; $\lambda_{\text {máx em 9AA }}=425,450$ e $480 \mathrm{~nm} ; \lambda_{\text {máx abs Sf }}=536 \mathrm{~nm}$.

O sistema marcado com 9AA e safranina O, denotado por CS_Sf_9AA foi preparado em 2-propanol, sendo que a razão molar precursor/catalisador/água continuou a mesma usada na preparação das partículas CS anteriores. Ambos os corantes foram adicionados ao meio reacional a uma concentração de $1.10^{-4} \mathrm{~mol} \cdot \mathrm{L}^{-1}$.

Todo o processo foi realizado sob agitação constante, à temperatura ambiente e com um total de $800 \mu \mathrm{L}$ de TEOS como precursor. Inicialmente, foi 
formado um núcleo rico em safranina $\mathrm{O}$ a partir de $300 \mu \mathrm{L}$ de TEOS e o sistema ficou reagindo por 12 horas. Em seguida foi feita uma série de adições de alíquotas de TEOS em intervalos de 15 minutos, para que se formasse uma camada de sílica branca (1 hora de reação). Na sequência, uma solução contendo 9AA e $300 \mu \mathrm{L}$ de TEOS foi incorporada ao meio reacional, que reagiu por mais três horas, formando uma camada de sílica contendo 9-aminoacridina. Finalmente, novas alíquotas de TEOS foram adicionadas com o objetivo de formar uma casa de sílica branca.

Seguindo o procedimento acima descrito, sugere-se que as nanopartículas formadas tenham a seguinte configuração:

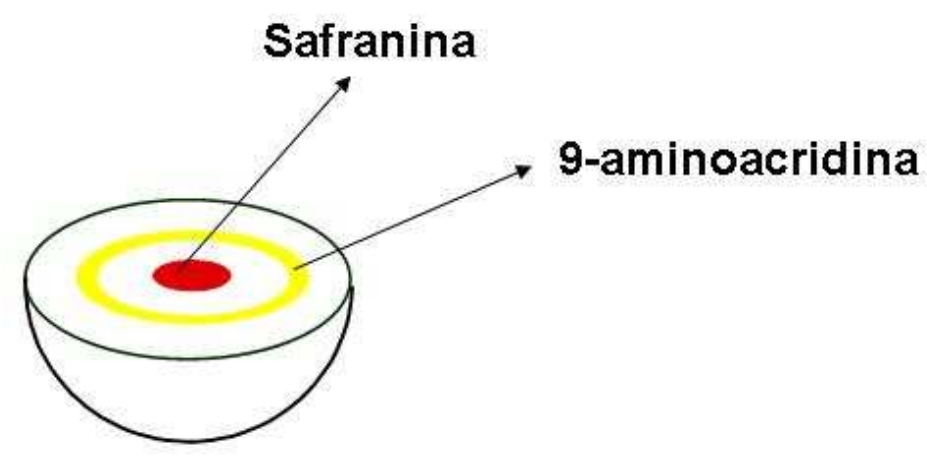

Figura 59: llustração idealizada do sistema CS_Sf_9AA.

A imagem, obtida por microscopia eletrônica de varredura, do sistema CS_Sf_9AA (Figura 60), mostra claramente que as nanopartículas com dois corantes encapsulados são esféricas e com baixo grau de agregação. Porém, em relação ao tamanho, são observadas nanopartículas de 150 nm até 300 nm. Esta dispersão no tamanho, provavelmente é consequência do procedimento experimental realizado. As subsequentes adições de precursor e os tempos de reação certamente influenciaram os tamanhos das partículas obtidas. 


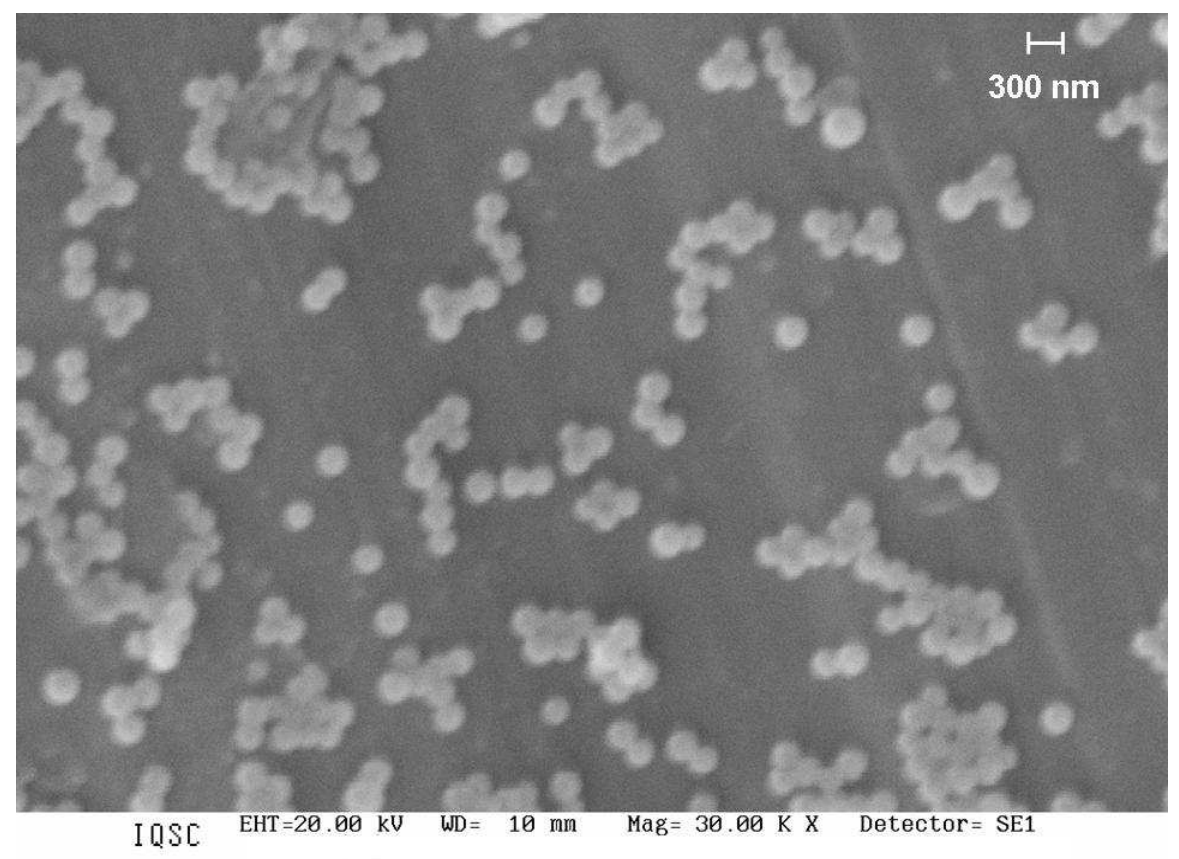

Figura 60: Imagem de MEV das partículas CS_Sf_9AA. Partículas com diâmetros de 150 a $300 \mathrm{~nm}$.

Ainda assim, como se trata de nanoesferas com dois marcadores, 0 CS_Sf_9AA se mostra um material interessante para ser avaliado, pois permite 0 estudo de processos fotofísicos envolvendo dois corantes dentro da mesma nanopartícula.

Para confirmar a incorporação de ambos os marcadores no CS_Sf_9AA, foram realizadas medidas de excitação e emissão de fluorescência, cobrindo os comprimentos de ondas referentes aos dois corantes. As curvas normalizadas dos espectros estão mostradas na Figura 61, que confirma a presença de 9aminoacridina e de safranina $O$ nas nanopartículas. 


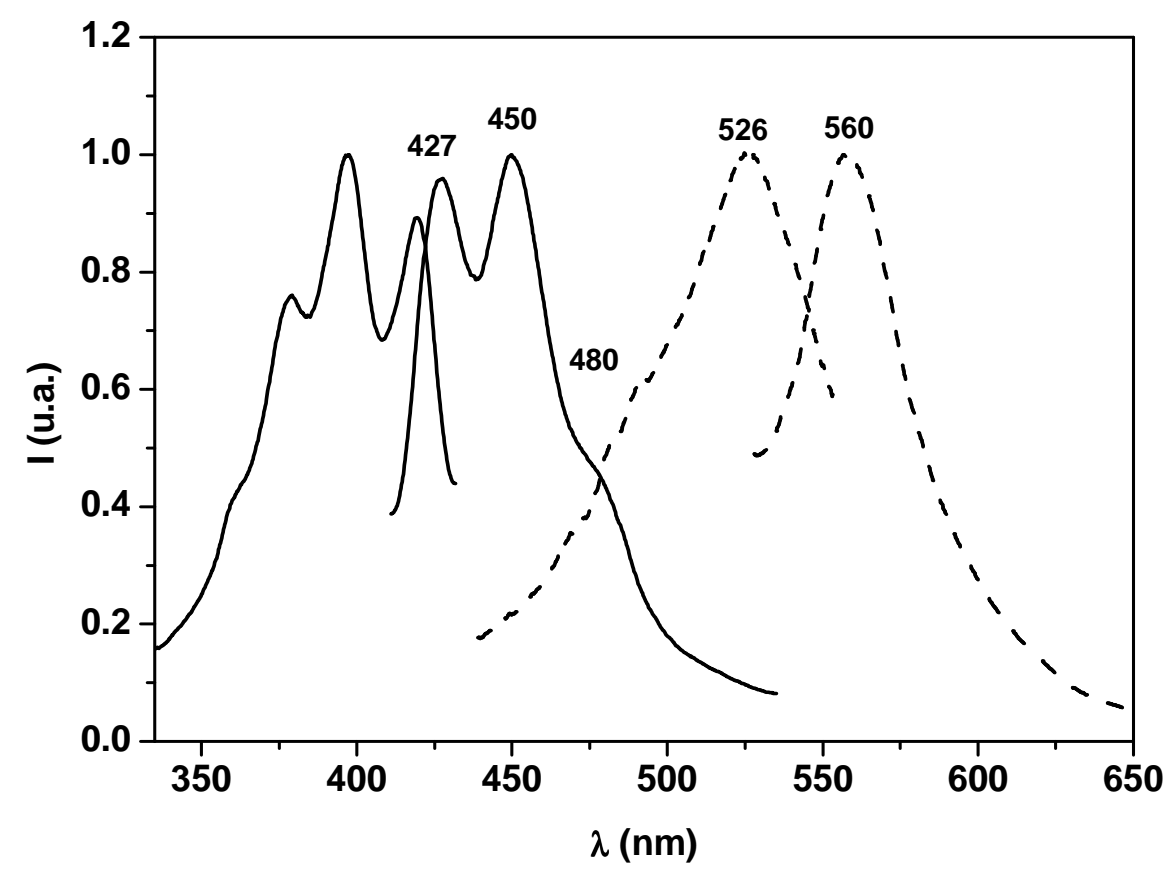

Figura 61: Espectros de excitação e emissão estacionária do sistema CS_Sf_9AA; (-) $\lambda_{\text {exc }}=400 \mathrm{~nm}$ e (---) $\lambda_{\text {exc }}=525 \mathrm{~nm}$; no estado sólido. $\lambda_{\text {máx exc 9AA }}=378,397$ e $418 \mathrm{~nm} ; \lambda_{\text {máx em 9AA }}=427,450$ e 480 $\mathrm{nm} ; \lambda_{\text {máx exc Sf }}=526 \mathrm{~nm} ; \lambda_{\text {máx em Sf }}=560 \mathrm{~nm}$.

Os espectros da Figura 61 foram apresentados normalizados apenas com o intuito de explicitar a presença de ambos os marcadores. Podem ser observadas as bandas características de emissão de 9AA, com máximos em 427, 450 e 480 nm e da safranina $O$ com máximo em $560 \mathrm{~nm}$.

Foram realizadas medidas de decaimento de fluorescência dos sistemas CS_9AA e CS_Sf_9AA, para se avaliar o comportamento da sonda 9-aminoacridina. Para tal, as nanopartículas foram suspensas em metanol e as medidas foram realizadas com $\lambda_{\text {exc }}=400 \mathrm{~nm}$ (região de excitação da 9AA).

As curvas de decaimento obtidas apresentaram um perfil não usual, sendo observados picos de emissão, que se repetem aleatoriamente, sem uma sequência temporal definida, mas especialmente nas regiões entre 5 e $10 \mathrm{~ns}$, como pode ser visto no gráfico da Figura 62. 


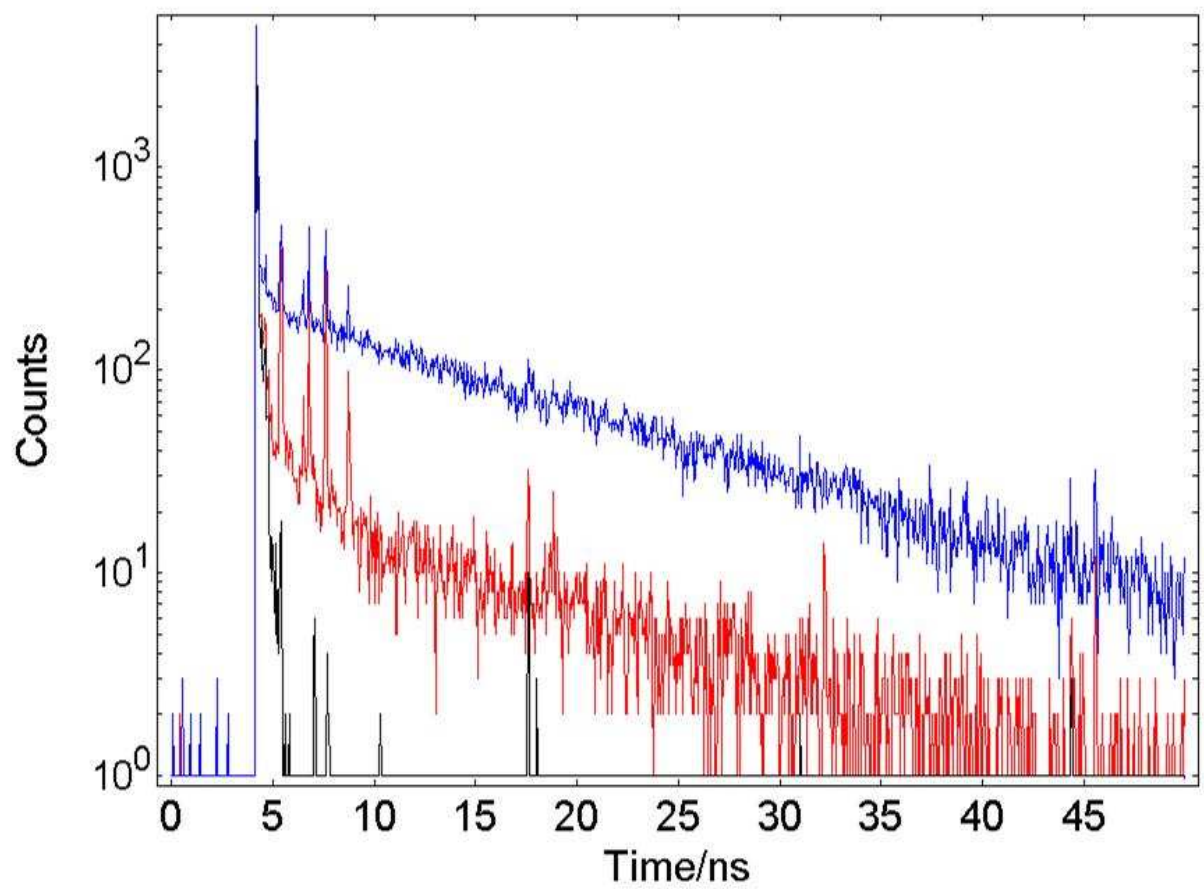

Figura 62: Decaimentos de fluorescência de dos sistemas contendo 9AA e safranina $O$, em metanol: ( - ) IRF, ( - ) CS_9AA e ( - ) CS_Sf_9AA; $\lambda_{\mathrm{exc}}=400 \mathrm{~nm}$.

Embora seja nítida a supressão causada pela safranina $O$ na desativação da 9AA, os picos ou cintilações (sparks) presentes em ambas as medidas, no início das curvas de decaimento, impedem um bom ajuste em relação à resposta instrumental do equipamento, dificultando a determinação dos tempos de vida de fluorescência e suas contribuições ponderadas. Um fato curioso é que os picos dos decaimentos estão correlacionados (ocorrem praticamente no mesmo tempo), e não guardam uma relação exata com flutuações do pulso de excitação (IRF) em tempo e intensidade, sendo, portanto, uma característica intrínseca da amostra.

$\mathrm{Na}$ tentativa de se contornar este efeito, foram realizadas medidas com as amostras mais diluídas e também no estado sólido. Em todos os casos foram obtidas curvas de decaimento com o mesmo perfil, ou seja, ainda com os picos de emissão no início da curva de decaimento. Trata-se, provavelmente, de 
espalhamento da própria sílica e também de algum tipo de emissão estimulada gerada na cavidade da nanopartícula que possui um diâmetro da ordem do comprimento de onda de excitação. Assim algum modo longitudinal $L=m \lambda / 2$ para $m$ inteiro (no caso $m=1$ ) pode se sustentar considerando a faixa de comprimentos de onda da 9AA de $400-500 \mathrm{~nm}$. Assim, partículas de diâmetro entre 150 até $300 \mathrm{~nm}$ (que é a faixa de tamanho das nanoparticulas preparadas, vide figura 60) podem em um meio com contraste de índice de refração (funciona como espelho) apresentar ressonância e emissão estimulada provocando o efeito observado. O que não é entendido é a correlação dos eventos entre duas amostras medidas em situações distintas são não correlacionadas. $O$ efeito deveria aparecer de forma aleatória na escala de tempo, contrariando as observações feitas.

Estudos espectroscópicos de suspensões de sílica são muitas vezes limitados, devido ao espalhamento de luz causado pelas partículas em meio aquoso ou alcoólico, mesmo em regimes diluídos, devido à considerável diferença entre os índices de refração da sílica e do solvente (água ou álcool) ${ }^{[40,72]}$.

Buscando eliminar os picos de emissão observados nos decaimentos, uma alternativa foi a utilização de partículas dispersas em solventes com índices de refração próximos ao da sílica $(n=1,456)$. Solventes como clorofórmio $(n=1,446)$ e hexadecano $(n=1,434)$ são usualmente empregados para este fim, pois aumentam a estabilidade coloidal pela minimização das forças de atração de van der Waals e diminuem drasticamente o espalhamento ${ }^{[40,72,73]}$.

De fato, a suspensão passa de turva à transparente, conforme o índice de refração do solvente usado se aproxima ao da sílica. Assim, novas medidas de decaimento foram realizadas com suspensões de CS_9A e CSA_Sf_9AA em clorofórmio. 


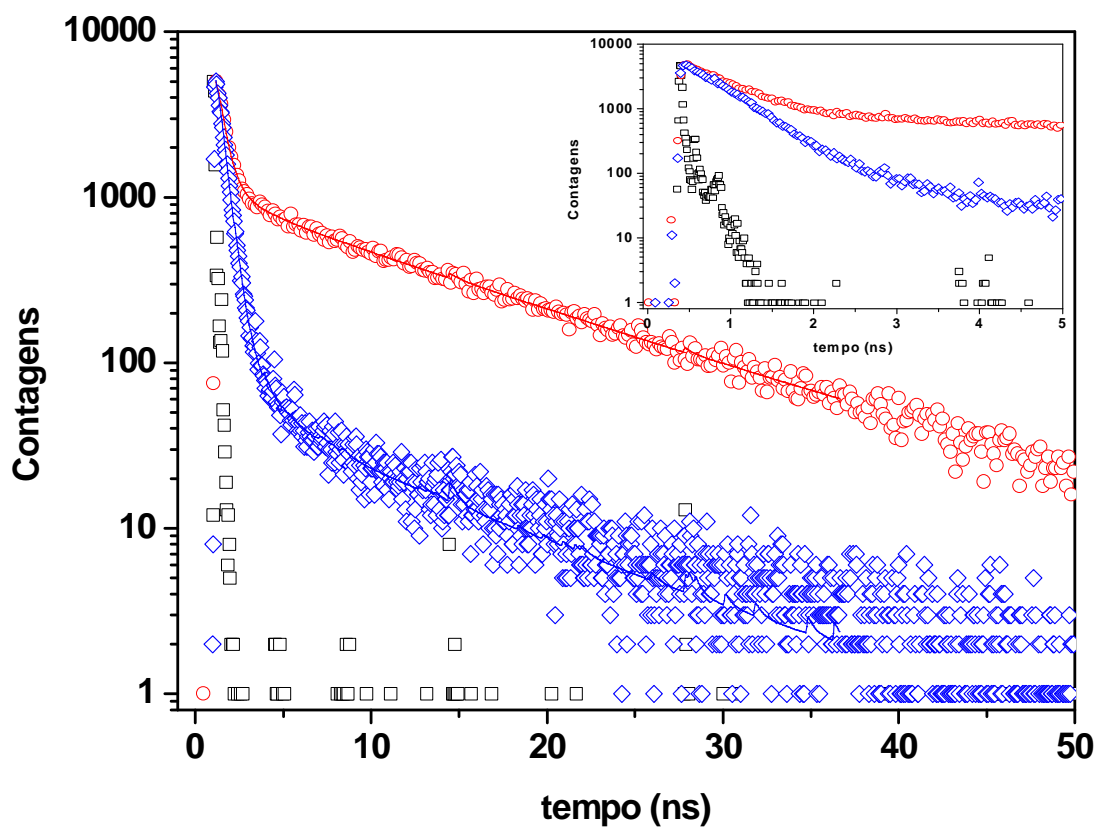

Figura 63: Decaimentos de fluorescência de dos sistemas contendo 9AA e safranina $O$, em clorofórmio: $(\square)$ IRF, ( O ) CS_9AA e $(\diamond)$ CS_Sf_9AA. (detalhe: a mesma medida realizada em uma janela de tempo menor); $\lambda_{\mathrm{exc}}=400 \mathrm{~nm}$.

Pode-se observar que o emprego de um solvente com índice de refração próximo ao da sílica eliminou os efeitos de espalhamento ou cavidade.

As curvas apresentadas na Figura 63 representam os decaimentos de fluorescência dos sistemas CS_9AA e CS_Sf_9AA em vermelho e azul, respectivamente, e através destas medidas é possível determinar os tempos de vida de fluorescência da 9AA em ambos os casos.

Os tempos de vida da 9AA e suas contribuições estão listados na Tabela 3. 
Tabela 3: Tempos de vida de fluorescência de CS_9AA e CS_Sf_9AA

\begin{tabular}{ccccc} 
& $\tau_{1} / \mathrm{ns}$ & $\tau_{2} / \mathrm{ns}$ & $\tau_{3} / \mathrm{ns}$ & $\chi^{2}$ \\
& $(\%$ relativa $)$ & (\% relativa) & (\% relativa) & \\
CS_9AA & 0,441 & 1,88 & 12,2 & 1,092 \\
& $(18)$ & $(4)$ & $(78)$ & \\
CS_Sf_9AA & 0,411 & 1,57 & 9,71 & 1,284 \\
& $(80)$ & $(7)$ & $(13)$ & \\
\hline
\end{tabular}

Os valores de tempos de vida obtidos nas análises da curva de decaimento do sistema CS_9AA estão de acordo com o reportado na literatura, para espécies acridínicas $^{[34]}$. Trata-se de uma dinâmica triexponencial com tempos de vida $\tau_{1}=$ 0,441 ns, $\tau_{2}=1,88$ ns e $\tau_{3}=12,2$ ns. $O$ tempo de vida mais curto é referente à moléculas de 9AA participando de ligação de hidrogênio com os grupos silanol residuais na superfície da sílica, através de grupamentos $\mathrm{NH}$. Já o tempo de vida intermediário (1,88 ns) é relativo às moléculas de 9AA neutras, enquanto que o tempo de vida mais longo $(12,2)$ é proveniente da desativação da 9AA protonada, da mesma ordem dos tempos de vida deste corante em outros meios ${ }^{[11,28,30,74]}$.

Deve-se reforçar que o tempo de vida mais longo, proveniente da 9AA protonada, apresenta uma contribuição relativa de $78 \%$, ou seja, a maioria das moléculas de corante se encontra protonada.

Quando a nanopartícula de sílica é preparada com 9AA e safranina O, observa-se que o sistema mantém sua característica triexponencial, isto é, ainda há no interior das partículas diferentes espécies acridínicas. Contudo, pode-se observar que a presença da safranina $O$ de fato suprimiu a emissão da 9AA protonada que passou a apresentar tempo de vida de 9,71. Maior atenção ainda deve ser dada à 
contribuição da emissão da 9AA protonada que cai bruscamente, passando a apenas $13 \%$. No caso das partículas CS-Sf-9AA grande parte da emissão é proveniente de espécies 9AA fazendo ligação de hidrogênio na superfície da sílica.

O raio de Förster para o par 9AA-Sf é da ordem de $90 \AA^{[75]}$, distância menor que a separação dos dois corantes na estrutura core-shell em camadas ideais. A existência de transferência de energia de forma eficiente indica que durante a formação, ou quando em suspensão, ocorre uma inter-difusão das espécies, possibilitando assim uma sobreposição de densidades ou gradiente de concentração dos corantes que permite a existência de pares D/A próximos, capazes de transferir energia. 
5 - CONCLUSÃO 


\section{5 - CONCLUSÃo}

Uma série de compostos fluorescentes foi incorporada a partículas comerciais de sílica, nanopartículas preparadas pelo método de Stöber e pela metodologia casca-caroço.

A incorporação de 9-aminoacridinametilenodietilmalonato e 9aminoacridinametilenocianoetilacetato em sílica comercial foi realizada com sucesso após a sililação da superfície. Os espectros de emissão estacionária revelaram a ausência da banda de ICT que ocorre nestes compostos, quando em solução, confirmando a incorporação. Embora marcadas, as partículas se mostraram inviáveis para o estudo fotofísico dos corantes, devido a sua irregularidade.

As nanopartículas preparadas pelo método de Stöber em etanol (TEOS 1: $\mathrm{H}_{2} \mathrm{O}$ 21: catalisador 14), marcadas com 9VA, 9AAll ou Sf, apresentaram-se altamente aglomeradas e com grande dispersão de tamanho, ou seja, embora tenham sido observados altos sinais de emissão, trata-se de sistemas irregulares.

Já as preparações realizadas pelo método de Stöber em 2-propanol (TEOS 1: $\mathrm{H}_{2} \mathrm{O} 21$ : catalisador 0,5$)$ resultaram em nanoesferas com diâmetro médio de $100 \mathrm{~nm}$, sem agregação e com baixa distribuição de tamanho. Estes sistemas foram marcados com 9AAll, Sf ou 9AA, todos apresentando altos sinais de emissão.

As nanopartículas do tipo casca-caroço (CS) apresentaram uma boa morfologia e tamanhos maiores $(\mathrm{d}=250 \mathrm{~nm})$ que as partículas de Stöber. Do ponto de vista fotofísico, os sistemas CS são considerados um melhor resultado, mesmo apresentando um menor grau de incorporação de marcador, quando comparadas às de Stöber, pelo fato de sua estrutura retardar a difusão das moléculas de marcador para fora das nanopartículas. 
As nanopartículas CS marcadas com o polímero PMMA-9AAlll apresentaram aglomeração e formação de pescoços interparticulares. Os espectros de emissão do polímero na presença de sílica branca e incorporados em nanopartículas CS revelaram uma estruturação da banda e um deslocamento de $22 \mathrm{~nm}$ no comprimento de onda máximo de emissão, devido a interações entre grupamentos $\mathrm{N}-\mathrm{H}$ do corante e grupos silanol residuais na superfície da sílica.

Os sistemas marcados com Sf e 9AA na mesma nanopartícula apresentou as bandas de excitação e emissão de fluorescência referentes aos dois corantes, confirmando sua incorporação. Análises dos decaimentos de fluorescência das nanopartículas com 9AA e com Sf/9AA revelaram que os tempos de vida de fluorescência referentes ao cromóforo acridina passaram de 12,2 ns para 9,71 ns. Esta supressão, indica a inter-difusão das duas espécies aproximando as espécies doadora e receptora de energia. 


\section{6- REFERÊNCIAS BIBLIOGRÁFICAS}




\section{6 - REFERÊNICAS BIBLIOGRÁFICAS}

[1] DE, E.; GHOSH, P.S.; ROTELLO, V.M. Applications of nanoparticles in biology. Advanced Materials, v. 20, p. 4225, 2008.

[2] PIAO, Y.; BURNS, A.; KIM, J.; WIESNER, U.; HYEON, T. Designed fabrication of silica-based nanostructured particle systems for nanomedicine applications.

Advanced Functional Materials, v. 18, p. 3745, 2008.

[3] ROSSI, L.M.; SHI, L.; QUINA, F.H.; ROSENZWEIG, Z. Stöber synthesis of monodispersed luminescent silica nanoparticles for bioanalytical assays. Langmuir, v. 21, p. 4277, 2005.

[4] ROSSI, L.M.; SHI, L.; ROSENZWEIG, N.; ROSENZWEIG, Z. Fluorescent silica nanospheres for digital counting bioassay of the breast cancer marker HER2/nue. Biosensors and Bioelectronics, v. 21, p. 1900, 2006.

[5] TADA, D.B.; VONO, L.L.R.; DUARTE, E.L.; ITRI, R.; KIYOHARA, P.K.;

BAPTISTA, M.S.; ROSSI, L.M. Methylene blue-contaning silica-coated magnetic particles: a potential magnetic carrier for photodynamic therapy. Langmuir, v. 23, p. 8194, 2007.

[6] SHTYKOV, S.N.; RUSANOVA, T.Y. Nanomaterials and nanotechnologies in chemical and biochemical sensors: capabilities and applications. Russian Journal of General Chemistry, v. 78, p. 521, 2008.

[7] GODOI, R.H.M.; MARQUES, R.F.C.; VARANDA, L.C.; JAFELICCI JUNIOR, M. Yttrium iron garnet heterocoagulated by sílica. IEEE Transactions on Magnetics, $v$. 38, p. 2625, 2002.

[8] KOBER, U.A.; CAMPO, L.F.; COSTA, T.M.H.; STEFANI, V.; RAMMINGER, G.O.; GALLAS, M.R. Fluorescence behavior of powders and high-pressure compacts of silica containing silyl-functionalized benzazole dyes. Journal of Photochemistry and Photobiology A: Chemistry, v. 186, p. 24, 2007.

[9] COSTA, T.M.H.; STEFANI, V.; GALLAS, M.R.; BALZARETTI, N.M.; da JORNADA, J.A.H. Fluorescent compacts prepared by the entrapment of benzoxazole type dyes into a silica matrix at high pressure. Journal of Noncrystalline Solids, v. 333, p. 221, 2003. 
[10] COSTA, T.M.H.; HOFFMANN, H.S.; BENEVENUTTI, E.V.; STEFANI, V.; GALLAS, M.R. Pressure-induced changes on the optical properties and microstructure of silica gel matrices doped with rhodamine 6G. Optical Materials, v. 27, p. 1819, 2004.

[11] GEHLEN, M.H.; PEREIRA, R.V.; GALLAS, M.R.; COSTA, T.M.H.; STEFANI, V. Time-resolved fluorescence spectroscopy of cationic dyes incorporated in silica matrix by high pressure compaction. Journal of Photochemistry and Photobiology A: Chemistry, v. 181, p. 147, 2006.

[12] STÖBER, W.; FINK, A. Controlled growth of monodisperse silica spheres in the micron size range. Journal of Colloid and Interface Science, v. 26, p. 62, 1968.

[13] BRINKER, C.J.; SCHERER, G.W. Sol-gel science: the physics and chemistry of sol-gel processing. Londres: Academic Press, 1990. 908p.

[14] BUCKLEY, A.M.; GREENBLATT, M. The sol-gel preparation of silica gels. Journal of Chemical Education, v. 71, p. 599, 1994.

[15] NASSAR, E.J.; MESSADDEQ, Y.; RIBEIRO, S.J.L. Influência da catálise ácida e básica na preparação da sílica funcionalizada pelo método sol-gel. Química Nova, v. 25 , n. 1, p. 27, 2002.

[16] FINNIE, K.S.; BARTLETT, J.R.; BARBÉ, C.J.A.; KONG, L. Formation of silica nanoparticles in microemulsions. Langmuir, v. 23, n. 6, p. 3017, 2007.

[17] MATSOUKAS, T.; GULARI, E. Dynamics of growth of silica particles from ammonia-catalyzed hydrolysis of tetra-ethyl-ortosilicate. Journal of Colloid and Interface Science, v. 124, p. 252, 1988.

[18] MATSOUKAS, T.; GULARI, E. Monomer addition growth with a slow initiation step: a growth model for silica particles from alkoxides. Journal of Colloid and Interface Science, v. 132, p. 13, 1989.

[19] BOGUSH, G.H.; ZUKOSKI, C.F. Studies of the kinetics of the precipitation of uniform silica particles through the hydrolysis and condensation of silicon alkoxides. Journal of Colloid and Interface Science, v. 142, p. 1, 1991. 
[20] BOGUSH, G.H.; ZUKOSKI, C.F. Uniform silica particle precipitation: an aggregative growth model. Journal of Colloid and Interface Science, v. 142, p. 19, 1991.

[21] LA MER, V.K. Nucleation in phase transitions. Industrial and Engeneering Chemistry, v. 44, p. 1270, 1952.

[22] HARRIS M.T.; BRUNSON, R.R.; BYERS, C.H. The base-catalyzed hydrolysis and condensation reactions of dilute and concentrated TEOS solutions. Journal of Non-Crystalline Solids, v. 121, p. 397, 1990.

[23] VAN BLAADEREN, A.; VAN GEEST, J.; VRIJ, A. Monodisperse colloidal silica spheres from tetraalkoxysilanes: particle formation and growth mechanism. Journal of Colloid and Interface Science, v. 154, p. 481, 1992

[24] LEITE, A.P.; SOUZA, E.F.; GALEMBECK, F. Core-and-shell nature of Stöber silica Particles. Journal of Brazilian Chemiical Society, v. 12, n. 4, p. 519, 2001.

[25] LEE, K,; SATHYAGAL, A.N.; McCORMICK, A.V. A closer look at an aggregation model of Stöber process. Colloids and surfaces A, v. 144, p. 115, 1998.

[26] BAGWE, R.P.; HILLIARD, L.R.; TAN W. Surface modification of silica nanoparticles to reduce aggregation and nonspecific binding. Langmuir, v. 22, n. 9 , p. 4357, 2006.

[27] BAGWE, R.P.; YANG, C.; HILLIARD, L.R.; TAN, W. Optimization of dye-doped silica nanoparticles prepared using a reverse microemulsion method. Langmuir, $v$. 20, n. 19, p. 8336, 2004.

[28] OLIVEIRA, H.P.M.; GEHLEN, M. Time resolved fluorescence anisotropy of basic dyes bound to poly (methacrylic acid) in solution. Journal of Brazilian Chemical Society, v. 14, p. 738, 2003.

[29] GREEN, F. The Sigma-Aldrich handbook of stains, dyes and indicators. Milwaukee: Aldrich Chemical Company, 1990. 763 p.

[30] PEREIRA, R.V.; FERREIRA, A.P.G.; GEHLEN, M.H. Excited-state intramolecular charge transfer in 9-aminoacridine derivative. Journal of Physical Chemistry A, v. 109, n. 27, p. 5978, 2005. 
[31] PEREIRA, R.V.; GEHLEN, M.H. Photoinduced intramolecular charge transfer in 9- aminoacridinium derivatives assisted by intramolecular $\mathrm{H}$-bond. Journal of Physical Chemistry A, v. 110, n. 24, p. 7539, 2006.

[32] PEREIRA, R.V.; GEHLEN, M.H. Polymerization and conformational transition of poly(methacrylic acid) probed by electronic spectroscopy of aminoacridines.

Macromolecules, v. 40, n. 6, p. 2219, 2007.

[33] ROHATGI-MUKHERJEE, K.K. Fundamentals of photochemistry. New Deli: Wiley, 1978. 371p.

[34] MASON, W.T. Fluorescent and luminescent probes for biological activity. London: Academic Press, 1993. 433p.

[35] LAKOWICZ, J.R. Principles of fluorescence spectroscopy. New York: Springer, 2006. 954p.

[36] HEINEN, W.; ROSEMOLLER, C.H.; WENZWL, C.B.; DE GROOT, H.J.M.; LUGTENBURG, J.; VAN DUIN, M. ${ }^{13} \mathrm{C}$ NMR study of the grafting of maleic anhydride onto polyethene, polypropene, and ehtene-propene copolymers. Macromolecules, v. 29, n. 4, p. 1151, 1996.

[37] ZHANG, M.; DUHAMEL, J.; VAN DUIN, M.; MEESSEN, P. Characterization by fluorescence of the distribution of maleic anhydride grafted onto ethylene-propylene copolymers. Macromolecules, v. 37, n. 5, p. 1877, 2004.

[38] SOUTAR, I.; SWANSON, L. Luminescence studies of polyelectrolyte behavior in solution. 3. time-resolved fluorescence anisotropy measurements of the conformational behavior of poly(methacrylic acid) in dilute aqueous solution.

Macromolecules, v. 27,p. 4304, 1994.

[39] O'CONNOR, D.; PHILLIPS, D. Time correlated single photon counting. London: Academic Press, 1984. 288 p.

[40] LIZ-MARZÁN, L.M.; GIERSIG, M.; MULVANEY,P. Synthesis of nanosized goldsilica core-shell particles. Langmuir, v. 12, p. 4329, 1996.

[41] PARK, S.J.; DUNCAN, T.V.; SANCHEZ-GAYTAN, B.L.; PARK, S.J. Bifunctional nanostructures composed of fluorescent core and metal shell subdomains with controllable geometry. Journal of Physical Chemistry C, v. 112, p. 11205, 2008. 
[43] LIN, J.; BAERNER, K. Tunable photoluminescence in sol-gel derived silica xerogels. Materials Letters, v. 46, p. 86, 2000.

[43] EREMENKO, A.M.; SMIRNOVA, N.P.; OGENKO, V.M.; CHUILO, A.A. Luminescence of organic dyes in silica matrices. Research on Chemical Intermediates, v. 19, n. 9, p.855, 1993.

[44] SOTERO, P.; ARCE, R. Surface and adsorbates effects in the photochemistry and photophysics of adsorbed perylene on unactivated silica gel and alumina.

Journal of Photochemistry and Photobiology A: Chemistry, v. 167, p. 191, 2004.

[45] NEGRON-ENCARNACION, I.; ARCE, R.; JIMENEZ, M. Characterization of acridine species adsorbed on $\left(\mathrm{NH}_{4}\right)_{2} \mathrm{SO}_{4}, \mathrm{SiO}_{2}, \mathrm{Al}_{2} \mathrm{O} 3$, and $\mathrm{MgO}$ by steady-state and time-resolved fluorescence and diffuse reflectance techniques. Journal of Physical Chemistry A, v. 109, n. 5, p. 787, 2005.

[46] HSU, W.P.; YU, R,; MATIJEVIC, E. Adsorption of dyes on nanosized modified particles. Dyes and Pigments, v. 19, p. 179, 1992.

[47] WU, G.; KOLIADIMA, A.; HER, Y.S.; MATIJEVIC. Well-defined colloidal pigments: monodispersed inorganic spherical particles containing organic dyes.

Journal of Colloid and Interface Science, v. 195, p. 222, 1997.

[48] MOMTALTI, M.; PRODI, L.; ZACCHERONI, N.; ZATTONI, A; RESCHIGLIAN, P.; FALINI, G. Energy transfer in fluorescence silica nanoparticles. Langmuir, v. 20, n. 7, p. 2989, 2004.

[49] PAVAN, F.A; LEAL, S.; COSTA, T.M.H.; BENVENUTTI, E. A sol-gel synthesis for thermally stable aniline/silica material. Journal of Sol-Gel Science and Technology, v. 23, p. 129, 2002.

[50] CUI, Y.; REN, H.; YU, J.; WANG, J.; QIAN, G. An indanone-based alkoxysilane dye with second order nonlinear optical properties. Dyes and Pigments, v. 81, p. 53, 2009 .

[51] BURNS, A.A.; VIDER, J.; OW, H.; HERZ, E.; PENATE-MEDINA, O.; BAUMGART, M.; LARSON, S.M.; WIESNER, U.; BRADBURY, M. Fluorescent silica nanoparticles with efficient urinary excretion for nanomedicine. Nanoletters, v. 9, p. 442, 2009. 
[52] NEDELCEV, T.; RACKO, D.; KRUPA, I. Preparationd and characterization of a new derivative of rhodamine $B$ with an alkoxysilane moiety. Dyes and Pigments, $v$. 76, p. 550, 2008.

[53] CALERO, P.; MARTINEZ-MÁNEZ, R.; SANCERÓN, F.; TOTO, J. Synthesis, characterization and optical properties of silica nanoparticles coated with anthracene fluorophore and thiourea hydrogen-bonding subunits. European Journal of Inorganic Chemistry, v. 36, p. 5649, 2008.

[54] PEREIRA, R.V.; FERREIRA, A.P.G.; GEHLEN, M.H. Fluorescent probes with malonitrile side group in methylmethacrylate copolymers. Journal of

Photochemistry and Photobiology A: Chemistry, v. 198, p. 69, 2008.

[55] EVANS, J.; ZAKI, A.B.; EI-SHEIKH, M.Y.; EI-SAFTY, S.A. Incorporation of transition-metal complexes in functionalized mesoporous silica and their activity toward the oxidation of aromatic amines. Journal of Physical Chemistry B, v. 104, p. $10271,2000$.

[56] FERREIRA, A.P.G.; GEHLEN, M.H. 9-aminoacridinium Derivative Incorporated in Silica Particles Obtained Commercially or Prepared by Reversed Microemulsion Method. In: INTERNATIONAL CONFERENCE OF PHOTOCHEMISTRY, 23., 2007, Cologne. Book of abstract ... Wächtersbach: PM-GrafikDesign, 2007. ref. P192.

[57] PEREIRA, R.V.; GEHLEN, M.H. Fluorescence of acridinic dyes in anionic surfactant solution. Spectrochimica Acta Part A, v. 61, p. 2926, 2005.

[58] GEHLEN, M.H.; NEUMANN, M.G. The interaction of cationic dyes with anionic surfactants in the premicellar region. Journal of Colloid and Interface Science, v. 135, n. 1. p. 209, 1990.

[59] LAPIERRE, S.C.; MULLENS, J.W.; L'ESPÉRRANCE, D.; CHRONISTER, E.L. Optical energy transfer and trapping in 9-aminoacridine doped sol-gel glasses.

Chemical Physics Letters, v. 243, p. 114, 1995.

[60] STOMPHORST, R.G.; SCHAAFSMA, T.J.; VAN DER ZWAN, G. Spectral effects of excitonic interactions in disordered solid films. Journal of Physical Chemistry A, v. 105, n. 17, p. $4226,2001$.

[61] BORSARELLI, C.D., BERTOLOTTI, S.G., PREVITALI, C.M. Thermodynamic changes in the photoinduced proton-transfer reaction of the triplet state of safranine. hotochemical and Photobiology Sciences, v. 1, p. 574, 2002. 
[62] GÓMEZ, M.L., PREVITALE, C.M., MONTEJANO, H.A. Photophysical properties of safranine O in protic solvents. Spectrochimica Acta Part A, v. 60, p. 2433, 2004.

[63] VARANDA, L.V. Nanopartículas aciculares metálicas de Fe, FeCo, FeTR e FeCoTR (TR = La-Tb) para tecnologia avançada de gravação magnética. 2003. 126 f. Tese (Doutorado em Química) - Instituto de Química de Araraquara, Universidade Estadual Paulista "Julio de Mesquita Filho", Araraquara, 2003.

[64] HUN, X.; ZHANG, Z. Functionalized fluorescent core-shell nanoparticles used as a fluorescent labels in fluoroimmunoassay for IL-6. Biosensors and Bioelectronics, v. 22, p. 2743, 2007.

[65] OW, H.; LARSON, D.R.; SRIVASTAVA, M.; BAIRD, B.A.; WEBB, W.; WIESNER, U. Bright and stable core-shell fluorescent silica nanoparticles. Nanoletters, v. 5, n. 1, p. 113, 2005.

[66] LARSON, D.R.; OW, H.; VISHWASRAO, H.D.; HEIKAL, A.A.; WIESNER, U WEBB, W. Silica nanoparticle architecture determines radiative properties of encapsulated fluorophores. Chemistry of Materials, v. 20, n. 8, p. 2677, 2008.

[67] MACHULEK JUNIOR, A.; OLIVEIRA, H.P.M.; GEHLEN, M.H. Preparation of silver nanoprisms using poly( $N$-vinyl-2-pyrrolidone) as a colloid-stabilizing agent and the effect of silver nanoparticles on the photophysical properties of cationic dyes.

Photochemical and Photobiological Sciences, v. 2, p. 921, 2003.

[68] FERREIRA, L.F.V.; GARCIA, A.R.; FREIXO, M.R.; COSTA, S.M.B. J. Photochemistry on surfaces: solvent-matrix effect on the swelling of cellulose.

Chemical Society Faraday Transactions, v. 89, p. 1937, 1993

[69] CHANGENET, P.; ZHANG, H.; MEER, M.J. van der; GLASBEEK, M.; PLAZA, P.; MARTIN, M.M. Fluorescence quenching of auramine in fluid solutions: a femtosecond spectroscopy study. Journal of Fluorescence, v. 10, p. 155, 2000.

[70] MONTALTI, M.; PRODI, L.; ZACCHERONI, N.; FALINI, G. Solvent-induced modulation of collective photophysical processes in fluorescent silica nanoparticles. Journal of the American Chemical Society, v. 124, p. 13540, 2002.

[71] LIANOS, P. Study of solid transparent nanocomposite organic/inorganic matrices and thin films by time-resolved fluorescence techniques. Journal of Fluorescence, v. 12, p. 303, 2002.

[72] VARADAN, P.; SOLOMON, M.J. Shear-induced microstructural evolution of a thermoreversible colloidal gel. Langmuir, v. 17, p. 2918, 2001. 
[73] LEE, M.H.; BEYER, F.L.; FURST, E.M. Synthesis of monodisperse fluorescent core-shell silica particles using a modified Stöber method for imaging individual particles in dense colloidal suspensions. Journal of Colloid and Interface Science, v. 228, p. 114, 2005.

[74] OLIVEIRA, H.P.M.; CAMARGO, A.J.; MACEDO, L.G.M.; GEHLEN, M.H.; SILVA, A.B.F. A quantum chemical and photophysical study of acridina-9- $N$-methacrylamide. Journal of Molecular Structure, v. 673, p. 213, 2004.

[75] OLIVEIRA, H.P.M.; MACHULEK JUNIOR, A.; LEGENDRE, A.O.; GEHLEN, M.H. Transferência de energia entre corantes catiônicos em sistemas homogêneos. Química Nova, v. 26, p. 564, 2003. 